\title{
Anti-Markovnikov Hydroamination of Unactivated Alkenes with Primary Alkyl Amines
}

David C. Miller, ${ }^{\dagger+}$ Jacob M. Ganley, ${ }^{\dagger+}$ Andrew J. Musacchio, ${ }^{\dagger}$ Trevor C. Sherwood, ${ }^{\S}$ William R. Ewing, ${ }^{\S}$ and Robert R. Knowles*广

$\dagger$ Department of Chemistry, Princeton University, Princeton, New Jersey 08544, United States

$\S$ Discovery Chemistry, Bristol-Myers Squibb, Lawrenceville, New Jersey 08543, United States

*Corresponding author. Email: rknowles@princeton.edu

Supporting Information

Table of Contents

General Information

Page

Synthesis and Characterization of Photocatalysts

S2

Synthesis and Characterization of TRIP Thiol

S2

General Procedure for the Photocatalytic Hydroamination of Primary Amines Synthesis and Characterization of Products

${ }^{1} \mathrm{H},{ }^{13} \mathrm{C}$, and ${ }^{19} \mathrm{~F}$ Spectra of Products

S10

Synthesis and Characterization of Tertiary Amine Side Products

$\mathrm{S} 22$

Stern-Volmer Experiments

S54

References

S57

S60 


\section{General Information}

Commercial reagents were purified prior to use following the guidelines of Perrin and Armarego. ${ }^{1}$ All solvents were purified according to the method of Grubbs. ${ }^{2}$ Organic solutions were concentrated under reduced pressure on a Büchi rotary evaporator. Chromatographic purification of products was accomplished by flash chromatography on Silicycle F60 silica gel, Sorbent Technologies neutral alumina, or Biotage KP-NH according to the method of Still. ${ }^{3}$ All reactions were carried out in well-ventilated fume hoods. Thin-layer chromatography (TLC) was performed on Silicycle $250 \mu \mathrm{m}$ silica gel plates, Sorbent Technologies $250 \mu \mathrm{m}$ neutral alumina plates or Biotage KP-NH plates. Visualization of the developed chromatogram was performed by irradiation with UV light or treatment with a solution of potassium permanganate or cobalt(II) thiocyanate stain followed by heating.

${ }^{1} \mathrm{H}$ and ${ }^{13} \mathrm{C}$ NMR spectra were recorded on a Bruker 500 (500 and $126 \mathrm{MHz}$ ) instrument, and are internally referenced to residual solvent signals, $\mathrm{CDCl}_{3}$ referenced at $\delta 7.26$ and $77.0 \mathrm{ppm}$. Data for ${ }^{1} \mathrm{H}$ NMR are reported as follows: chemical shift $(\delta \mathrm{ppm})$, integration, multiplicity ( $\mathrm{s}=$ singlet, $\mathrm{d}=$ doublet, $\mathrm{t}=$ triplet, $\mathrm{q}=$ quartet, $\mathrm{p}=$ pentad, sext $=$ sextet, hept $=$ septet, $\mathrm{m}=$ multiplet, brs $=$ broad singlet), and coupling constant $(\mathrm{Hz})$. Data for ${ }^{13} \mathrm{C} \mathrm{NMR}$ are reported in terms of chemical shift, multiplicity $(\mathrm{s}=$ singlet, $\mathrm{d}=$ doublet, $\mathrm{t}=$ triplet, $\mathrm{q}=$ quartet, $\mathrm{p}=$ pentet, $\mathrm{sext}=$ sextet, hept $=$ heptet, $\mathrm{m}=$ multiplet. brs = broad singlet), coupling constant $(\mathrm{Hz})$ and no special nomenclature is used for equivalent carbons. IR spectra were recorded on a Perkin Elmer Paragon 1000 spectrometer and are reported in terms of frequency of absorption $\left(\mathrm{cm}^{-1}\right)$. High resolution mass spectra were obtained at Princeton University mass spectrometry facilities using an Agilent 6210 TOF LC/MS. Gas chromatography-mass spectrometry (GC-MS) was performed on an Agilent 6890 GC-5975C MSD. Gas chromatography (GC) was performed on an Agilent Technologies 7890A GC system equipped with a split-mode capillary injection system and flame ionization detectors.

\section{Synthesis and Characterization of Photocatalysts}

2-(2,4-difluorophenyl)-5-(trifluoromethyl)pyridine

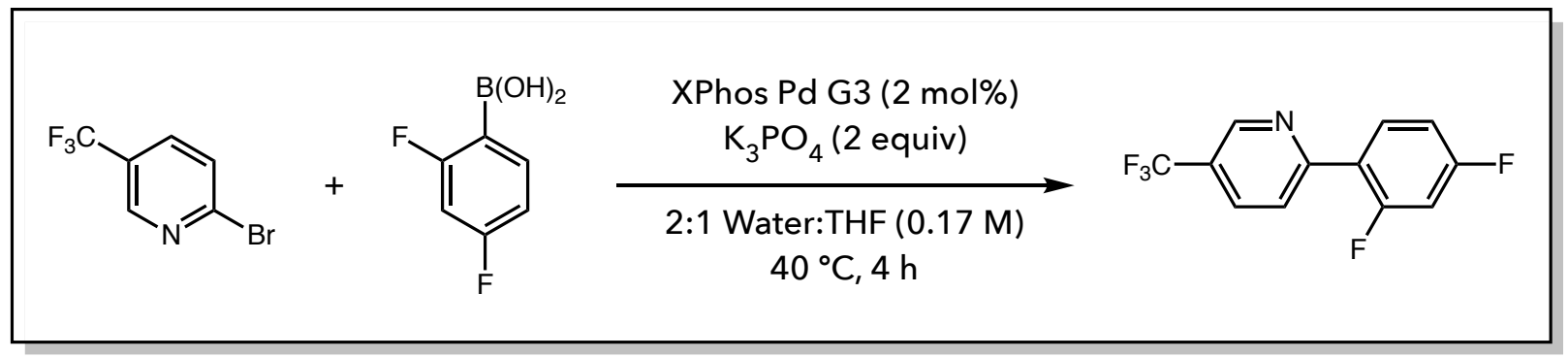

To a $100 \mathrm{~mL}$ round-bottom flask was added $\mathrm{K}_{3} \mathrm{PO}_{4}(4.61 \mathrm{~g}, 20 \mathrm{mmol}, 2.0$ equiv) and water (40 $\mathrm{mL}$ ). This solution was degassed by sparging with $\mathrm{N}_{2}$ for 20 minutes. To a $250 \mathrm{~mL}$ round-bottom flask charged with a magnetic stir bar was added 2-bromo-5-(trifluoromethyl)pyridine (2.26 g, 10 mmol, 1.0 equiv), (2,4-difluorophenyl)boronic acid ( $2.37 \mathrm{~g}, 15 \mathrm{mmol}, 1.5$ equiv), and XPhos Pd G3 (169 mg, $0.20 \mathrm{mmol}, 2 \mathrm{~mol} \%$ ). The flask was evacuated and backfilled with $\mathrm{N}_{2}$ three times. To this flask was added THF $(20 \mathrm{~mL})$ and the aqueous $\mathrm{K}_{3} \mathrm{PO}_{4}$ solution. The reaction was heated to 
$40{ }^{\circ} \mathrm{C}$ with vigorous stirring for $4 \mathrm{~h}$. The reaction mixture was then cooled to room temperature and diluted with water $(70 \mathrm{~mL})$ and $\mathrm{Et}_{2} \mathrm{O}(70 \mathrm{~mL})$. The aqueous phase was separated in a separatory funnel and washed with ether $(30 \mathrm{~mL})$ three times. The combined organic layers were washed with brine $(50 \mathrm{~mL})$, then dried over $\mathrm{Na}_{2} \mathrm{SO}_{4}$. Following removal of the solvent in vacuo, the crude residue was purified by flash chromatography (gradient from 100\% hexane to 5\% EtOAc/hexane) to afford 2-(2,4-difluorophenyl)-4-(trifluoromethyl)pyridine (2.45 g) as a light yellow solid in 95\% yield. Characterization data was consistent with reported literature values. ${ }^{4}$

\section{$\underline{\text { 2-(2,4-difluorophenyl)-5-methylpyridine }}$}

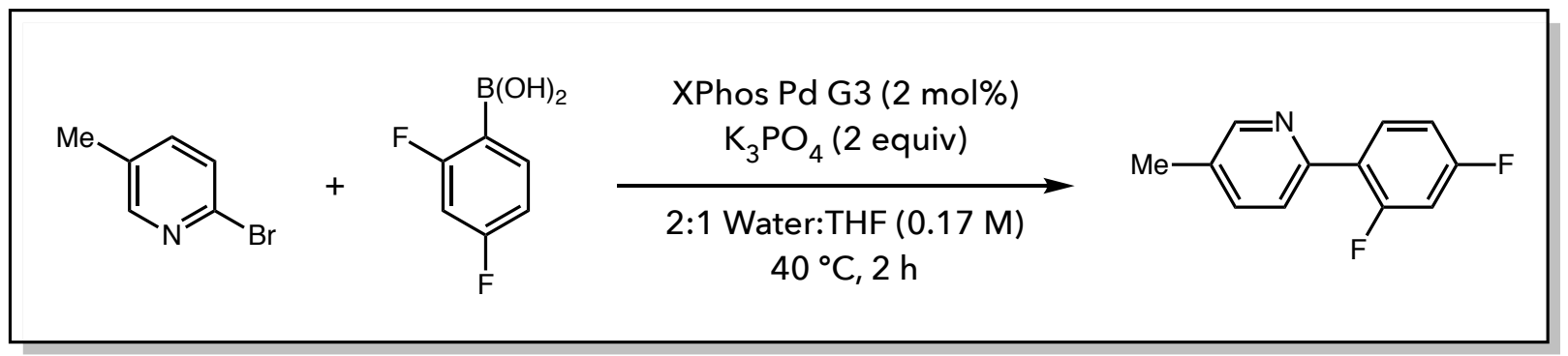

To a $50 \mathrm{~mL}$ round-bottom flask was added $\mathrm{K}_{3} \mathrm{PO}_{4}(2.30 \mathrm{~g}, 10 \mathrm{mmol}, 2.0$ equiv) and water $(20 \mathrm{~mL})$. This solution was degassed by sparging with $\mathrm{N}_{2}$ for 20 minutes. To a $100 \mathrm{~mL}$ round-bottom flask charged with a magnetic stir bar was added 2-bromo-5-methylpyridine ( $0.86 \mathrm{~g}, 5 \mathrm{mmol}, 1.0$ equiv), (2,4-difluorophenyl)boronic acid (1.18 g, $7.5 \mathrm{mmol}, 1.5$ equiv), and XPhos Pd G3 (85 mg, 0.10 mmol, 2 mol\%). The flask was evacuated and backfilled with $\mathrm{N}_{2}$ three times. To this flask was added THF $(10 \mathrm{~mL})$ and the aqueous $\mathrm{K}_{3} \mathrm{PO}_{4}$ solution. The reaction was heated to $40{ }^{\circ} \mathrm{C}$ with vigorous stirring for $2 \mathrm{~h}$. The reaction mixture was then cooled to room temperature and diluted with water $(30 \mathrm{~mL})$ and $\mathrm{Et}_{2} \mathrm{O}(30 \mathrm{~mL})$. The aqueous phase was separated in a separatory funnel and washed with ether $(20 \mathrm{~mL})$ three times. The combined organic layers were washed with brine $(30 \mathrm{~mL})$, then dried over $\mathrm{Na}_{2} \mathrm{SO}_{4}$. Following removal of the solvent in vacuo, the crude residue was purified by silica gel chromatography (gradient from $100 \%$ hexane to $5 \% \mathrm{EtOAc/hexane)}$ to afford 2-(2,4-difluorophenyl)-5-methylpyridine $(0.44 \mathrm{~g})$ as a pale yellow solid in $43 \%$ yield. Characterization data was consistent with reported literature values. ${ }^{5}$

\section{4,4'-bis(trifluoromethyl)-2,2'-bipyridine}

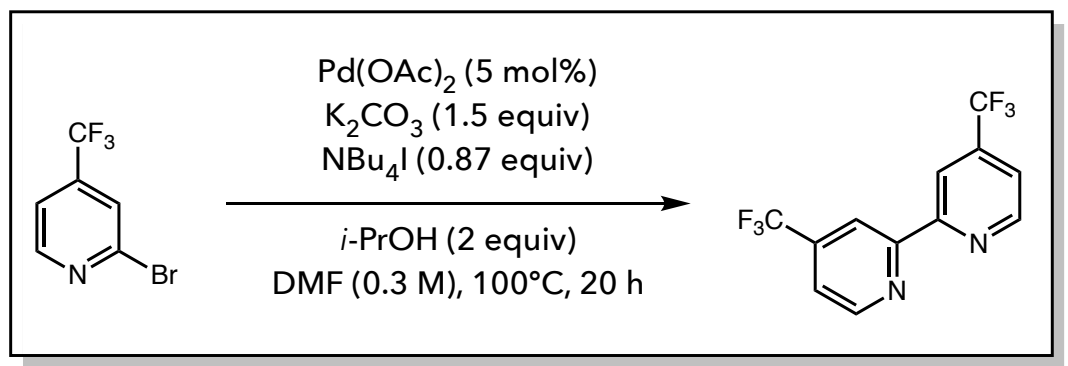

To a $100 \mathrm{~mL}$ round-bottom flask charged with a stir bar was added $\mathrm{Pd}(\mathrm{OAc})_{2}(112 \mathrm{mg}, 0.50 \mathrm{mmol}$, $5 \mathrm{~mol} \%$ ), $\mathrm{K}_{2} \mathrm{CO}_{3}$ (2.07 g, $15 \mathrm{mmol}, 1.5$ equiv), and $\mathrm{NBu}_{4} \mathrm{I}$ (3.2 g, $8.7 \mathrm{mmol}, 0.87$ equiv). The flask was evacuated and backfilled with $\mathrm{N}_{2}$ three times. To this flask was added $i$-PrOH (1.54 mL, 20 mmol, 2.0 equiv) and dry DMF $(33 \mathrm{~mL}, 0.30 \mathrm{M})$. The reaction was heated to $100^{\circ} \mathrm{C}$ with vigorous stirring for $20 \mathrm{~h}$. The reaction mixture was then cooled to room temperature and filtered, washing 
copiously with EtOAc. The organics were washed three times with $40 \mathrm{~mL}$ of $10 \%(\mathrm{w} / \mathrm{w})$ aqueous $\mathrm{LiCl}$. The aqueous layer was backwashed once with EtOAc $(50 \mathrm{~mL})$ and the combined organics washed with water $(40 \mathrm{~mL})$ and sat. brine $(40 \mathrm{~mL})$ before drying over $\mathrm{Na}_{2} \mathrm{SO}_{4}$. Following removal of the solvent in vacuo, the crude residue was purified by silica gel chromatography (gradient from $100 \%$ hexane to $5 \%$ EtOAc/hexane) to afford 4,4'-bis(trifluoromethyl)-2,2'-bipyridine (1.36 g) as a white solid in $93 \%$ yield. Characterization data was consistent with reported literature values. ${ }^{6}$

\section{$\left[\operatorname{Ir}\left(\mathrm{dF}\left(\mathrm{CF}_{3}\right) \text { ppy }\right)_{2} \mathrm{Cl}\right]_{2}$-dimer}
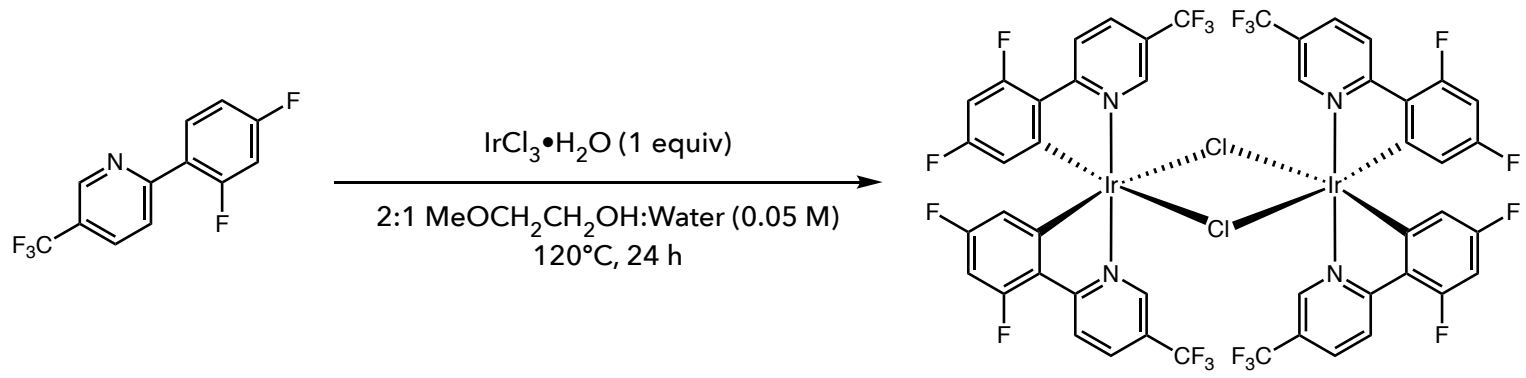

To a flame-dried $250 \mathrm{~mL}$ three-necked round-bottom flask with a reflux condenser and stir bar was added $\mathrm{IrCl}_{3} \bullet \mathrm{H}_{2} \mathrm{O}(1.19 \mathrm{~g}, 3.76 \mathrm{mmol}, 1.0$ equiv) and 2-(2,4-difluorophenyl)-5(trifluoromethyl)pyridine ( $2.0 \mathrm{~g}, 7.72 \mathrm{mmol}, 2.05$ equiv). The flask was evacuated and backfilled with $\mathrm{N}_{2}$ three times. 2-Methoxyethanol $(50 \mathrm{~mL})$ and water $(25 \mathrm{~mL})$, each degassed by sparging $\mathrm{N}_{2}$ for 20 minutes, were added and the reaction was heated to $120^{\circ} \mathrm{C}$ overnight. The reaction mixture was cooled to room temperature, which resulted in the formation of a large amount of yellow precipitate. The solid was filtered and washed with water $(50 \mathrm{~mL})$ three times to afford $2.23 \mathrm{~g}$ of the crude dimer in $80 \%$ yield. The crude dimer was carried on without any further purification.

\section{$\left[\operatorname{Ir}\left(\mathrm{dF}(\mathrm{Me}) \mathrm{ppy}_{2}\right)_{2} \mathrm{Cl}_{2}\right.$-dimer}<smiles>Cc1ccc(-c2ccc(F)cc2F)nc1</smiles>
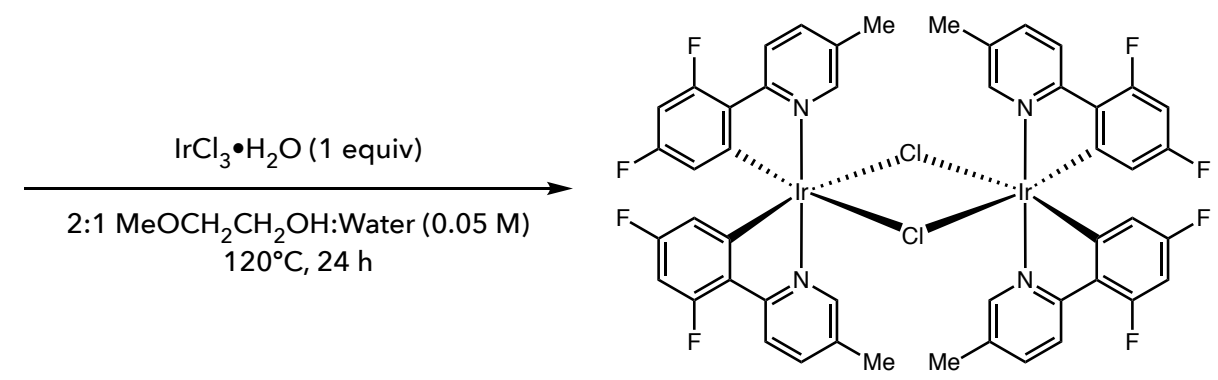

To a flame-dried $250 \mathrm{~mL}$ three-necked round-bottom flask with a reflux condenser and stir bar was added $\mathrm{IrCl}_{3} \bullet \mathrm{H}_{2} \mathrm{O}(0.32 \mathrm{~g}, 1.00 \mathrm{mmol}, 1.0$ equiv) and 2-(2,4-difluorophenyl)-5- methylpyridine ( $0.42 \mathrm{~g}, 2.05 \mathrm{mmol}, 2.05$ equiv). The flask was evacuated and backfilled with $\mathrm{N}_{2}$ three times. 2Methoxyethanol $(13.3 \mathrm{~mL})$ and water $(6.7 \mathrm{~mL})$, each degassed by sparging $\mathrm{N}_{2}$ for 20 minutes, were added and the reaction was heated to $120^{\circ} \mathrm{C}$ overnight. The reaction mixture was cooled to room temperature, which resulted in the formation of a large amount of yellow precipitate. The solid was filtered and washed with water $(20 \mathrm{~mL})$ three times to afford $0.487 \mathrm{~g}$ of the crude dimer in $77 \%$ yield. The crude dimer was carried on without any further purification. 


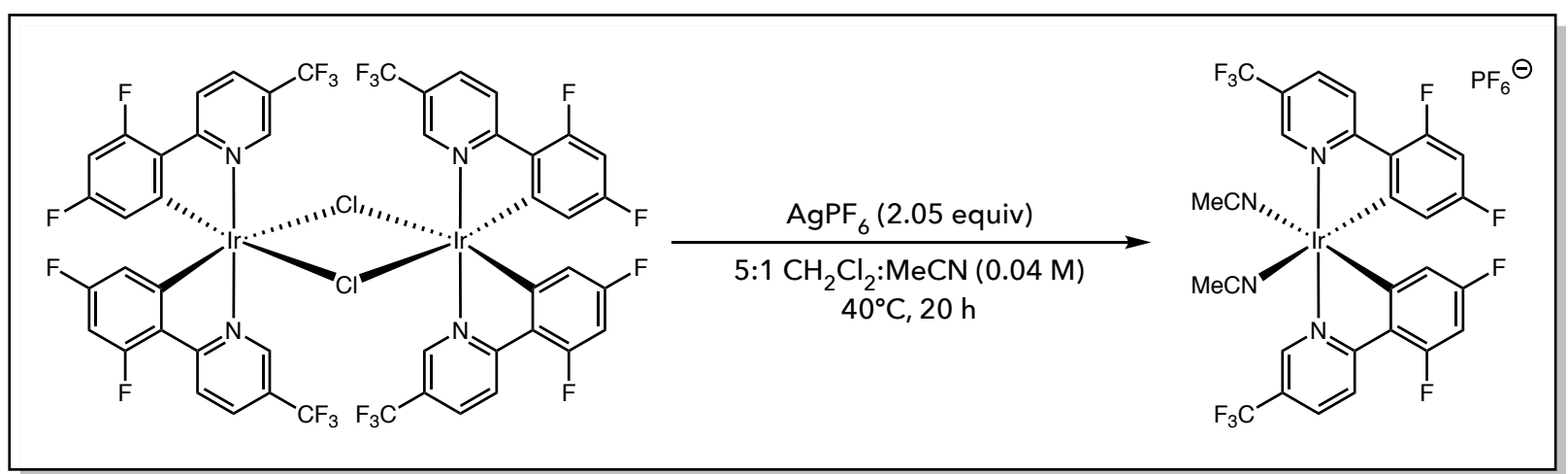

To a $100 \mathrm{~mL}$ three-necked round-bottom flask charged with a stir bar was added the crude $\left[\operatorname{Ir}\left(\mathrm{dF}\left(\mathrm{CF}_{3}\right) \text { ppy }\right)_{2} \mathrm{Cl}\right]_{2}$-dimer $(2.23 \mathrm{~g}, 1.5 \mathrm{mmol}, 1.0$ equiv) from the previous step. The flask was pumped into a glovebox wherein $\mathrm{AgPF}_{6}(0.78 \mathrm{~g}, 3.08 \mathrm{mmol}, 2.05$ equiv $)$ was added and the flask capped. After exchanging a cap for a reflux condenser, the flask was evacuated and backfilled with $\mathrm{N}_{2}$ three times. Dry $\mathrm{CH}_{2} \mathrm{Cl}_{2}(30 \mathrm{~mL})$ and $\mathrm{MeCN}(6 \mathrm{~mL})$ were added and the reaction mixture was heated to $40{ }^{\circ} \mathrm{C}$ for $20 \mathrm{~h}$. The reaction mixture was cooled to room temperature and solvent removed in vacuo. After taking up the crude residue in acetone, the $\mathrm{AgCl}$ salts were filtered off. Pentane was added to the filtrate to afford $2.30 \mathrm{~g}$ of $\left[\operatorname{Ir}\left(\mathrm{dF}_{(}\left(\mathrm{CF}_{3}\right) \text { ppy }\right)_{2}(\mathrm{MeCN})_{2}\right] \mathrm{PF}_{6}$ as a fluffy yellow solid in $90 \%$ yield. The crude product was carried on without any further purification.

$\left[\mathrm{Ir}\left(\mathrm{dF}(\mathrm{Me}) \mathrm{ppy}_{2}\right)_{2}(\mathrm{MeCN})_{2}\right] \mathrm{PF}_{6}$

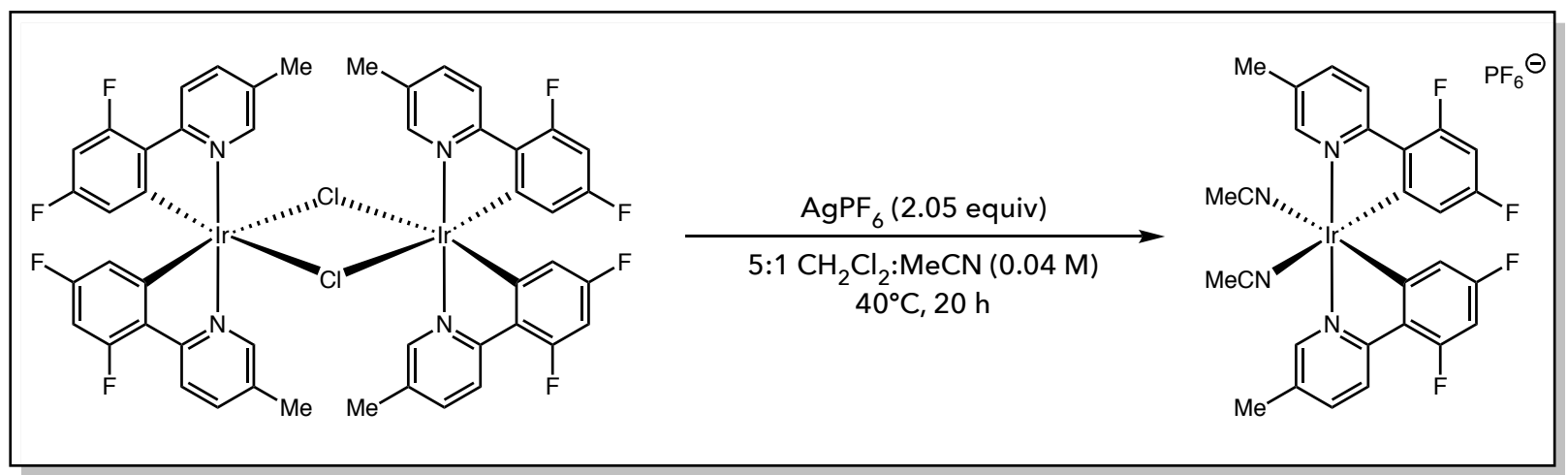

To a $50 \mathrm{~mL}$ three-necked round-bottom flask charged with a stir bar was added the crude $\left[\operatorname{Ir}(\mathrm{dF}(\mathrm{Me}) \text { ppy })_{2} \mathrm{Cl}\right]_{2}$-dimer $(0.48 \mathrm{~g}, 0.38 \mathrm{mmol}, 1.0$ equiv $)$ from the previous step. The flask was pumped into a glovebox wherein $\mathrm{AgPF}_{6}(0.20 \mathrm{~g}, 0.78 \mathrm{mmol}, 2.05$ equiv $)$ was added and the flask capped. After exchanging a cap for a reflux condenser, the flask was evacuated and backfilled with $\mathrm{N}_{2}$ three times. Dry $\mathrm{CH}_{2} \mathrm{Cl}_{2}(8 \mathrm{~mL})$ and $\mathrm{MeCN}(1.6 \mathrm{~mL})$ were added and the reaction mixture was heated to $40{ }^{\circ} \mathrm{C}$ for $20 \mathrm{~h}$. The reaction mixture was cooled to room temperature and solvent removed in vacuo. After taking up the crude residue in acetone, the $\mathrm{AgCl}$ salts were filtered off. Pentane was added to the filtrate to afford $0.48 \mathrm{~g}$ of $\left[\operatorname{Ir}\left(\mathrm{dF}\left(\mathrm{CF}_{3}\right) \mathrm{ppy}\right)_{2}(\mathrm{MeCN})_{2}\right] \mathrm{PF}_{6}$ as a yellow solid in $85 \%$ yield. The crude product was carried on without any further purification. 
$\left[\operatorname{Ir}\left(\mathrm{dF}\left(\mathrm{CF}_{3}\right) \mathrm{ppy}_{2}\right)_{2}\left(4,4^{\prime}-\mathrm{dCF}_{3} \underline{-b p y)}\right] \mathrm{PF}_{6}\right.$

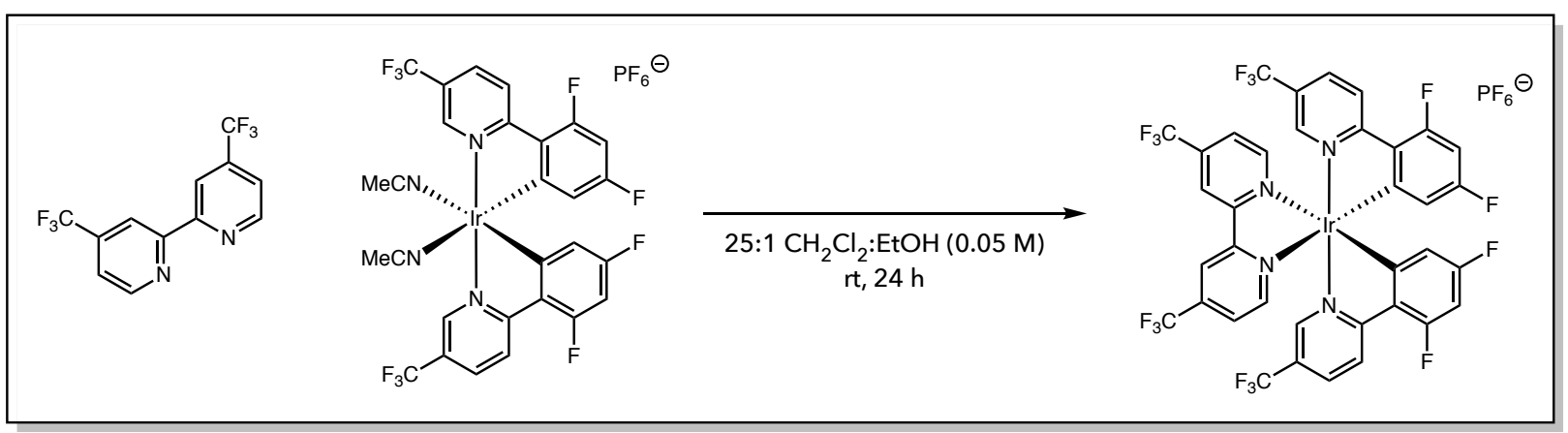

To a $100 \mathrm{~mL}$ round-bottom flask with a stir bar was added $\left[\operatorname{Ir}\left(\mathrm{dF}\left(\mathrm{CF}_{3}\right) \mathrm{ppy}\right)_{2}(\mathrm{MeCN})_{2}\right] \mathrm{PF}_{6}(2.30 \mathrm{~g}$, $2.69 \mathrm{mmol}, 1.0$ equiv) and 4,4'-bis(trifluoromethyl)-2,2'- bipyridine ( $0.95 \mathrm{~g}, 3.23 \mathrm{mmol}, 1.2$ equiv). $\mathrm{CH}_{2} \mathrm{Cl}_{2}(52 \mathrm{~mL})$ and EtOH $(2 \mathrm{~mL})$ were added and the reaction mixture was stirred at $\mathrm{rt}$ overnight. The reaction mixture was filtered through a pad of celite and washed copiously with $\mathrm{CH}_{2} \mathrm{Cl}_{2}$ to dissolve as much of the crude iridium complex as possible. The resulting filtrate was concentrated in vacuo and recrystallized from acetone and pentane to afford $2.36 \mathrm{~g}$ of $\left[\operatorname{Ir}\left(\mathrm{dF}\left(\mathrm{CF}_{3}\right) \text { ppy }\right)_{2}\left(4,4^{\prime}-\right.\right.$ $\left.\mathrm{dCF}_{3}-\mathrm{bpy}\right) \mathrm{PF}_{6}$ as yellow crystals in $77 \%$ yield. Characterization data was consistent with reported literature values. ${ }^{7}$

\section{$\left[\operatorname{Ir}(\mathrm{dF}(\mathrm{Me}) \operatorname{ppy})_{2}(\mathrm{dtbbpy)}] \mathrm{PF} 6\right.$}

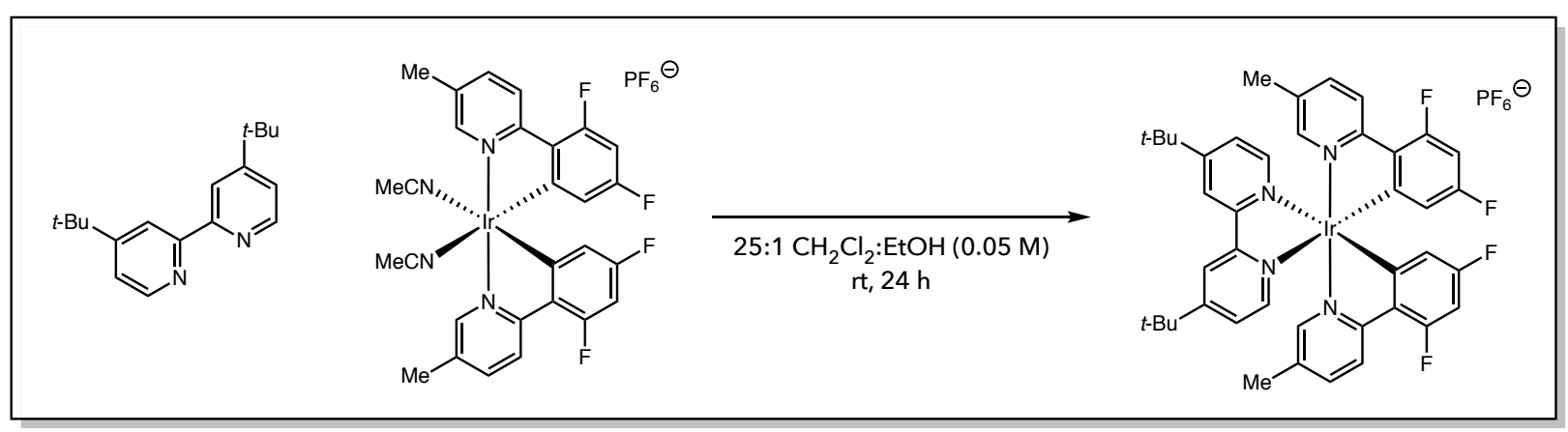

To a $100 \mathrm{~mL}$ round-bottom flask with a stir bar was added $\left[\operatorname{Ir}(\mathrm{dF}(\mathrm{Me}) \mathrm{ppy})_{2}(\mathrm{MeCN})_{2}\right] \mathrm{PF}_{6}(0.48 \mathrm{~g}$, $0.65 \mathrm{mmol}, 1.0$ equiv) and 4,4'-di-tert-butyl-2,2'- bipyridine ( $0.21 \mathrm{~g}, 0.77 \mathrm{mmol}, 1.2 \mathrm{equiv})$. $\mathrm{CH}_{2} \mathrm{Cl}_{2}(12 \mathrm{~mL})$ and $\mathrm{EtOH}(0.5 \mathrm{~mL})$ were added and the reaction mixture was stirred at $\mathrm{rt}$ overnight. The reaction mixture was filtered through a pad of celite and washed copiously with $\mathrm{CH}_{2} \mathrm{Cl}_{2}$ to dissolve as much of the crude iridium complex as possible. The resulting filtrate was concentrated in vacuo and recrystallized from acetone and pentane to afford $0.54 \mathrm{~g}$ of $\left[\operatorname{Ir}\left(\mathrm{dF}(\mathrm{Me}) \mathrm{ppy}_{2}(\mathrm{dtbbpy})\right] \mathrm{PF}_{6}\right.$ as yellow crystals in $82 \%$ yield. Characterization data was consistent with reported literature values. ${ }^{8}$ 


\section{Synthesis of TRIP Thiol}

\section{2,4,6-triisopropylbenzenethiol}

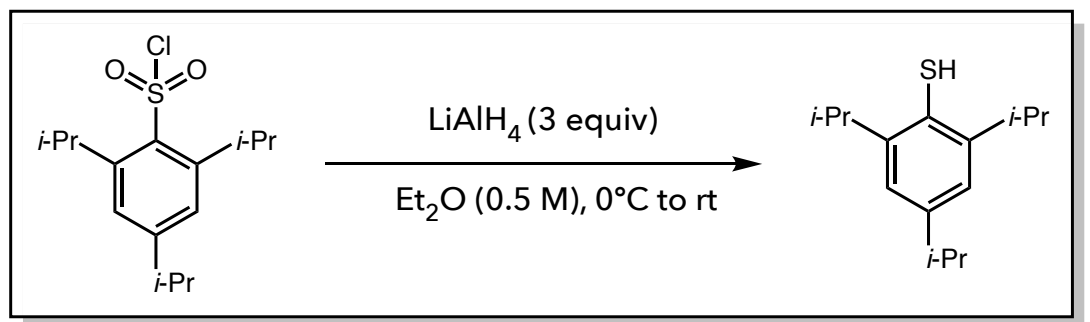

To a dry 100-mL round bottom flask, lithium aluminum hydride $\left(\mathrm{LiAlH}_{4}\right)(1.52 \mathrm{~g}, 40.0 \mathrm{mmol}, 2.0$ equiv) was added. Dry $\mathrm{Et}_{2} \mathrm{O}(20 \mathrm{~mL})$ was then added to form a suspension and cooled to $0{ }^{\circ} \mathrm{C}$. To this mixture, a solution of 2,4,6-triisopropylbenzene-1-sulfonyl chloride (6.06 g, $20 \mathrm{mmol}$ ) in Et $\mathrm{t}_{2} \mathrm{O}$ $(20 \mathrm{ml})$ was added slowly. After completion of addition, an additional load of $\mathrm{LiAlH}_{4}(0.76 \mathrm{~g}, 20$ mmol, 1.0 equiv) was added. The reaction was allowed to warm to $\mathrm{rt}$ as it was stirred overnight. Upon completion, the reaction was cooled to $0{ }^{\circ} \mathrm{C}$ and diluted with $40 \mathrm{~mL} \mathrm{Et}_{2} \mathrm{O}$. The reaction was quenched with water $\left(1 \mathrm{~mL}\right.$ per gram of $\left.\mathrm{LiAlH}_{4}\right), 15 \%(\mathrm{w} / \mathrm{w}) \mathrm{NaOH}$ solution $(1 \mathrm{~mL}$ per gram of $\left.\mathrm{LiAlH}_{4}\right)$ and water $\left(3 \mathrm{~mL}\right.$ per gram of $\left.\mathrm{LiAlH}_{4}\right)$. The reaction was stirred for $10 \mathrm{~min}$ at $0{ }^{\circ} \mathrm{C}$ before $\mathrm{MgSO}_{4}$ was added. The resulting white slurry was allowed to stir for 30 minutes at $\mathrm{rt}$. The white solids were removed via filtration, with $\mathrm{Et}_{2} \mathrm{O}$ rinsing. The solution was then concentrated and distilled at reduced pressure to provide $4.08 \mathrm{~g}$ of 2,4,6-triisopropylbenzenethiol as a colorless oil in $86 \%$ yield. Notably, it is critical to keep the reaction temperature as low as possible when adding the substrate and reagents and during the quenching process. Warming may result in reductive desulfurization, forming a mixture of the desired compound and 1,3,5-triisopropylbenzene that is difficult to separate.

\section{General Procedure for the Photocatalytic Hydroamination of Primary Amines}

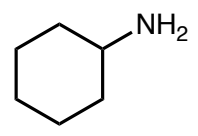

$0.2 \mathrm{mmol}$

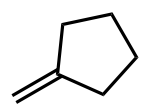

$\mathrm{X}$ equiv

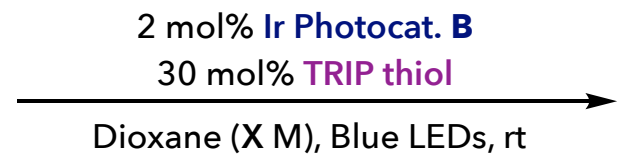

Dioxane (X M), Blue LEDs, rt

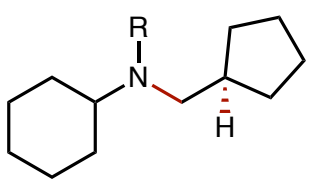

2: $\mathrm{R}=\mathrm{H}$

2a: $R$ = cyclopentylmethyl

Method A (reaction optimization): An oven-dried 2-dram vial was equipped with an oven-dried Teflon stir bar and charged with 2,4,6-triisopropylbenzenethiol (TRIP thiol) (14.2 mg, $0.06 \mathrm{mmol}$,

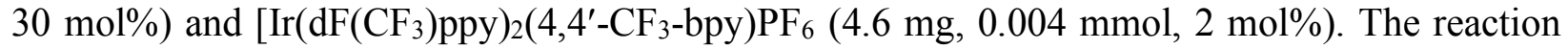
vessel was then brought into the glovebox wherein it was sealed with a Teflon septa and capped. Electrical tape was used to seal the sides of the cap, and reaction vessel removed from the glovebox. Degassed anhydrous dioxane was then added via syringe, followed by cyclohexylamine (23 $\mu \mathrm{L}, 0.2 \mathrm{mmol}, 1.0$ equiv) and methylene cyclopentane. The resulting pale-yellow solution was 
irradiated by a single 34W Kessil KSH150B blue LED lamp and magnetically stirred for $24 \mathrm{~h}$. Throughout irradiation, a small rotary fan was placed adjacent to the vial to cool the reaction. A typical reaction was measured to run at about $35^{\circ} \mathrm{C}$. The yields for $\mathbf{2}$ and $\mathbf{2 a}$ were determined via GC using 1,1'-biphenyl (31 mg, $0.2 \mathrm{mmol}, 1.0$ equiv) as an internal standard.

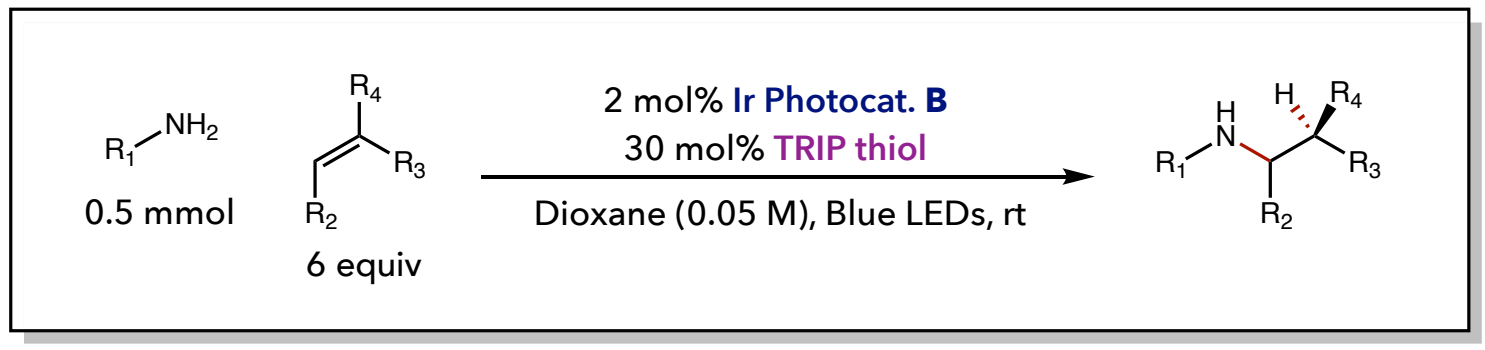

Method B (preparative scale): An oven-dried $16 \times 125 \mathrm{~mm}$ screw cap culture tube was equipped with an oven-dried Teflon stir bar and charged with 2,4,6-triisopropylbenzenethiol (TRIP thiol) (35.5 mg, $0.15 \mathrm{mmol}, 30 \mathrm{~mol} \%)$ and $\left[\operatorname{Ir}\left(\mathrm{dF}\left(\mathrm{CF}_{3}\right) \text { ppy }\right)_{2}\left(4,4^{\prime}-\mathrm{CF}_{3}-\mathrm{bpy}\right) \mathrm{PF}_{6}(11.5 \mathrm{mg}, 0.01 \mathrm{mmol}, 2\right.$ $\mathrm{mol} \%$ ). The reaction vessel was then brought into the glovebox wherein it was sealed with a Teflon septa and capped. Electrical tape was used to seal the sides of the cap, and reaction vessel removed from the glovebox. Degassed anhydrous dioxane $(10 \mathrm{~mL}, 0.05 \mathrm{M})$ was then added via syringe, followed by amine ( $0.5 \mathrm{mmol}, 1.0$ equiv) and olefin ( $3.0 \mathrm{mmol}, 6.0$ equiv). The resulting paleyellow solution was irradiated by a single $34 \mathrm{~W}$ Kessil KSH150B blue LED lamp and magnetically stirred until conversion of the amine starting material ceased, as judged by GC. Throughout irradiation, a small rotary fan was placed adjacent to the vial to cool the reaction. A typical reaction was measured to run at about $35^{\circ} \mathrm{C}$. Once completed, the reaction mixture was purified using the specified purification procedure.

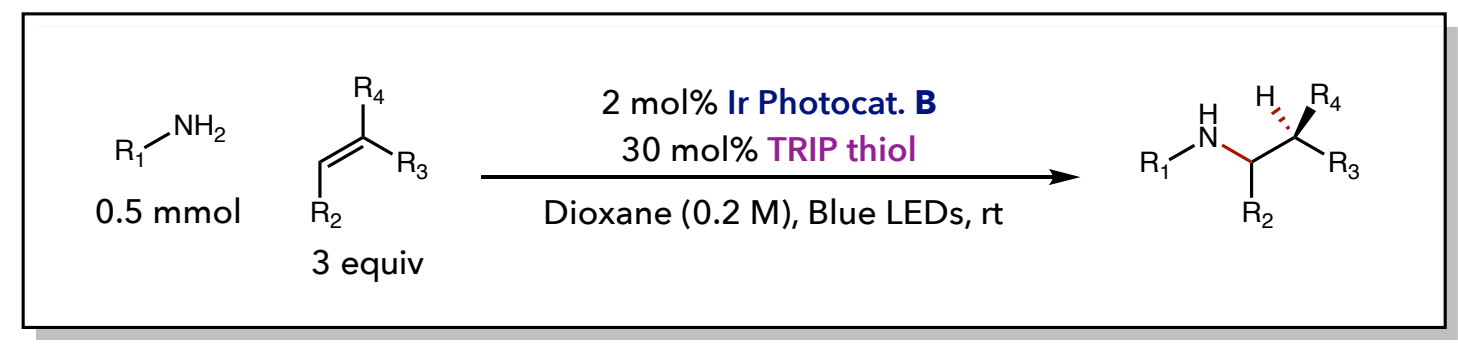

Method C (preparative scale): An oven-dried $16 \times 125 \mathrm{~mm}$ screw cap culture tube was equipped with an oven-dried Teflon stir bar and charged with 2,4,6-triisopropylbenzenethiol (TRIP thiol) (35.5 mg, $0.15 \mathrm{mmol}, 30 \mathrm{~mol} \%)$ and $\left[\operatorname{Ir}\left(\mathrm{dF}\left(\mathrm{CF}_{3}\right) \text { ppy }\right)_{2}\left(4,4^{\prime}-\mathrm{CF}_{3}-\mathrm{bpy}\right) \mathrm{PF}_{6}(11.5 \mathrm{mg}, 0.01 \mathrm{mmol}, 2\right.$ $\mathrm{mol} \%$ ). The reaction vessel was then brought into the glovebox wherein it was sealed with a Teflon septa and capped. Electrical tape was used to seal the sides of the cap, and reaction vessel removed from the glovebox. Degassed anhydrous dioxane $(2.5 \mathrm{~mL}, 0.2 \mathrm{M})$ was then added via syringe, followed by amine ( $0.5 \mathrm{mmol}, 1.0$ equiv) and olefin ( $1.5 \mathrm{mmol}, 3.0$ equiv). The resulting paleyellow solution was irradiated by a single 34W Kessil KSH150B blue LED lamp and magnetically stirred until conversion of the amine starting material ceased, as judged by GC. Throughout irradiation, a small rotary fan was placed adjacent to the vial to cool the reaction. A typical reaction 
was measured to run at about $35^{\circ} \mathrm{C}$. Once completed, the reaction mixture was purified using the specified purification procedure.

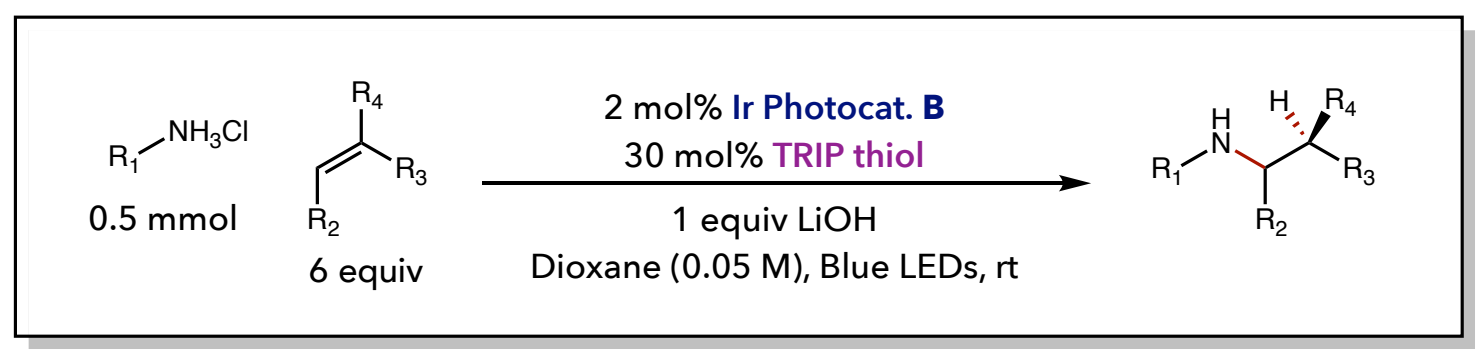

Method D (preparative scale): An oven-dried $16 \times 125 \mathrm{~mm}$ screw cap culture tube was equipped with an oven-dried Teflon stir bar and charged with 2,4,6-triisopropylbenzenethiol (TRIP thiol) (35.5 mg, $0.15 \mathrm{mmol}, 30 \mathrm{~mol} \%),\left[\operatorname{Ir}\left(\mathrm{dF}\left(\mathrm{CF}_{3}\right)\right.\right.$ ppy) $2\left(4,4^{\prime}-\mathrm{CF}_{3}-\mathrm{bpy}\right) \mathrm{PF}_{6}$ (11.5 mg, $0.01 \mathrm{mmol}, 2$ $\mathrm{mol} \%$ ), $\mathrm{LiOH}$ (12 $\mathrm{mg}, 0.5 \mathrm{mmol}, 1.0$ equiv), and the amine $\cdot \mathrm{HCl}$ salt ( $0.5 \mathrm{mmol}, 1.0$ equiv). The reaction vessel was then brought into the glovebox wherein it was sealed with a Teflon septa and capped. Electrical tape was used to seal the sides of the cap, and reaction vessel removed from the glovebox. Degassed anhydrous dioxane $(10 \mathrm{~mL}, 0.05 \mathrm{M})$ was then added via syringe, followed by olefin ( $3.0 \mathrm{mmol}, 6.0$ equiv). The resulting pale-yellow solution was irradiated by a single $34 \mathrm{~W}$ Kessil KSH150B blue LED lamp and magnetically stirred until conversion of the amine starting material ceased, as judged by GC. Throughout irradiation, a small rotary fan was placed adjacent to the vial to cool the reaction. A typical reaction was measured to run at about $35{ }^{\circ} \mathrm{C}$. Once completed, the reaction mixture was purified using the specified purification procedure.

Notes: The reported yield is the average of two individual experiments. The procedure can be adapted to utilize standard Schlenk technique to degas the vials in lieu of the glovebox technique, albeit with slightly diminished yields.

\section{Workup Procedure}

Upon completion of the reaction, the solvent was removed via rotary evaporation. The crude residue was then diluted with $40 \mathrm{~mL}$ EtOAc and extracted twice with $100 \mathrm{~mL} 1 \mathrm{~N} \mathrm{HCl}$. The combined aqueous layers were washed with $\mathrm{Et}_{2} \mathrm{O}$, then the $\mathrm{pH}$ adjusted to $\mathrm{pH} 10$ with $15 \%$ (w/w) $\mathrm{NaOH}$ solution. The resulting solution was then extracted with three times with $75 \mathrm{~mL} \mathrm{CH}_{2} \mathrm{Cl}_{2}$. The combined organic $\mathrm{CH}_{2} \mathrm{Cl}_{2}$ extracts were dried over magnesium sulfate and concentrated to obtain the named product. 


\section{Synthesis and Characterization of Products}

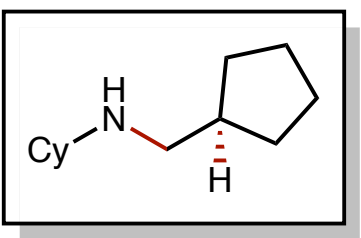

\section{$N$-(Cyclopentylmethyl)cyclohexanamine (2)}

The reaction was set up following general procedure B using cyclohexylamine (50 mg, $0.5 \mathrm{mmol})$ and methylene cyclopentane ( $246 \mathrm{mg}, 3 \mathrm{mmol}, 6.0$ equiv). The reaction was purified by the general workup procedure to give the title compound in an average isolated yield of $77 \%$ (70.0 $\mathrm{mg})$. IR (neat): 2927, 2853, 1449, 1368, 1129, 890, 844, 730. ${ }^{1} \mathbf{H}$ NMR (500 MHz, CDCl $) \delta 2.57$ (d, $J=$ $7.2 \mathrm{~Hz}, 2 \mathrm{H}), 2.40$ (tt, $J=10.5,3.7 \mathrm{~Hz}, 1 \mathrm{H}), 2.00$ (hept, $J=7.6 \mathrm{~Hz}, 1 \mathrm{H}), 1.93-1.85$ (m, 2H), 1.84 - $1.71(\mathrm{~m}, 4 \mathrm{H}), 1.67-1.50(\mathrm{~m}, 5 \mathrm{H}), 1.33$ - $1.04(\mathrm{~m}, 9 \mathrm{H}) .{ }^{13} \mathbf{C}$ NMR (126 MHz, CDCl $) \delta 57.3$, $53.2,40.4,33.9,31.1,26.4,25.5,25.3$. HRMS (ESI) exact mass calculated for $[\mathrm{M}+\mathrm{H}]^{+}\left(\mathrm{C}_{12} \mathrm{H}_{24} \mathrm{~N}\right)$ requires $\mathrm{m} / \mathrm{z} 181.18305$, found $\mathrm{m} / \mathrm{z} 181.18288$, difference $0.93 \mathrm{ppm}$.

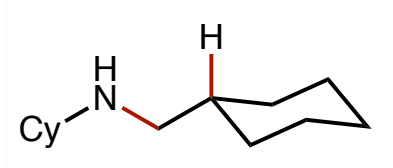

$N$-(Cyclohexylmethyl)cyclohexanamine (3)

The reaction was set up following general procedure B using cyclohexylamine ( $50 \mathrm{mg}, 0.5 \mathrm{mmol})$ and methylene cyclohexane ( $289 \mathrm{mg}, 3 \mathrm{mmol}, 6.0$ equiv). The reaction was purified by the general workup procedure to give the title compound in an average isolated yield of $77 \%$ (75.5 $\mathrm{mg})$. IR (neat): 2920, 2850, 1448, 1347, 1130, 889, 720. ${ }^{\mathbf{1}} \mathbf{H}$ NMR (500 MHz, CDCl 3$) ~ \delta 2.43(\mathrm{~d}, J=6.7$ $\mathrm{Hz}, 2 \mathrm{H}), 2.35(\mathrm{tt}, J=10.5,3.6 \mathrm{~Hz}, 1 \mathrm{H}), 1.85(\mathrm{dd}, J=12.8,3.8 \mathrm{~Hz}, 2 \mathrm{H}), 1.76-1.56(\mathrm{~m}, 9 \mathrm{H}), 1.41$ $(\operatorname{tdp}, J=10.3,6.7,3.5 \mathrm{~Hz}, 1 \mathrm{H}), 1.22(\mathrm{qd}, J=12.5,6.0 \mathrm{~Hz}, 4 \mathrm{H}), 1.14(\mathrm{tt}, J=12.5,2.9 \mathrm{~Hz}, 2 \mathrm{H})$, 1.04 (qd, $J=12.4,3.4 \mathrm{~Hz}, 2 \mathrm{H}), 0.87$ (qd, $J=13.8,13.0,3.8 \mathrm{~Hz}, 2 \mathrm{H}) .{ }^{13} \mathbf{C}$ NMR (126 MHz, CDCl $)$ $\delta$ 57.0, 53.8, 38.2, 33.6, 31.7, 26.8, 26.3, 26.2, 25.2. HRMS (ESI) exact mass calculated for $[\mathrm{M}+\mathrm{H}]^{+}\left(\mathrm{C}_{13} \mathrm{H}_{26} \mathrm{~N}\right)$ requires $\mathrm{m} / \mathrm{z} 196.20598$, found $\mathrm{m} / \mathrm{z} 196.20588$, difference $0.49 \mathrm{ppm}$.

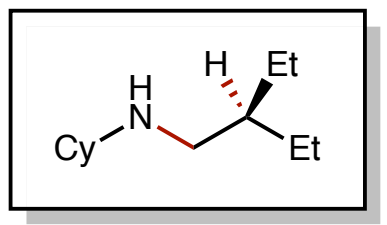

$N$-(2-Ethylbutyl)cyclohexanamine (4)

The reaction was set up following general procedure B using cyclohexylamine ( $50 \mathrm{mg}, 0.5 \mathrm{mmol})$ and 3-methylenepentane ( $252 \mathrm{mg}, 3 \mathrm{mmol}, 6.0$ equiv). The reaction was purified by the general workup procedure to give the title compound in an average isolated yield of $66 \%(60.7 \mathrm{mg})$. IR (neat): 2959, 2924, 2853, 1452, 1128, 721. ${ }^{\mathbf{H}} \mathbf{H} \mathbf{N M R}\left(\mathbf{5 0 0} \mathbf{~ M H z}, \mathbf{C D C l}_{3}\right) \delta 2.53(\mathrm{~d}, J=4.9 \mathrm{~Hz}$, 2H), 2.39 (tt, $J=10.5,3.7 \mathrm{~Hz}, 1 \mathrm{H}), 1.94-1.85(\mathrm{~m}, 2 \mathrm{H}), 1.74(\mathrm{dt}, J=12.4,3.2 \mathrm{~Hz}, 2 \mathrm{H}), 1.63$ (dt, $J=12.4,3.3 \mathrm{~Hz}, 1 \mathrm{H}), 1.41-1.23(\mathrm{~m}, 7 \mathrm{H}), 1.19(\mathrm{tt}, J=12.2,3.1 \mathrm{~Hz}, 1 \mathrm{H}), 1.08$ (qd, $J=12.6,3.2$ Hz, 2H), 0.89 (t, $J=7.1 \mathrm{~Hz}, 6 \mathrm{H}) .{ }^{13} \mathbf{C}$ NMR (126 MHz, $\left.\mathbf{C D C l}_{3}\right) \delta$ 57.3, 50.0, 41.2, 33.9, 26.4, 
25.3, 24.2, 11.0. HRMS (ESI) exact mass calculated for $[\mathrm{M}+\mathrm{H}]^{+}\left(\mathrm{C}_{12} \mathrm{H}_{26} \mathrm{~N}\right)$ requires $\mathrm{m} / \mathrm{z}$ 183.19870, found $\mathrm{m} / \mathrm{z} 183.19852$, difference $0.99 \mathrm{ppm}$.

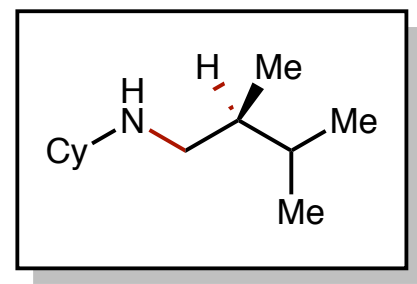

N-(2,3-Dimethylbutyl)cyclohexanamine (5)

The reaction was set up following general procedure B using cyclohexylamine ( $50 \mathrm{mg}, 0.5 \mathrm{mmol})$ and 2,3-dimethylbut-1-ene ( $252 \mathrm{mg}, 3 \mathrm{mmol}, 6.0$ equiv). The reaction was purified by the general workup procedure to give the title compound in an average isolated yield of $70 \%(64.0 \mathrm{mg})$. IR (neat): 2955, 2853, 1450, 1365, 1119, 889, 722. ${ }^{1} \mathbf{H}$ NMR (500 MHz, CDCl $\mathbf{~ M}_{3} \delta 2.64$ (dd, $J=11.4$, $5.6 \mathrm{~Hz}, 1 \mathrm{H}), 2.39(\mathrm{ddd}, J=12.8,9.3,5.5 \mathrm{~Hz}, 2 \mathrm{H}), 1.94-1.86(\mathrm{~m}, 2 \mathrm{H}), 1.74(\mathrm{ddd}, J=13.0,5.7$, $2.6 \mathrm{~Hz}, 2 \mathrm{H}), 1.71-1.60(\mathrm{~m}, 2 \mathrm{H}), 1.50$ (hept, $J=6.8,6.5,5.7 \mathrm{~Hz}, 1 \mathrm{H}), 1.33-1.23(\mathrm{~m}, 3 \mathrm{H}), 1.19$ $(\mathrm{tt}, J=12.3,3.2 \mathrm{~Hz}, 1 \mathrm{H}), 1.15-1.04(\mathrm{~m}, 2 \mathrm{H}), 0.91(\mathrm{~d}, J=6.8 \mathrm{~Hz}, 3 \mathrm{H}), 0.84(\mathrm{dd}, J=9.9,6.8 \mathrm{~Hz}$, 6H). ${ }^{13} \mathbf{C}$ NMR (126 MHz, $\left.\mathbf{C D C l}_{3}\right) \delta$ 57.1, 51.2, 39.0, 33.7, 33.6, 30.2, 26.2, 25.2, 20.6, 17.7, 13.9. HRMS (ESI) exact mass calculated for $[\mathrm{M}+\mathrm{H}]^{+}\left(\mathrm{C}_{12} \mathrm{H}_{26} \mathrm{~N}\right)$ requires $\mathrm{m} / \mathrm{z} 183.19870$, found $\mathrm{m} / \mathrm{z}$ 183.19883, difference 0.69 ppm.

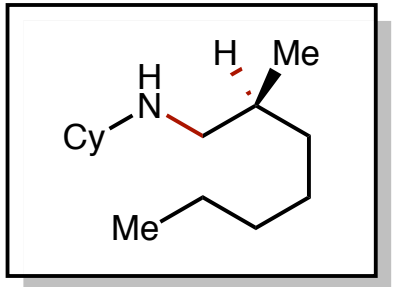

\section{$N$-(2-Methylheptyl)cyclohexanamine (6)}

The reaction was set up following general procedure $\mathrm{C}$ using cyclohexylamine $(50 \mathrm{mg}, 0.5 \mathrm{mmol})$ and 2-methylhept-1-ene (168 mg, $1.5 \mathrm{mmol}, 3.0$ equiv). The reaction was purified by the general workup procedure to give the title compound in an average isolated yield of $65 \%(68.3 \mathrm{mg})$. IR (neat): 2927, 2853, 1453, 1375, 1127, 888, 724. ${ }^{1} \mathbf{H}$ NMR (500 MHz, $\left.\mathbf{C D C l}_{3}\right) \delta 2.54$ (dd, $J=11.4$, $5.8 \mathrm{~Hz}, 1 \mathrm{H}), 2.37(\mathrm{dd}, J=11.4,7.2 \mathrm{~Hz}, 2 \mathrm{H}), 1.92-1.82(\mathrm{~m}, 2 \mathrm{H}), 1.71(\mathrm{dt}, J=12.9,3.8 \mathrm{~Hz}, 2 \mathrm{H})$, $1.63-1.52(\mathrm{~m}, 2 \mathrm{H}), 1.36-1.19(\mathrm{~m}, 9 \mathrm{H}), 1.19-1.11(\mathrm{~m}, 1 \mathrm{H}), 1.11-1.00(\mathrm{~m}, 3 \mathrm{H}), 0.90-0.84$ $(\mathrm{m}, 6 \mathrm{H}) .{ }^{13} \mathbf{C}$ NMR (126 MHz, $\left.\mathbf{C D C l}_{3}\right) \delta$ 57.2, 52.5, 35.0, 32.4, 32.1, 29.7, 26.5, 25.8, 25.1, 22.7, 18.2, 14.1. HRMS (ESI) exact mass calculated for $[\mathrm{M}+\mathrm{H}]^{+}\left(\mathrm{C}_{14} \mathrm{H}_{30} \mathrm{~N}\right)$ requires $\mathrm{m} / \mathrm{z} 211.23000$, found $\mathrm{m} / \mathrm{z} 211.22973$, difference $1.28 \mathrm{ppm}$.

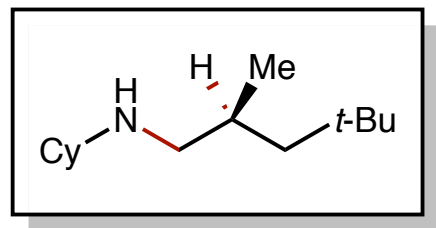

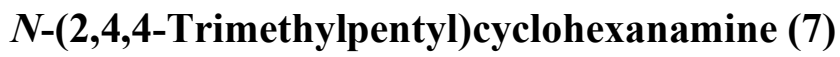


The reaction was set up following general procedure $\mathrm{C}$ using cyclohexylamine ( $50 \mathrm{mg}, 0.5 \mathrm{mmol}$ ) and 2,4,4-trimethylpent-1-ene (168 $\mathrm{mg}, 1.5 \mathrm{mmol}, 3.0$ equiv). The reaction was purified by the general workup procedure to give the title compound in an average isolated yield of $72 \%$ (76.3 mg). IR (neat): 2926, 2853, 1465, 1450, 1364, 1129, 717. ${ }^{\mathbf{1}} \mathbf{H}$ NMR (500 MHz, CDCl $) \delta 2.55$ $(\mathrm{dd}, J=11.3,5.5 \mathrm{~Hz}, 1 \mathrm{H}), 2.45-2.33(\mathrm{~m}, 2 \mathrm{H}), 1.93-1.85(\mathrm{~m}, 2 \mathrm{H}), 1.74(\mathrm{ddd}, J=12.5,5.8,2.7$ $\mathrm{Hz}, 2 \mathrm{H}), 1.69-1.59(\mathrm{~m}, 2 \mathrm{H}), 1.33-1.15(\mathrm{~m}, 4 \mathrm{H}), 1.15-1.01(\mathrm{~m}, 3 \mathrm{H}), 0.97$ (d, J=6.7 Hz, 3H), 0.92 (s, 9H). ${ }^{13} \mathbf{C}$ NMR (126 MHz, $\left.\mathbf{C D C l}_{3}\right) \delta$ 57.0, 55.3, 49.6, 33.8, 33.7, 30.1, 29.9, 26.4, 25.3, 21.2. HRMS (ESI) exact mass calculated for $[\mathrm{M}+\mathrm{H}]^{+}\left(\mathrm{C}_{14} \mathrm{H}_{30} \mathrm{~N}\right)$ requires $\mathrm{m} / \mathrm{z} 211.23000$, found $\mathrm{m} / \mathrm{z} 211.22976$, difference $1.14 \mathrm{ppm}$.

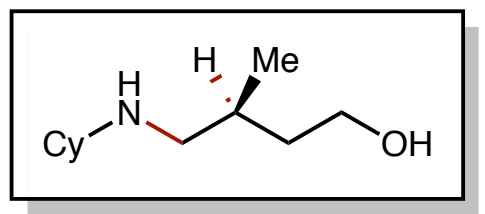

\section{4-(Cyclohexylamino)-3-methylbutan-1-ol (8)}

The reaction was set up following general procedure B using cyclohexylamine $(50 \mathrm{mg}, 0.5 \mathrm{mmol})$ and 3-methylbut-3-en-1-ol (258 mg, $3 \mathrm{mmol}, 6.0$ equiv). The reaction was purified by the general workup procedure to give the title compound in an average isolated yield of 54\% (50.0 mg). IR (neat): $3265,2926,2852,1450,1370,1097,1057,995,891,844,730 .{ }^{1}$ H NMR (500 MHz, $\left.\mathbf{C D C l}_{3}\right) \delta 3.66(\mathrm{ddd}, J=11.5,5.6,2.9 \mathrm{~Hz}, 1 \mathrm{H}), 3.51(\mathrm{ddd}, J=11.7,9.6,2.1 \mathrm{~Hz}, 1 \mathrm{H}), 2.70(\mathrm{dd}, J$ $=11.6,2.7 \mathrm{~Hz}, 1 \mathrm{H}), 2.41(\mathrm{tt}, J=10.5,3.8 \mathrm{~Hz}, 1 \mathrm{H}), 2.34(\mathrm{dd}, J=11.7,9.6 \mathrm{~Hz}, 1 \mathrm{H}), 1.97-1.85$ $(\mathrm{m}, 2 \mathrm{H}), 1.76-1.68(\mathrm{~m}, 3 \mathrm{H}), 1.65-1.57(\mathrm{~m}, 3 \mathrm{H}), 1.45(\mathrm{dtd}, J=14.6,9.4,2.8 \mathrm{~Hz}, 1 \mathrm{H}), 1.31-$ $1.01(\mathrm{~m}, 6 \mathrm{H}), 0.95(\mathrm{~d}, J=7.0 \mathrm{~Hz}, 3 \mathrm{H}) .{ }^{13} \mathbf{C}$ NMR (126 MHz, $\left.\mathbf{C D C l}_{3}\right) \delta$ 61.3, 56.9, 53.6, 41.4, 35.4, 33.6, 32.9, 26.1, 25.2, 25.1, 20.9. HRMS (ESI) exact mass calculated for $[\mathrm{M}+\mathrm{H}]^{+}$ $\left(\mathrm{C}_{11} \mathrm{H}_{24} \mathrm{NO}\right)$ requires $\mathrm{m} / \mathrm{z} 185.17796$, found $\mathrm{m} / \mathrm{z} 185.17829$, difference $1.77 \mathrm{ppm}$.

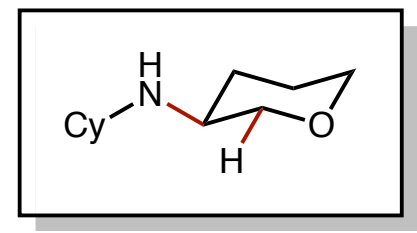

\section{N-Cyclohexyltetrahydro-2H-pyran-3-amine (9)}

The reaction was set up following general procedure $\mathrm{C}$ using cyclohexylamine $(50 \mathrm{mg}, 0.5 \mathrm{mmol})$ and 2,4,4-trimethylpent-1-ene (168 $\mathrm{mg}, 1.5 \mathrm{mmol}, 3.0$ equiv). The reaction was purified by the general workup procedure to give a 3:1 mixture of desired product:hemiaminal (the product of the acid-catalyzed addition). This was further purified via flash chromatography on silica gel, eluting with 3\% acetone in $\mathrm{CH}_{2} \mathrm{Cl}_{2}$. The title compound was isolated in an average isolated yield of 54\% (49.6 mg). IR (neat): 2924, 2850, 1465, 1449, 1067, 913, 859, 731. ${ }^{\mathbf{1}} \mathbf{H}$ NMR (500 MHz, CDCl $\left.\mathbf{~}_{3}\right)$ $\delta 3.90-3.85(\mathrm{~m}, 1 \mathrm{H}), 3.78(\mathrm{dt}, J=10.9,3.8 \mathrm{~Hz}, 1 \mathrm{H}), 3.39$ (td, $J=11.0,3.0 \mathrm{~Hz}, 1 \mathrm{H}), 3.12(\mathrm{dd}, J$ $=10.8,8.7 \mathrm{~Hz}, 1 \mathrm{H}), 2.75(\mathrm{dt}, J=8.9,4.6 \mathrm{~Hz}, 1 \mathrm{H}), 2.50(\mathrm{dd}, J=14.3,6.8 \mathrm{~Hz}, 1 \mathrm{H}), 1.99-1.89(\mathrm{~m}$, $1 \mathrm{H}), 1.89-1.78(\mathrm{~m}, 2 \mathrm{H}), 1.72(\mathrm{dd}, J=9.8,4.6 \mathrm{~Hz}, 2 \mathrm{H}), 1.66(\mathrm{dt}, J=8.4,4.4 \mathrm{~Hz}, 1 \mathrm{H}), 1.60(\mathrm{dq}, J$ $=9.6,5.0,3.8 \mathrm{~Hz}, 2 \mathrm{H}), 1.26$ (dddd, $\mathrm{J}=28.8,16.0,9.9,3.4 \mathrm{~Hz}, 3 \mathrm{H}), 1.14$ (ddd, J = 15.9, 12.2, 3.3 $\mathrm{Hz}, 1 \mathrm{H}), 1.03$ (dddd, $J=19.0,12.2,8.0,4.0 \mathrm{~Hz}, 2 \mathrm{H}) .{ }^{13} \mathbf{C}$ NMR (126 MHz, CDCl 3 ) $\delta 73.3,68.3$, 53.8, 50.1, 34.4, 34.3, 31.1, 26.2, 25.29, 25.26, 24.9. HRMS (ESI) exact mass calculated for $[\mathrm{M}+\mathrm{H}]^{+}\left(\mathrm{C}_{11} \mathrm{H}_{22} \mathrm{NO}\right)$ requires $\mathrm{m} / \mathrm{z} 183.16231$, found $\mathrm{m} / \mathrm{z} 183.16247$, difference $0.85 \mathrm{ppm}$. 


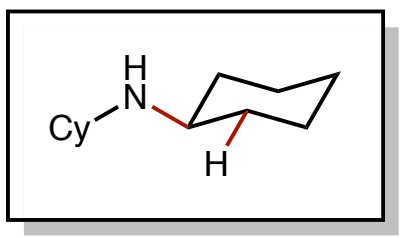

\section{Dicyclohexylamine (10)}

The reaction was set up following general procedure B using cyclohexylamine ( $50 \mathrm{mg}, 0.5 \mathrm{mmol})$ and cyclohexene (246 mg, $3 \mathrm{mmol}, 6.0$ equiv). The reaction was purified by the general workup procedure to give the title compound in an average isolated yield of $62 \%$ (56.4 mg). Spectral data matches published literature spectra. ${ }^{9}$

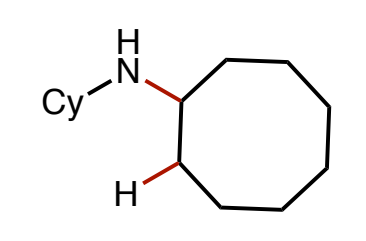

\section{$\mathrm{N}$-Cyclohexylcyclooctanamine (11)}

The reaction was set up following general procedure B using cyclohexylamine (50 $\mathrm{mg}, 0.5 \mathrm{mmol})$ and ( $Z$ )-cyclooctene ( $331 \mathrm{mg}, 3 \mathrm{mmol}, 6.0$ equiv). The reaction was purified by the general workup procedure to give the title compound in an average isolated yield of $57 \%$ (59.8 $\mathrm{mg}$ ). IR (neat): 2918, 2850, 1465, 1446, 1365, 1114, 887, 696. ${ }^{1} \mathbf{H}$ NMR (500 MHz, $\left.\mathbf{C D C l}_{3}\right) \delta 2.81$ (tt, $J=7.9$, $3.3 \mathrm{~Hz}, 1 \mathrm{H}), 2.47(\mathrm{tt}, J=10.6,3.8 \mathrm{~Hz}, 1 \mathrm{H}), 1.85(\mathrm{dd}, J=11.9,3.5 \mathrm{~Hz}, 2 \mathrm{H}), 1.71$ (ddt, $J=11.8$, 8.1, 4.3 Hz, 6H), $1.64-1.52(\mathrm{~m}, 4 \mathrm{H}), 1.51-1.38(\mathrm{~m}, 7 \mathrm{H}), 1.25$ (qt, $J=12.6,3.4 \mathrm{~Hz}, 3 \mathrm{H}), 1.15$

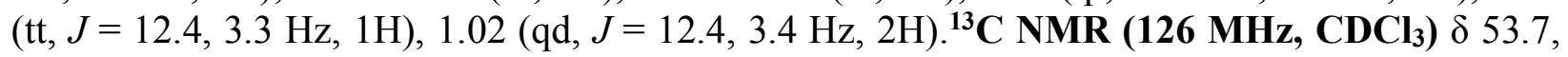
53.5, 34.2, 33.3, 27.3, 26.2, 25.9, 25.4, 24.3. HRMS (ESI) exact mass calculated for $[\mathrm{M}+\mathrm{H}]^{+}$ $\left(\mathrm{C}_{14} \mathrm{H}_{28} \mathrm{~N}\right)$ requires $\mathrm{m} / \mathrm{z} 209.21435$, found $\mathrm{m} / \mathrm{z} 209.21400$, difference $1.65 \mathrm{ppm}$.

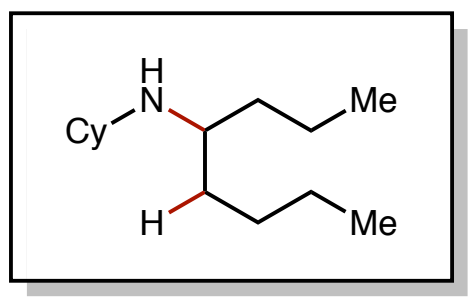

\section{$N$-(Octan-4-yl)cyclohexanamine (12)}

The reaction was set up following general procedure B using cyclohexylamine ( $50 \mathrm{mg}, 0.5 \mathrm{mmol})$ and either cis- or trans-4-octene ( $337 \mathrm{mg}, 3 \mathrm{mmol}, 6.0$ equiv). The reaction was purified by the general workup procedure to give the title compound in an average isolated yield of $68 \%$ (72.1 $\mathrm{mg}$ ) from trans-4-octene and 56\% (59.4 mg) from cis-4-octene. IR (neat): 2929, 2855, 1449, 1421, 1247, 1183, 1048, 893, 670. ${ }^{1} \mathbf{H}$ NMR (500 MHz, $\left.\mathbf{C D C l}_{3}\right) \delta 2.58(\mathrm{p}, J=5.6 \mathrm{~Hz}, 1 \mathrm{H}), 2.45$ $(\mathrm{tt}, J=10.3,3.7 \mathrm{~Hz}, 1 \mathrm{H}), 1.87(\mathrm{dt}, J=12.5,3.8 \mathrm{~Hz}, 2 \mathrm{H}), 1.73(\mathrm{dt}, J=13.0,3.7 \mathrm{~Hz}, 2 \mathrm{H}), 1.62(\mathrm{dt}$, $J=12.9,3.9 \mathrm{~Hz}, 1 \mathrm{H}), 1.41-1.22(\mathrm{~m}, 12 \mathrm{H}), 1.18(\mathrm{tt}, J=12.3,3.3 \mathrm{~Hz}, 1 \mathrm{H}), 1.03(\mathrm{qd}, J=12.5,3.5$ $\mathrm{Hz}, 2 \mathrm{H}), 0.96-0.86(\mathrm{~m}, 6 \mathrm{H}) .{ }^{13} \mathbf{C} \mathbf{N M R}\left(126 \mathbf{M H z}, \mathbf{C D C l}_{3}\right) \delta 54.1,54.0,37.5,34.9,34.6,28.2$, 
26.4, 25.5, 23.2, 19.2, 14.6, 14.3. HRMS (ESI) exact mass calculated for $[\mathrm{M}+\mathrm{H}]^{+}\left(\mathrm{C}_{14} \mathrm{H}_{30} \mathrm{~N}\right)$ requires $\mathrm{m} / \mathrm{z} 211.23000$, found $\mathrm{m} / \mathrm{z} 211.23038$, difference $1.81 \mathrm{ppm}$.

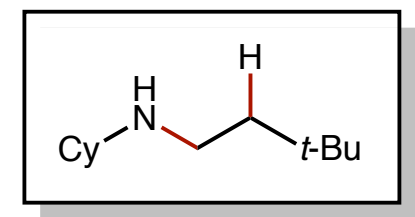

$N$-(3,3-Dimethylbutyl)cyclohexanamine (13)

The reaction was set up following general procedure B using cyclohexylamine (50 $\mathrm{mg}, 0.5 \mathrm{mmol})$ and 3,3-dimethylbut-1-ene ( $252 \mathrm{mg}, 3 \mathrm{mmol}, 6.0$ equiv). The reaction was purified by the general workup procedure to give the title compound in an average isolated yield of $43 \%$ (39.6 $\mathrm{mg})$. IR (neat): 2925, 2852, 1450, 1364, 1450, 1128, 733. ${ }^{1} \mathbf{H}$ NMR (500 MHz, $\left.\mathbf{C D C l}_{3}\right) \delta 2.65-2.58(\mathrm{~m}$, 2H), $2.42(\mathrm{tt}, J=10.6,3.7 \mathrm{~Hz}, 1 \mathrm{H}), 1.89(\mathrm{dd}, J=12.7,3.6 \mathrm{~Hz}, 2 \mathrm{H}), 1.72(\mathrm{dt}, J=12.9,3.6 \mathrm{~Hz}, 2 \mathrm{H})$, $1.61(\mathrm{dt}, J=12.4,3.2 \mathrm{~Hz}, 1 \mathrm{H}), 1.42-1.36(\mathrm{~m}, 2 \mathrm{H}), 1.31-1.20(\mathrm{~m}, 3 \mathrm{H}), 1.16(\mathrm{tt}, J=12.3,3.3 \mathrm{~Hz}$, 1H), $1.11-1.02(\mathrm{~m}, 2 \mathrm{H}), 0.90$ (s, 9H). ${ }^{13} \mathbf{C}$ NMR (126 MHz, $\left.\mathbf{C D C l}_{3}\right) \delta$ 57.3, 44.6, 43.2, 33.8, 30.0, 29.8, 26.3, 25.3. HRMS (ESI) exact mass calculated for $[\mathrm{M}+\mathrm{H}]^{+}\left(\mathrm{C}_{12} \mathrm{H}_{26} \mathrm{~N}\right)$ requires $\mathrm{m} / \mathrm{z}$ 183.19870, found $\mathrm{m} / \mathrm{z} 183.19897$, difference $1.47 \mathrm{ppm}$.

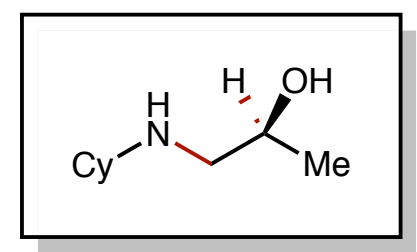

\section{1-(Cyclohexylamino)propan-2-ol (14)}

The reaction was set up following general procedure B using cyclohexylamine $(50 \mathrm{mg}, 0.5 \mathrm{mmol})$ and trimethyl(prop-1-en-2-yloxy)silane (391 mg, $3 \mathrm{mmol}, 6.0$ equiv). The reaction was purified by the general workup procedure to give the title compound in an average isolated yield of 74\% (58.5 mg). IR (neat): 3316, 2927, 2853, 1647, 1450, 1372, 1123, 922, 892, 843, 730. ${ }^{\mathbf{1}} \mathbf{H}$ NMR $\left(\mathbf{5 0 0} \mathbf{M H z}, \mathbf{C D C l}_{3}\right) \delta 3.71(\mathrm{dqt}, J=9.3,6.2,2.4 \mathrm{~Hz}, 1 \mathrm{H}), 2.78(\mathrm{dd}, J=12.0,3.2 \mathrm{~Hz}, 1 \mathrm{H}), 2.46-$ $2.32(\mathrm{~m}, 2 \mathrm{H}), 2.32-2.16(\mathrm{~m}, 2 \mathrm{H}), 1.90(\mathrm{t}, J=13.4 \mathrm{~Hz}, 2 \mathrm{H}), 1.72(\mathrm{dt}, J=12.4,3.8 \mathrm{~Hz}, 2 \mathrm{H}), 1.60$ (ddd, $J=12.6,6.2,3.7 \mathrm{~Hz}, 1 \mathrm{H}), 1.31-1.18(\mathrm{~m}, 3 \mathrm{H}), 1.14$ (d, $J=6.2 \mathrm{~Hz}, 3 \mathrm{H}), 1.05$ (ddd, $J=12.8$, 10.6, $3.3 \mathrm{~Hz}, 2 \mathrm{H}) .{ }^{13} \mathbf{C}$ NMR (126 MHz, $\left.\mathbf{C D C l}_{3}\right) \delta$ 66.0, 56.7, 53.9, 34.1, 33.6, 26.2 2 25.18, 25.15, 20.6. HRMS (ESI) exact mass calculated for $[\mathrm{M}+\mathrm{H}]^{+}\left(\mathrm{C}_{9} \mathrm{H}_{20} \mathrm{NO}\right)$ requires $\mathrm{m} / \mathrm{z} 157.14666$, found $\mathrm{m} / \mathrm{z} 157.14639$, difference $1.74 \mathrm{ppm}$.

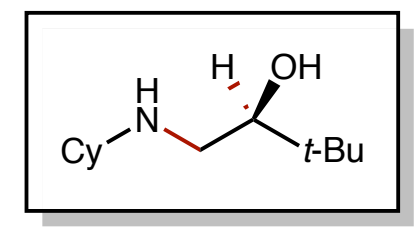

\section{1-(Cyclohexylamino)-3,3-dimethylbutan-2-ol (15)}

The reaction was set up following general procedure B using cyclohexylamine $(50 \mathrm{mg}, 0.5 \mathrm{mmol})$ and ((3,3-dimethylbut-1-en-2-yl)oxy)trimethylsilane (259 mg, $1.5 \mathrm{mmol}, 3.0$ equiv). The reaction was purified by the general workup procedure to give the title compound in an average isolated yield of $80 \%$ (80.0 mg). IR (neat): 3250, 2927, 2849, 1770, 1383, 1244, 1089, 925, 873. ${ }^{1} \mathbf{H}$ NMR 
(500 MHz, CDCl $\mathbf{3}) \delta 3.17(\mathrm{dd}, J=10.6,2.9 \mathrm{~Hz}, 1 \mathrm{H}), 2.84(\mathrm{dd}, J=11.8,3.0 \mathrm{~Hz}, 1 \mathrm{H}), 2.44-2.33$ $(\mathrm{m}, 2 \mathrm{H}), 1.95-1.83(\mathrm{~m}, 2 \mathrm{H}), 1.72$ (ddd, $J=13.7,6.0,2.9 \mathrm{~Hz}, 2 \mathrm{H}), 1.64-1.56(\mathrm{~m}, 1 \mathrm{H}), 1.32-$

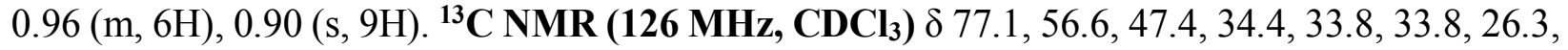
25.9, 25.22, 25.19. HRMS (ESI) exact mass calculated for $[\mathrm{M}+\mathrm{H}]^{+}\left(\mathrm{C}_{12} \mathrm{H}_{26} \mathrm{NO}\right)$ requires $\mathrm{m} / \mathrm{z}$ 199.19361, found $\mathrm{m} / \mathrm{z} 199.19346$, difference $0.76 \mathrm{ppm}$.

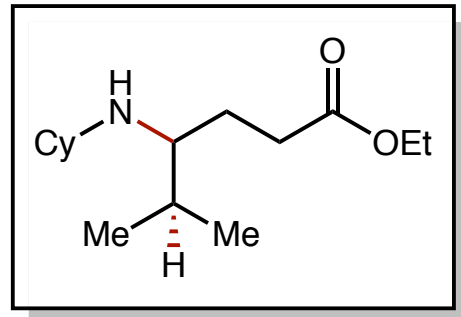

Ethyl 4-(cyclohexylamino)-5-methylhexanoate (16)

The reaction was set up following general procedure B using cyclohexylamine (50 mg, $0.5 \mathrm{mmol}$ ) and ethyl 5-methylhex-4-enoate (469 mg, $3 \mathrm{mmol}, 6.0$ equiv). The reaction was purified by the general workup procedure to give the title compound in an average isolated yield of $56 \%(71.7$ mg). IR (neat): 2928, 2854, 1733, 1674, 1448, 1421, 1247, 1182, 730, 672. ${ }^{\mathbf{1}} \mathbf{H}$ NMR (500 MHz, $\left.\mathbf{C D C l}_{3}\right) \delta 4.11(\mathrm{q}, J=7.1 \mathrm{~Hz}, 2 \mathrm{H}), 2.44-2.36(\mathrm{~m}, 2 \mathrm{H}), 2.36-2.28(\mathrm{~m}, 2 \mathrm{H}), 1.82-1.65(\mathrm{~m}, 6 \mathrm{H})$, 1.57 (ddd, $J=11.3,5.7,3.0 \mathrm{~Hz}, 1 \mathrm{H}), 1.44(\mathrm{dtd}, J=13.3,7.5,5.5 \mathrm{~Hz}, 1 \mathrm{H}), 1.24(\mathrm{t}, J=7.1 \mathrm{~Hz}, 4 \mathrm{H})$, 1.16 (ddt, $J=27.3,12.2,4.0 \mathrm{~Hz}, 3 \mathrm{H}), 1.00$ (tddd, $J=16.2,12.7,8.1,3.7 \mathrm{~Hz}, 2 \mathrm{H}), 0.87$ (d, $J=6.9$ $\mathrm{Hz}, 3 \mathrm{H}), 0.84(\mathrm{~d}, J=6.9 \mathrm{~Hz}, 3 \mathrm{H}) .{ }^{13} \mathbf{C}$ NMR (126 MHz, CDCl $\left.\mathbf{3}\right)$ 174.4, 60.2, 58.8, 54.3, 34.5, 34.2, 31.6, 30.3, 26.5, 26.2, 25.2, 25.0, 18.9, 17.6, 14.3. HRMS (ESI) exact mass calculated for $[\mathrm{M}+\mathrm{H}]^{+}\left(\mathrm{C}_{15} \mathrm{H}_{30} \mathrm{NO}_{2}\right)$ requires $\mathrm{m} / \mathrm{z} 255.21983$, found $\mathrm{m} / \mathrm{z} 255.21959$, difference $0.95 \mathrm{ppm}$.

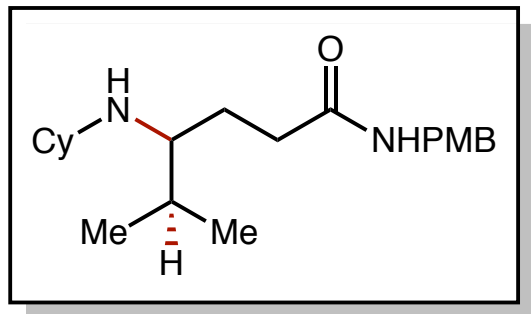

\section{4-(Cyclohexylamino)- $\mathrm{N}$-(4-methoxybenzyl)-5-methylhexanamide (17)}

The reaction was set up following general procedure B using cyclohexylamine (50 mg, $0.5 \mathrm{mmol})$ and $N$-(4-Methoxybenzyl)-5-methylhex-4-enamide (742 mg, $3 \mathrm{mmol}, 6.0$ equiv). The reaction was purified by the general workup procedure to give the title compound in an average isolated yield of $62 \%$ (107.2 mg). IR (neat): 3289, 2926, 2852, 1641, 1544, 1512, 1246, 1175, 1035, 909, 817, 729. ${ }^{1} \mathbf{H}$ NMR (500 MHz, $\left.\mathbf{C D C l}_{3}\right) \delta 7.33(\mathrm{~s}, 1 \mathrm{H}), 7.21(\mathrm{~d}, J=8.5 \mathrm{~Hz}, 2 \mathrm{H}), 6.85(\mathrm{~d}, J=8.6 \mathrm{~Hz}$, $2 \mathrm{H}), 4.35(\mathrm{~d}, J=5.5 \mathrm{~Hz}, 2 \mathrm{H}), 3.79(\mathrm{~s}, 3 \mathrm{H}), 2.45-2.37(\mathrm{~m}, 2 \mathrm{H}), 2.34(\mathrm{q}, J=6.8 \mathrm{~Hz}, 2 \mathrm{H}), 1.78(\mathrm{~m}$, $3 \mathrm{H}), 1.65(\mathrm{ddd}, J=12.2,8.4,3.8 \mathrm{~Hz}, 3 \mathrm{H}), 1.56(\mathrm{dt}, J=12.6,3.6 \mathrm{~Hz}, 2 \mathrm{H}), 1.43$ (dt, $J=13.4,7.5$ $\mathrm{Hz}, 2 \mathrm{H}), 1.27-1.01(\mathrm{~m}, 4 \mathrm{H}), 0.89(\mathrm{~d}, J=6.9 \mathrm{~Hz}, 3 \mathrm{H}), 0.82(\mathrm{~d}, J=6.8 \mathrm{~Hz}, 3 \mathrm{H}) .{ }^{13} \mathbf{C}$ NMR (126 $\left.\mathbf{M H z}, \mathbf{C D C l}_{3}\right) \delta 173.7,159.1,131.0,129.5,114.1,59.6,55.5,54.2,43.1,34.7,34.5,33.6,29.9$, 26.6, 26.2, 25.3, 25.0, 19.6, 17.0. HRMS (ESI) exact mass calculated for $[\mathrm{M}+\mathrm{H}]^{+}\left(\mathrm{C}_{21} \mathrm{H}_{35} \mathrm{~N}_{2} \mathrm{O}_{2}\right)$ requires $\mathrm{m} / \mathrm{z} 346.26203$, found $\mathrm{m} / \mathrm{z} 346.26198$, difference $0.14 \mathrm{ppm}$. 


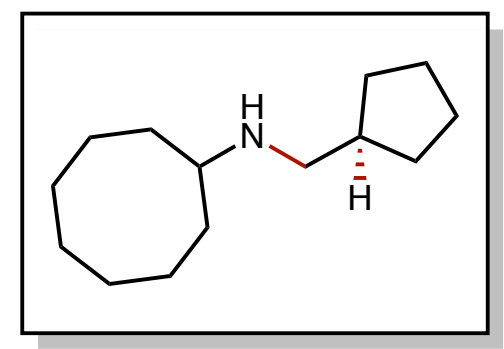

\section{$N$-(Cyclopentylmethyl)cyclooctanamine (18)}

The reaction was set up following general procedure B using cyclooctylamine ( $64 \mathrm{mg}, 0.5 \mathrm{mmol})$ and methylene cyclopentane ( $246 \mathrm{mg}, 3 \mathrm{mmol}, 6.0$ equiv). The reaction was purified by the general workup procedure to give the title compound in an average isolated yield of $68 \%(71.4 \mathrm{mg})$. IR (neat): 2930, 2856, 1770, 1447, 1243, 1115, 723. ${ }^{\mathbf{1}} \mathbf{H}$ NMR (500 MHz, $\left.\mathbf{C D C l}_{3}\right) \delta 2.69-2.63$ (m, $1 \mathrm{H}), 2.54(\mathrm{~d}, J=7.2 \mathrm{~Hz}, 2 \mathrm{H}), 2.01$ (hept, $J=7.7 \mathrm{~Hz}, 1 \mathrm{H}), 1.83-1.68(\mathrm{~m}, 6 \mathrm{H}), 1.66-1.42(\mathrm{~m}$, $15 \mathrm{H}), 1.16(\mathrm{dq}, J=15.0,7.4 \mathrm{~Hz}, 2 \mathrm{H}) .{ }^{13} \mathbf{C}$ NMR (126 MHz, $\left.\mathbf{C D C l}_{3}\right) \delta 58.4,53.6,40.3,33.0,31.2$, $27.4,26.0,25.5,24.4$. HRMS (ESI) exact mass calculated for $[\mathrm{M}+\mathrm{H}]^{+}\left(\mathrm{C}_{14} \mathrm{H}_{28} \mathrm{~N}\right)$ requires $\mathrm{m} / \mathrm{z}$ 209.21435, found $\mathrm{m} / \mathrm{z} 209.21451$, difference $0.78 \mathrm{ppm}$.

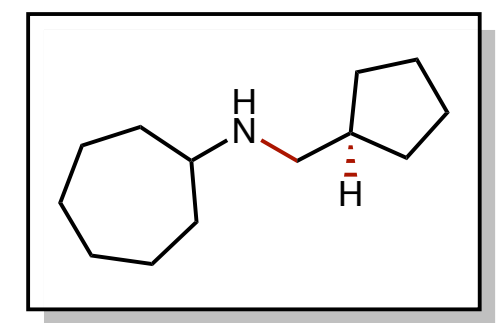

\section{$N$-(Cyclopentylmethyl)cycloheptylamine (19)}

The reaction was set up following general procedure B using cycloheptylamine ( $57 \mathrm{mg}, 0.5 \mathrm{mmol})$ and methylene cyclopentane ( $246 \mathrm{mg}, 3 \mathrm{mmol}, 6.0$ equiv). The reaction was purified by the general workup procedure to give the title compound in an average isolated yield of $81 \%$ (79 $\mathrm{mg}$ ). IR (neat): 2920, 2855, 1455, 1363, 1118, 948, 826, 724. ${ }^{1} \mathbf{H}$ NMR (500 MHz, $\left.\mathbf{C D C l}_{3}\right) \delta 2.57$ (tt, $J=$ 8.2, $4.0 \mathrm{~Hz}, 1 \mathrm{H}), 2.51$ (d, $J=7.2 \mathrm{~Hz}, 2 \mathrm{H}), 1.97$ (hept, $J=7.7 \mathrm{~Hz}, 1 \mathrm{H}), 1.85-1.70(\mathrm{~m}, 4 \mathrm{H}), 1.69-$ $1.45(\mathrm{~m}, 10 \mathrm{H}), 1.46-1.31(\mathrm{~m}, 4 \mathrm{H}), 1.19-1.08(\mathrm{~m}, 2 \mathrm{H}) .{ }^{13} \mathbf{C}$ NMR (126 MHz, CDCl $) \delta 59.5$, 53.6, 40.2 , 35.0, 31.0, 28.2, 25.3, 24.6. HRMS (ESI) exact mass calculated for $[\mathrm{M}+\mathrm{H}]^{+}\left(\mathrm{C}_{13} \mathrm{H}_{26} \mathrm{~N}\right)$ requires $\mathrm{m} / \mathrm{z} 195.19870$, found $\mathrm{m} / \mathrm{z} 195.19849$, difference $1.08 \mathrm{ppm}$.

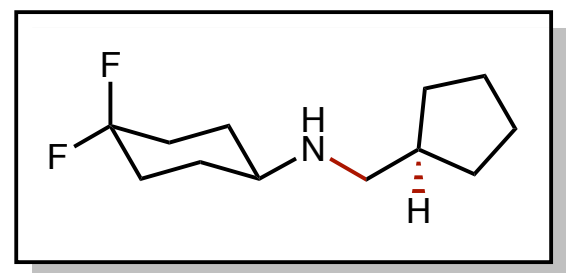

\section{$\mathrm{N}$-(Cyclopentylmethyl)-4,4-difluorocyclohexan-1-amine (20)}

The reaction was set up following general procedure D using 4,4-Difluorocyclohexanamine $\bullet \mathrm{HCl}$ ( $86 \mathrm{mg}, 0.5 \mathrm{mmol}$ ), methylene cyclopentane ( $246 \mathrm{mg}, 3 \mathrm{mmol}, 6.0$ equiv), and $\mathrm{LiOH}$ (12 mg, 0.5 mmol, 1 equiv). The reaction was purified by the general workup procedure to give the title compound in an average isolated yield of $61 \%(66.5 \mathrm{mg})$. IR (neat): 2929, 2855, 1770, 1449, 1375, 1245, 965, 735. ${ }^{1} \mathbf{H}$ NMR (500 MHz, $\left.\mathbf{C D C l}_{3}\right) \delta 2.63-2.55(\mathrm{~m}, 1 \mathrm{H}), 2.53(\mathrm{~d}, J=7.1 \mathrm{~Hz}$, 
2H), $2.14-2.04(\mathrm{~m}, 2 \mathrm{H}), 1.97$ (hept, $J=7.6 \mathrm{~Hz}, 1 \mathrm{H}), 1.91-1.84(\mathrm{~m}, 2 \mathrm{H}), 1.81-1.67(\mathrm{~m}, 4 \mathrm{H})$, $1.64-1.43(\mathrm{~m}, 6 \mathrm{H}), 1.17-1.09(\mathrm{~m}, 2 \mathrm{H}) .{ }^{13} \mathbf{C}$ NMR (126 MHz, CDCl$) \delta 123.6(\mathrm{t}, J=240.9 \mathrm{~Hz})$, 54.4, 53.4, 40.3, $31.8(\mathrm{t}, J=24.4 \mathrm{~Hz}), 31.1,29.0(\mathrm{t}, J=5.1 \mathrm{~Hz}), 25.4 .{ }^{19} \mathbf{F}$ NMR (282 MHz, CDCl 3$)$ $\delta-95.28(\mathrm{~d}, J=239.0 \mathrm{~Hz}),-99.12(\mathrm{~d}, J=241.8 \mathrm{~Hz})$. HRMS (ESI) exact mass calculated for $[\mathrm{M}+\mathrm{H}]^{+}\left(\mathrm{C}_{12} \mathrm{H}_{22} \mathrm{~F}_{2} \mathrm{~N}\right)$ requires $\mathrm{m} / \mathrm{z} 217.16421$, found $\mathrm{m} / \mathrm{z} 217.16395$, difference $0.78 \mathrm{ppm}$.

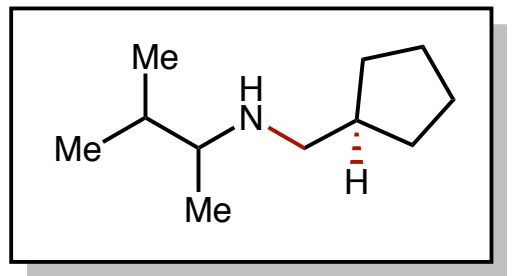

$N$-(Cyclopentylmethyl)-3-methylbutan-2-amine (21)

The reaction was set up following general procedure B using 3-methylbutan-2-amine (44 mg, 0.5 $\mathrm{mmol}$ ) and methylene cyclopentane ( $246 \mathrm{mg}, 3 \mathrm{mmol}, 6.0$ equiv). The reaction was purified by the general workup procedure to give the title compound in an average isolated yield of 56\% (47.6 mg). IR (neat): 2952, 2867, 1759, 1566, 1456, 1379, 1244, 1113, 733. ${ }^{1}$ H NMR (500 MHz, $\left.\mathbf{C D C l}_{3}\right) \delta 2.58(\mathrm{dd}, J=11.2,7.0 \mathrm{~Hz}, 1 \mathrm{H}), 2.45(\mathrm{td}, J=7.5,3.5 \mathrm{~Hz}, 2 \mathrm{H}), 2.01$ (hept, $J=7.8 \mathrm{~Hz}$, $1 \mathrm{H}), 1.82-1.73(\mathrm{~m}, 2 \mathrm{H}), 1.70(\mathrm{qd}, J=6.8,5.1 \mathrm{~Hz}, 1 \mathrm{H}), 1.63-1.47(\mathrm{~m}, 5 \mathrm{H}), 1.19-1.09(\mathrm{~m}, 2 \mathrm{H})$, $0.97(\mathrm{~d}, J=6.4 \mathrm{~Hz}, 3 \mathrm{H}), 0.90(\mathrm{~d}, \mathrm{~J}=6.8 \mathrm{~Hz}, 3 \mathrm{H}), 0.86(\mathrm{~d}, J=6.8 \mathrm{~Hz}, 3 \mathrm{H}) .{ }^{13} \mathbf{C}$ NMR (126 MHz, $\left.\mathbf{C D C l}_{3}\right) \delta 58.6,53.4,40.0,32.0,31.0,31.0,25.4,25.3,19.5,17.2,16.0$. HRMS (ESI) exact mass calculated for $[\mathrm{M}+\mathrm{H}]^{+}\left(\mathrm{C}_{11} \mathrm{H}_{24} \mathrm{~N}\right)$ requires $\mathrm{m} / \mathrm{z} 169.18305$, found $\mathrm{m} / \mathrm{z} 169.18293$, difference 0.70 ppm.

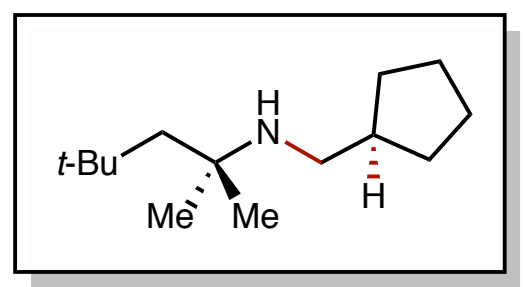

$\mathrm{N}$-(Cyclopentylmethyl)-2,4,4-trimethylpentan-2-amine (22)

The reaction was set up following general procedure B using tert-octylamine (65 $\mathrm{mg}, 0.5 \mathrm{mmol})$ and methylene cyclopentane ( $246 \mathrm{mg}, 3 \mathrm{mmol}, 6.0$ equiv). The reaction was purified by the general workup procedure to give the title compound in an average isolated yield of $55 \%(58.3 \mathrm{mg})$. IR (neat): 2945, 2867, 1474, 1381, 1363, 1229, 1147, 1099, 694. ${ }^{\mathbf{1}} \mathbf{H}$ NMR (500 MHz, CDCl 3 ) $\delta 2.46$ $(\mathrm{d}, J=7.0 \mathrm{~Hz}, 2 \mathrm{H}), 1.89$ (hept, $J=7.6 \mathrm{~Hz}, 1 \mathrm{H}), 1.81-1.72(\mathrm{~m}, 2 \mathrm{H}), 1.64-1.47(\mathrm{~m}, 5 \mathrm{H}), 1.42(\mathrm{~s}$, 2H), $1.17-1.08(\mathrm{~m}, 8 \mathrm{H}), 1.00$ (s, 9H). ${ }^{13} \mathbf{C}$ NMR (126 MHz, CDCl $) \delta ~ 54.1,53.5,47.9,41.0$, $31.9,31.8,31.2,29.0,25.5$. HRMS (ESI) exact mass calculated for $[\mathrm{M}+\mathrm{H}]^{+}\left(\mathrm{C}_{14} \mathrm{H}_{30} \mathrm{~N}\right)$ requires $\mathrm{m} / \mathrm{z} 211.23000$, found $\mathrm{m} / \mathrm{z} 211.23016$, difference $0.74 \mathrm{ppm}$. 


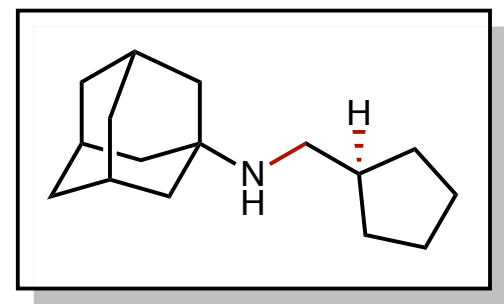

\section{$\mathrm{N}$-(Cyclopentylmethyl)adamantan-1-amine (23)}

The reaction was set up following general procedure B using adamantylamine ( $76 \mathrm{mg}, 0.5 \mathrm{mmol}$ ) and methylene cyclopentane ( $246 \mathrm{mg}, 3 \mathrm{mmol}, 6.0$ equiv). The reaction was purified by the general workup procedure to give the title compound in an average isolated yield of $73 \%(85 \mathrm{mg})$. IR (neat): 2904, 2848, 1469, 1451, 1356, 1311, 1150, 1099, 697. $\left.{ }^{1} \mathbf{H} \mathbf{~ N M R ~ ( 5 0 0 ~ M H z , ~} \mathbf{C D C l}_{3}\right) \delta 2.50$ (d, $J=7.1 \mathrm{~Hz}, 2 \mathrm{H}), 2.10-2.01(\mathrm{~m}, 3 \mathrm{H}), 1.92$ (hept, $J=7.6 \mathrm{~Hz}, 1 \mathrm{H}), 1.84-1.72(\mathrm{~m}, 2 \mathrm{H}), 1.72-$ $1.46(\mathrm{~m}, 17 \mathrm{H}), 1.18-1.05$ (m, 2H). ${ }^{13} \mathbf{C}$ NMR (126 MHz, $\left.\mathbf{C D C l}_{3}\right) \delta 50.1,46.3,42.8,40.7,36.8$, 31.0, 29.6, 25.3. HRMS (ESI) exact mass calculated for $[\mathrm{M}+\mathrm{H}]^{+}\left(\mathrm{C}_{16} \mathrm{H}_{28} \mathrm{~N}\right)$ requires $\mathrm{m} / \mathrm{z}$ 233.21435, found $\mathrm{m} / \mathrm{z} 233.21468$, difference $1.40 \mathrm{ppm}$.

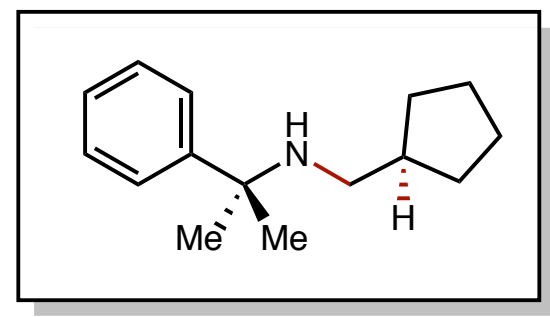

$\mathrm{N}$-(Cyclopentylmethyl)-2-phenylpropan-2-amine (24)

The reaction was set up following general procedure B using cumylamine (68 mg, $0.5 \mathrm{mmol}$ ) and methylene cyclopentane ( $246 \mathrm{mg}, 3 \mathrm{mmol}, 6.0$ equiv). The reaction was purified by the general workup procedure to give the title compound in an average isolated yield of $69 \%(75.2 \mathrm{mg})$. IR (neat): 2950, 2866, 1759, 1494, 1444, 1379, 1238, 1182, 1030, 763. ${ }^{\mathbf{1}} \mathbf{H} \mathbf{~ N M R}\left(\mathbf{5 0 0} \mathbf{~ M H z}, \mathbf{C D C l}_{\mathbf{3}}\right)$ $\delta 7.43(\mathrm{~d}, J=7.3 \mathrm{~Hz}, 2 \mathrm{H}), 7.32(\mathrm{t}, J=7.7 \mathrm{~Hz}, 2 \mathrm{H}), 7.21(\mathrm{t}, J=7.3 \mathrm{~Hz}, 1 \mathrm{H}), 2.24(\mathrm{~d}, J=7.1 \mathrm{~Hz}$, 2H), 1.90 (hept, $J=7.6 \mathrm{~Hz}, 1 \mathrm{H}), 1.78-1.69(\mathrm{~m}, 2 \mathrm{H}), 1.55-1.46(\mathrm{~m}, 5 \mathrm{H}), 1.45(\mathrm{~s}, 6 \mathrm{H}), 1.07$ (dddd, $J=14.7,13.1,7.1,4.3 \mathrm{~Hz}, 2 \mathrm{H}) .{ }^{13} \mathbf{C}$ NMR (126 MHz, $\left.\mathbf{C D C l}_{3}\right) \delta 148.2,128.2,126.2,125.9$, 55.7, 48.9, 40.9, 31.1, 29.8, 25.4. HRMS (ESI) exact mass calculated for $[\mathrm{M}+\mathrm{H}]^{+}\left(\mathrm{C}_{15} \mathrm{H}_{23} \mathrm{~N}\right)$ requires $\mathrm{m} / \mathrm{z} 217.18305$, found $\mathrm{m} / \mathrm{z} 217.18281$, difference $1.09 \mathrm{ppm}$.

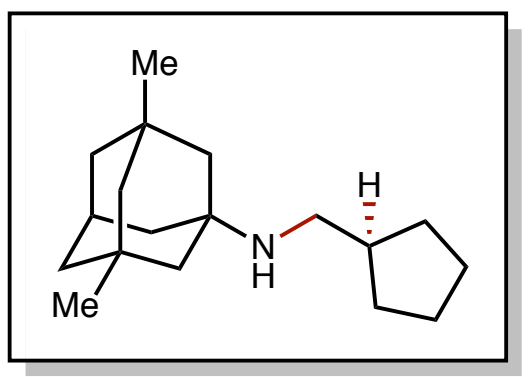

\section{$\mathrm{N}$-(Cyclopentylmethyl)-3,5-dimethyladamantan-1-amine (25)}

The reaction was set up following general procedure D using Memantine $\bullet \mathrm{HCl}(108 \mathrm{mg}, 0.5 \mathrm{mmol})$, methylene cyclopentane ( $246 \mathrm{mg}, 3 \mathrm{mmol}, 6.0$ equiv), and $\mathrm{LiOH}$ (12 mg, $0.5 \mathrm{mmol}, 1$ equiv). The reaction was purified by the general workup procedure to give the title compound in an average 
isolated yield of $67 \%$ ( $87.8 \mathrm{mg}$ ). IR (neat): $2943,2898,2862,2839,1453,1355,1337,1196$, 1117, 708, 681. ${ }^{1} \mathbf{H}$ NMR (500 MHz, $\left.\mathbf{C D C l}_{3}\right) \delta 2.49(\mathrm{~d}, J=7.1 \mathrm{~Hz}, 2 \mathrm{H}), 2.12(\mathrm{p}, J=3.2 \mathrm{~Hz}, 1 \mathrm{H})$, 1.91 (hept, $J=7.6 \mathrm{~Hz}, 1 \mathrm{H}), 1.81-1.72(\mathrm{~m}, 2 \mathrm{H}), 1.63-1.48(\mathrm{~m}, 4 \mathrm{H}), 1.46(\mathrm{~d}, J=3.1 \mathrm{~Hz}, 2 \mathrm{H})$, $1.33-1.19(\mathrm{~m}, 9 \mathrm{H}), 1.16-1.05(\mathrm{~m}, 4 \mathrm{H}), 0.83(\mathrm{~s}, 6 \mathrm{H}) .{ }^{13} \mathbf{C}$ NMR (126 MHz, CDCl $\left.\mathbf{3}\right) \delta 52.1,51.2$, 49.2, 46.7, 43.3, 41.5, 40.9, 32.5, 31.2, 30.54, 30.48, 25.5. HRMS (ESI) exact mass calculated for $[\mathrm{M}+\mathrm{H}]^{+}\left(\mathrm{C}_{18} \mathrm{H}_{32} \mathrm{~N}\right)$ requires $\mathrm{m} / \mathrm{z} 261.24565$, found $\mathrm{m} / \mathrm{z} 261.24528$, difference $1.42 \mathrm{ppm}$.

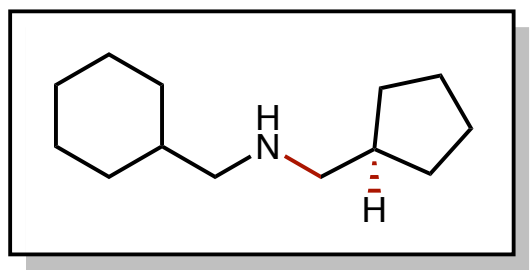

\section{1-Cyclohexyl- $N$-(cyclopentylmethyl)methanamine (26)}

The reaction was set up following general procedure B using cyclohexylmethanamine $(57 \mathrm{mg}, 0.5$ $\mathrm{mmol}$ ) and methylene cyclopentane $(246 \mathrm{mg}, 3 \mathrm{mmol}, 6.0$ equiv). The reaction was purified by the general workup procedure to give the title compound in an average isolated yield of $74 \%$ ( 72 mg). IR (neat): 2921, 2852, 1449, 1130, 738. ${ }^{1} \mathbf{H}$ NMR (500 MHz, $\left.\mathbf{C D C l}_{3}\right) \delta 2.50(\mathrm{~d}, J=7.2 \mathrm{~Hz}$, $2 \mathrm{H}), 2.43(\mathrm{~d}, J=6.7 \mathrm{~Hz}, 2 \mathrm{H}), 2.01$ (hept, $J=7.6 \mathrm{~Hz}, 1 \mathrm{H}), 1.83-1.41(\mathrm{~m}, 12 \mathrm{H}), 1.34-1.07$ (m, 6H), $0.97-0.80$ (m, 2H). ${ }^{13} \mathbf{C}$ NMR (126 MHz, $\left.\mathbf{C D C l}_{3}\right) \delta$ 57.1, 56.0, 40.0, 37.8, 31.5, 30.9, 26.7, 26.1, 25.3. HRMS (ESI) exact mass calculated for $[\mathrm{M}+\mathrm{H}]^{+}\left(\mathrm{C}_{13} \mathrm{H}_{26} \mathrm{~N}\right)$ requires $\mathrm{m} / \mathrm{z}$ 195.19870, found $\mathrm{m} / \mathrm{z} 195.19908$, difference $1.96 \mathrm{ppm}$.

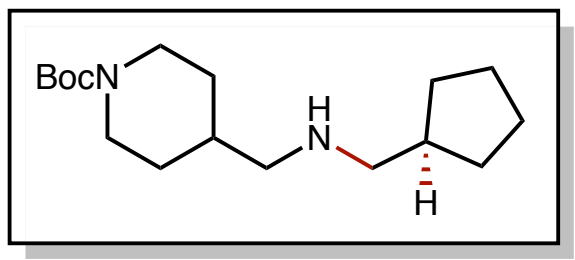

tert-Butyl 4-(((cyclopentylmethyl)amino)methyl)piperidine-1-carboxylate (27)

The reaction was set up following general procedure D using tert-butyl 4(aminomethyl)piperidine-1-carboxylate $\cdot \mathrm{HCl}(125 \mathrm{mg}, 0.5 \mathrm{mmol})$, methylene cyclopentane (246 $\mathrm{mg}, 3 \mathrm{mmol}, 6.0$ equiv), and $\mathrm{LiOH}(12 \mathrm{mg}, 0.5 \mathrm{mmol}, 1$ equiv). The reaction was purified by the general workup procedure to give the title compound in an average isolated yield of 56\% 82.9 mg). IR (neat): 2923, 2862, 1770, 1690, 1450, 1420, 1365, 1243, 1163, 1081, 867, 767. ${ }^{1} \mathbf{H}$ NMR $\left(\mathbf{5 0 0} \mathbf{~ M H z}, \mathbf{C D C l}_{3}\right) \delta 4.09(\mathrm{~s}, 2 \mathrm{H}), 2.80-2.61(\mathrm{~m}, 2 \mathrm{H}), 2.51(\mathrm{~d}, J=7.2 \mathrm{~Hz}, 2 \mathrm{H}), 2.48(\mathrm{~d}, J=6.7$ $\mathrm{Hz}, 2 \mathrm{H}), 2.00$ (hept, $J=7.7 \mathrm{~Hz}, 1 \mathrm{H}), 1.80-1.72$ (m, 2H), 1.69 (dd, $J=13.3,3.3 \mathrm{~Hz}, 2 \mathrm{H}), 1.65-$ $1.48(\mathrm{~m}, 6 \mathrm{H}), 1.45(\mathrm{~s}, 9 \mathrm{H}), 1.18-1.05(\mathrm{~m}, 4 \mathrm{H}) .{ }^{13} \mathbf{C}$ NMR (126 MHz, CDCl $) \delta$ 155.0, 79.4, 56.20, 56.18, 40.2, 36.6, 31.0, 30.6, 29.9, 28.6, 25.5. HRMS (ESI) exact mass calculated for $[\mathrm{M}+\mathrm{H}]^{+}\left(\mathrm{C}_{17} \mathrm{H}_{33} \mathrm{~N}_{2} \mathrm{O}_{2}\right)$ requires $\mathrm{m} / \mathrm{z} 296.24638$, found $\mathrm{m} / \mathrm{z} 296.24622$, difference $0.53 \mathrm{ppm}$. 


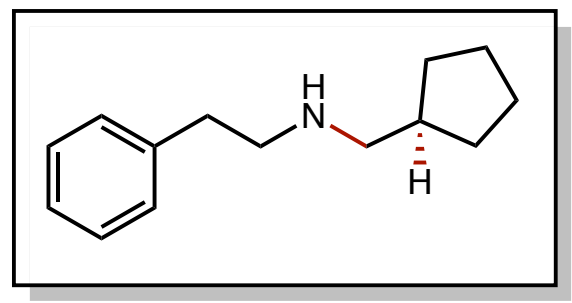

\section{$N$-(Cyclopentylmethyl)-2-phenylethan-1-amine (28)}

The reaction was set up following general procedure B using 2-phenylethanamine $(61 \mathrm{mg}, 0.5$ mmol) and methylene cyclopentane ( $246 \mathrm{mg}, 3 \mathrm{mmol}, 6.0$ equiv). The reaction was purified by the general workup procedure to give the title compound in an average isolated yield of 56\% (57.1 mg). IR (neat): 3027, 2944, 2864, 2808, 1496, 1453, 1336, 1126, 747. ${ }^{1}$ H NMR (500 MHz, $\left.\mathbf{C D C l}_{3}\right) \delta 7.29(\mathrm{t}, J=7.5 \mathrm{~Hz}, 2 \mathrm{H}), 7.24-7.18(\mathrm{~m}, 3 \mathrm{H}), 2.88(\mathrm{t}, J=6.7 \mathrm{~Hz}, 2 \mathrm{H}), 2.81(\mathrm{t}, J=6.9$ $\mathrm{Hz}, 2 \mathrm{H}), 2.56$ (d, $J=7.2 \mathrm{~Hz}, 2 \mathrm{H}), 1.99$ (hept, $J=7.6 \mathrm{~Hz}, 1 \mathrm{H}), 1.79-1.68(\mathrm{~m}, 2 \mathrm{H}), 1.64-1.47$ $(\mathrm{m}, 5 \mathrm{H}), 1.17-1.07(\mathrm{~m}, 2 \mathrm{H}) .{ }^{13} \mathbf{C}$ NMR (126 MHz, $\left.\mathbf{C D C l}_{3}\right) \delta 140.4,128.8,128.6,126.2,55.8$, $51.7,40.2$, 36.6, 31.0, 25.4. HRMS (ESI) exact mass calculated for $[\mathrm{M}+\mathrm{H}]^{+}\left(\mathrm{C}_{14} \mathrm{H}_{22} \mathrm{~N}\right)$ requires $\mathrm{m} / \mathrm{z} 203.16740$, found $\mathrm{m} / \mathrm{z} 203.16758$, difference $0.87 \mathrm{ppm}$.

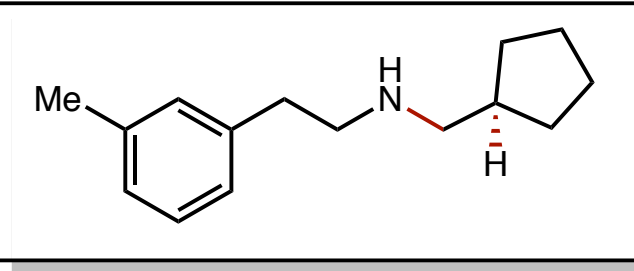

\section{$N$-(Cyclopentylmethyl)-2-(m-tolyl)ethan-1-amine (29)}

The reaction was set up following general procedure B using 2-( $m$-tolyl)ethanamine (68 $\mathrm{mg}, 0.5$ mmol) and methylene cyclopentane (246 mg, $3 \mathrm{mmol}, 6.0$ equiv). The reaction was purified by the general workup procedure to give the title compound in an average isolated yield of $49 \%$ (53.4 mg). IR (neat): 2944, 2865, 1609, 1453, 1336, 1126, 881, 778, 739. ${ }^{1} \mathbf{H}$ NMR (500 MHz, CDCl $\left.\mathbf{~}_{3}\right)$ $\delta 7.18(\mathrm{t}, J=7.8 \mathrm{~Hz}, 1 \mathrm{H}), 7.04-6.99(\mathrm{~m}, 3 \mathrm{H}), 2.86(\mathrm{t}, J=7.1 \mathrm{~Hz}, 2 \mathrm{H}), 2.77(\mathrm{t}, J=7.2 \mathrm{~Hz}, 2 \mathrm{H})$, $2.55(\mathrm{~d}, J=7.2 \mathrm{~Hz}, 2 \mathrm{H}), 2.33(\mathrm{~s}, 3 \mathrm{H}), 1.99$ (hept, $J=7.7 \mathrm{~Hz}, 1 \mathrm{H}), 1.74$ (dq, $J=11.5,6.3 \mathrm{~Hz}, 2 \mathrm{H})$, $1.64-1.46(\mathrm{~m}, 5 \mathrm{H}), 1.11(\mathrm{dq}, J=14.9,7.3 \mathrm{~Hz}, 2 \mathrm{H}) .{ }^{13} \mathbf{C ~ N M R}\left(\mathbf{1 2 6} \mathbf{~ M H z}, \mathbf{C D C l}_{3}\right) \delta 140.3,138.1$, 129.7, 128.5, 127.0, 125.8, 55.8, 51.7, 40.2, 36.5, 31.0, 25.4, 21.6. HRMS (ESI) exact mass calculated for $[\mathrm{M}+\mathrm{H}]^{+}\left(\mathrm{C}_{15} \mathrm{H}_{24} \mathrm{~N}\right)$ requires $\mathrm{m} / \mathrm{z} 217.18305$, found $\mathrm{m} / \mathrm{z} 217.18279$, difference 1.18 ppm.

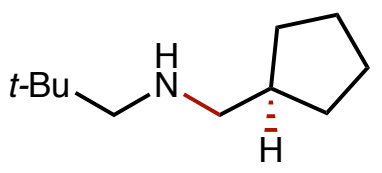

$\mathrm{N}$-(Cyclopentylmethyl)-2,2-dimethylpropan-1-amine (30)

The reaction was set up following general procedure B using neopentylamine ( $44 \mathrm{mg}, 0.5 \mathrm{mmol}$ ) and methylene cyclopentane ( $246 \mathrm{mg}, 3 \mathrm{mmol}, 6.0$ equiv). The reaction was purified by the general workup procedure to give the title compound in an average isolated yield of 59\% (50.2 mg). IR (neat): 2949, 2866, 2805, 1461, 1362, 1126, 741. ${ }^{\mathbf{1}} \mathbf{H}$ NMR (500 MHz, $\left.\mathbf{C D C l}_{3}\right) \delta 2.53(\mathrm{~d}, J=7.2$ 
$\mathrm{Hz}, 2 \mathrm{H}), 2.34$ (s, 2H), 2.05 (p, $J=7.7 \mathrm{~Hz}, 1 \mathrm{H}), 1.79-1.71(\mathrm{~m}, 2 \mathrm{H}), 1.63-1.48(\mathrm{~m}, 5 \mathrm{H}), 1.14(\mathrm{dq}$, $J=11.7,7.3 \mathrm{~Hz}, 2 \mathrm{H}), 0.91$ (s, 9H). ${ }^{13} \mathbf{C}$ NMR (126 MHz, $\left.\mathbf{C D C l}_{3}\right) \delta$ 62.7, 57.0, 39.9, 31.6, 31.0, 28.0, 25.5. HRMS (ESI) exact mass calculated for $[\mathrm{M}+\mathrm{H}]^{+}\left(\mathrm{C}_{11} \mathrm{H}_{24} \mathrm{~N}\right)$ requires $\mathrm{m} / \mathrm{z}$ 169.18305, found $\mathrm{m} / \mathrm{z} 169.18299$, difference $0.33 \mathrm{ppm}$.

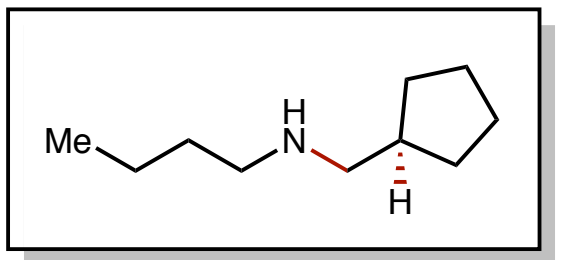

\section{$N$-(Cyclopentylmethyl)butan-1-amine (31)}

The reaction was set up following general procedure $\mathrm{C}$ using butylamine $(37 \mathrm{mg}, 0.5 \mathrm{mmol})$ and methylene cyclopentane ( $246 \mathrm{mg}, 3 \mathrm{mmol}, 6.0$ equiv). The reaction was purified by the general workup procedure to give the title compound in an average isolated yield of $43 \%$ ( $33.5 \mathrm{mg}$ ). IR (neat): 2951, 2866, 2805, 1456, 1377, 1130, 732. ${ }^{1} \mathbf{H}$ NMR (500 MHz, $\left.\mathbf{C D C l}_{3}\right) \delta 2.59(\mathrm{t}, J=7.5$ $\mathrm{Hz}, 2 \mathrm{H}), 2.52$ (d, $J=7.2 \mathrm{~Hz}, 2 \mathrm{H}), 2.01$ (hept, $J=7.7 \mathrm{~Hz}, 1 \mathrm{H}), 1.76$ (dq, $J=11.5,6.7 \mathrm{~Hz}, 2 \mathrm{H}), 1.64$ $-1.43(\mathrm{~m}, 7 \mathrm{H}), 1.33(\mathrm{dq}, J=14.5,7.3 \mathrm{~Hz}, 2 \mathrm{H}), 1.18-1.09(\mathrm{~m}, 2 \mathrm{H}), 0.91(\mathrm{t}, J=7.3 \mathrm{~Hz}, 3 \mathrm{H}) .{ }^{13} \mathbf{C}$ NMR (126 MHz, $\left.\mathbf{C D C l}_{3}\right) \delta 56.1,50.2,40.3,32.5,31.1,25.5,20.7,14.2$. HRMS (ESI) exact mass calculated for $[\mathrm{M}+\mathrm{H}]^{+}\left(\mathrm{C}_{10} \mathrm{H}_{22} \mathrm{~N}\right)$ requires $\mathrm{m} / \mathrm{z} 155.16740$, found $\mathrm{m} / \mathrm{z}$ 155.16758, difference 1.15 ppm.

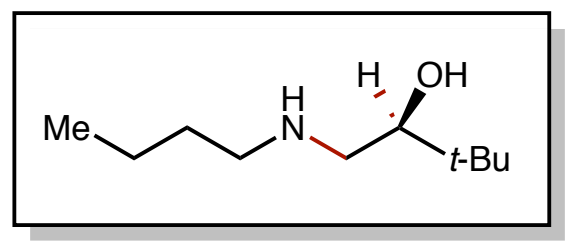

\section{1-(Butylamino)-3,3-dimethylbutan-2-ol (32)}

The reaction was set up following general procedure $\mathrm{C}$ using butylamine $(37 \mathrm{mg}, 0.5 \mathrm{mmol})$ and ((3,3-dimethylbut-1-en-2-yl)oxy)trimethylsilane ( $431 \mathrm{mg}, 2.5 \mathrm{mmol}, 5$ equiv). The reaction was purified by the general workup procedure to give the title compound in an average isolated yield of 57\% (49.4 mg). IR (neat): 3311, 2930, 2869, 1662, 1462, 1363, 1082, 1012, 734. ${ }^{1} \mathbf{H}$ NMR $\left(\mathbf{5 0 0} \mathbf{M H z}, \mathbf{C D C l}_{3}\right) \delta 3.25(\mathrm{dd}, J=10.7,2.9 \mathrm{~Hz}, 1 \mathrm{H}), 2.75(\mathrm{dd}, J=11.8,2.9 \mathrm{~Hz}, 1 \mathrm{H}), 2.66(\mathrm{dt}, J$ $=11.6,7.2 \mathrm{~Hz}, 1 \mathrm{H}), 2.57(\mathrm{dt}, J=11.6,7.1 \mathrm{~Hz}, 1 \mathrm{H}), 2.42(\mathrm{dd}, J=11.8,10.7 \mathrm{~Hz}, 1 \mathrm{H}), 1.50-1.43$ $(\mathrm{m}, 2 \mathrm{H}), 1.35$ (dq, $J=14.4,7.2 \mathrm{~Hz}, 2 \mathrm{H}), 0.94-0.87(\mathrm{~m}, 13 \mathrm{H}) .{ }^{13} \mathbf{C}$ NMR (126 MHz, $\left.\mathbf{C D C l}_{3}\right) \delta$ 76.5, 50.5, 49.4, 33.7, 32.5, 25.9, 20.5, 14.2. HRMS (ESI) exact mass calculated for $[\mathrm{M}+\mathrm{H}]^{+}$ $\left(\mathrm{C}_{10} \mathrm{H}_{24} \mathrm{NO}\right)$ requires $\mathrm{m} / \mathrm{z} 173.17796$, found $\mathrm{m} / \mathrm{z} 173.17808$, difference $0.65 \mathrm{ppm}$. 


\section{${ }^{1} \mathrm{H},{ }^{13} \mathrm{C}$, and ${ }^{19} \mathrm{~F}$ Spectra of Products}

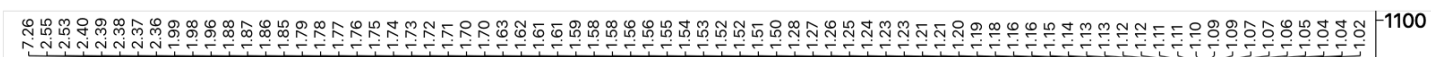

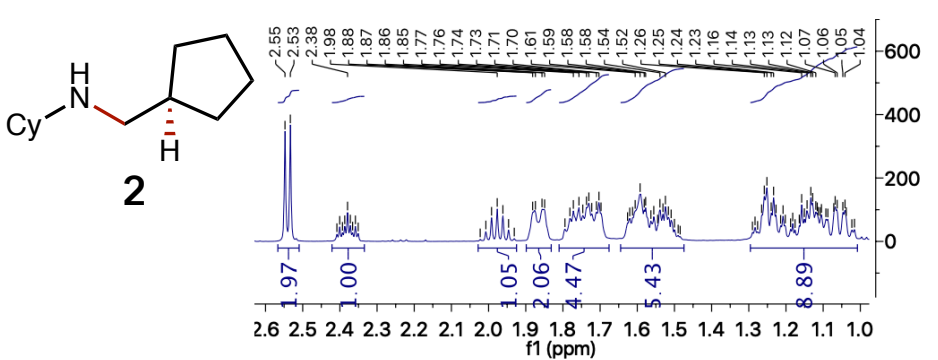

1000

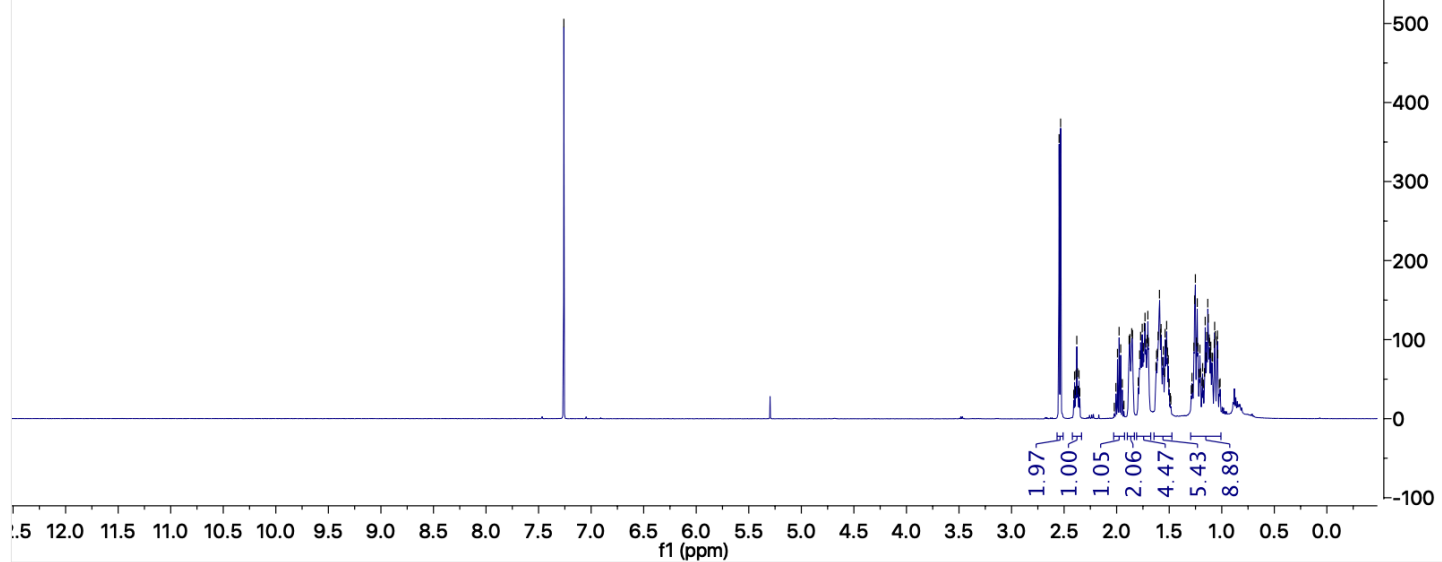<smiles>C1CCC(NCC2CCCC2)CC1</smiles>

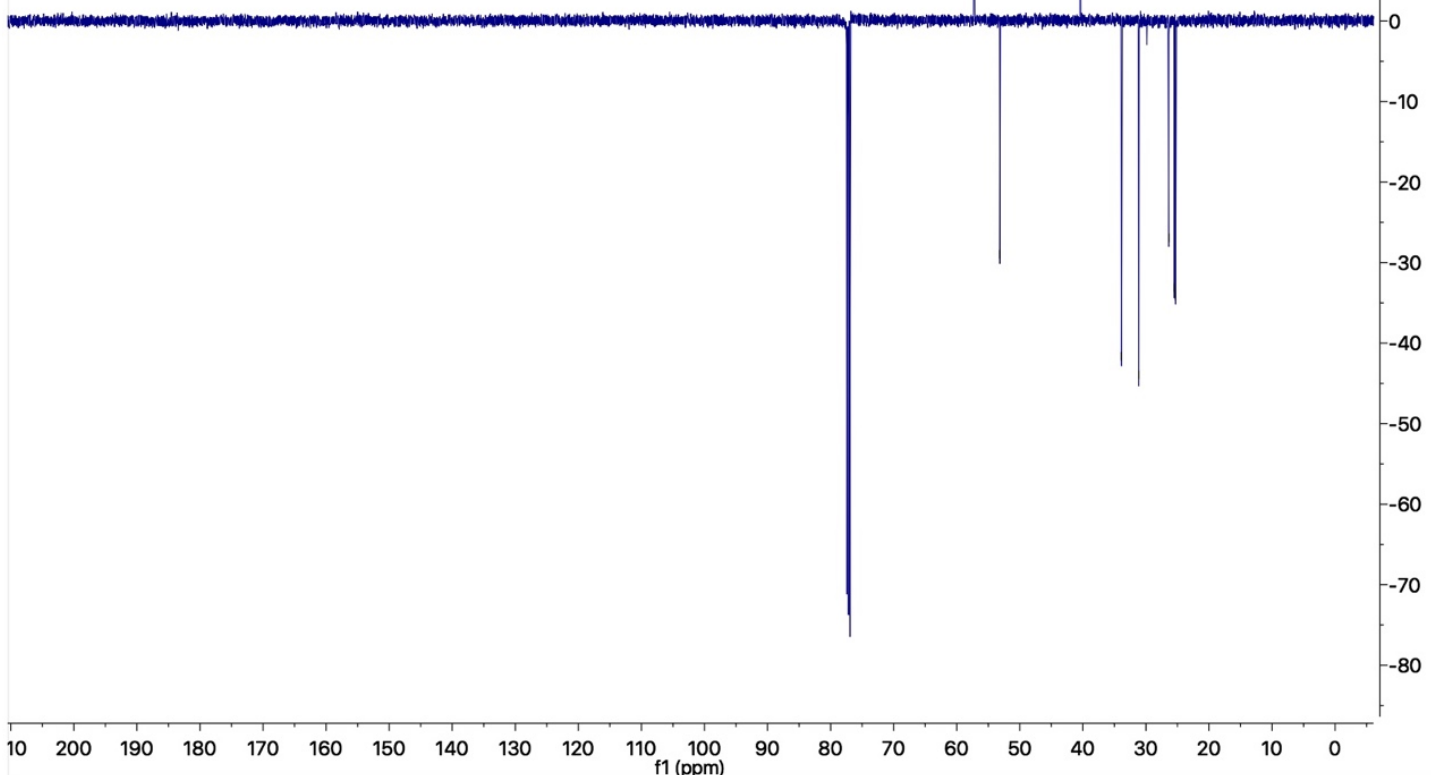




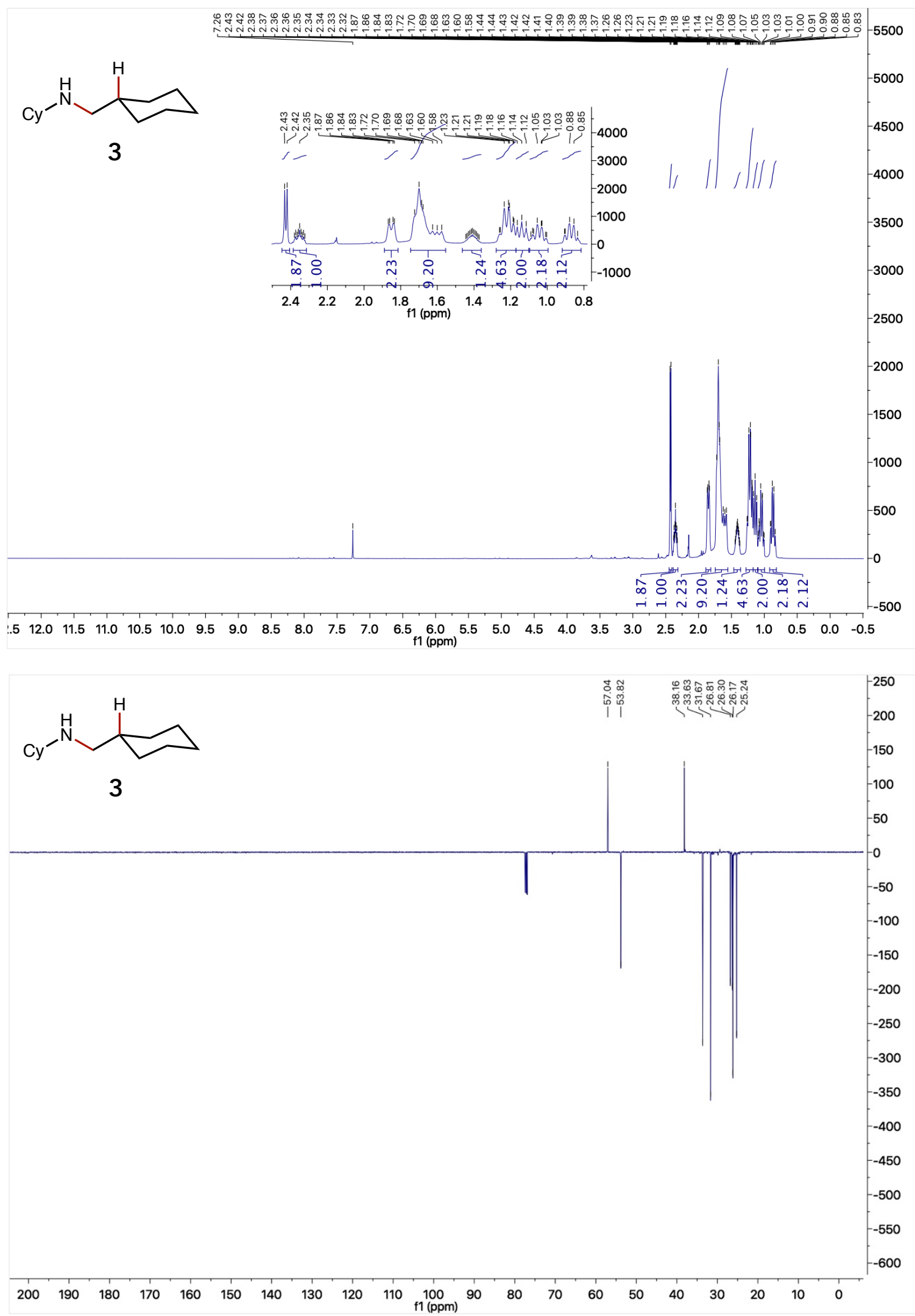




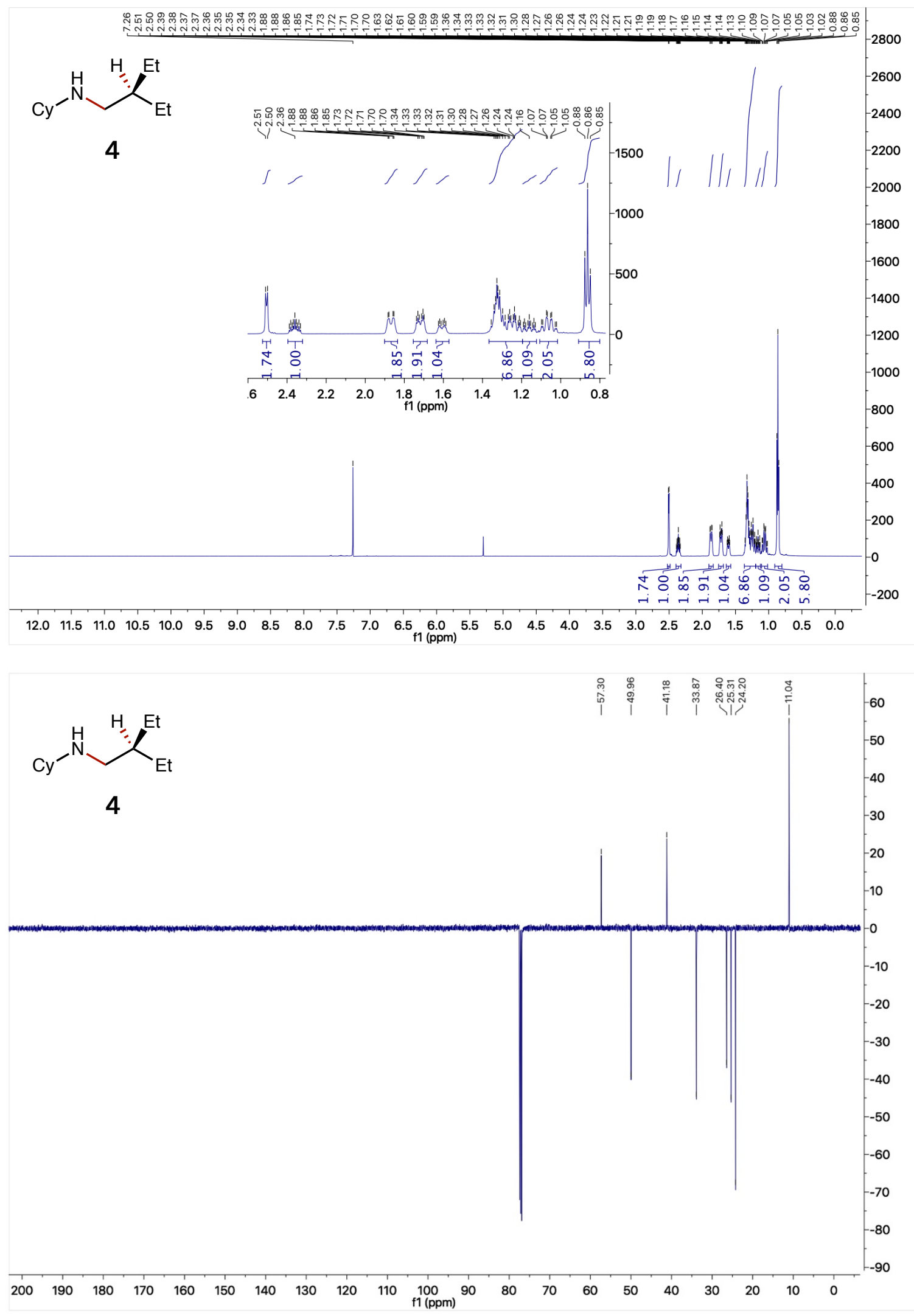




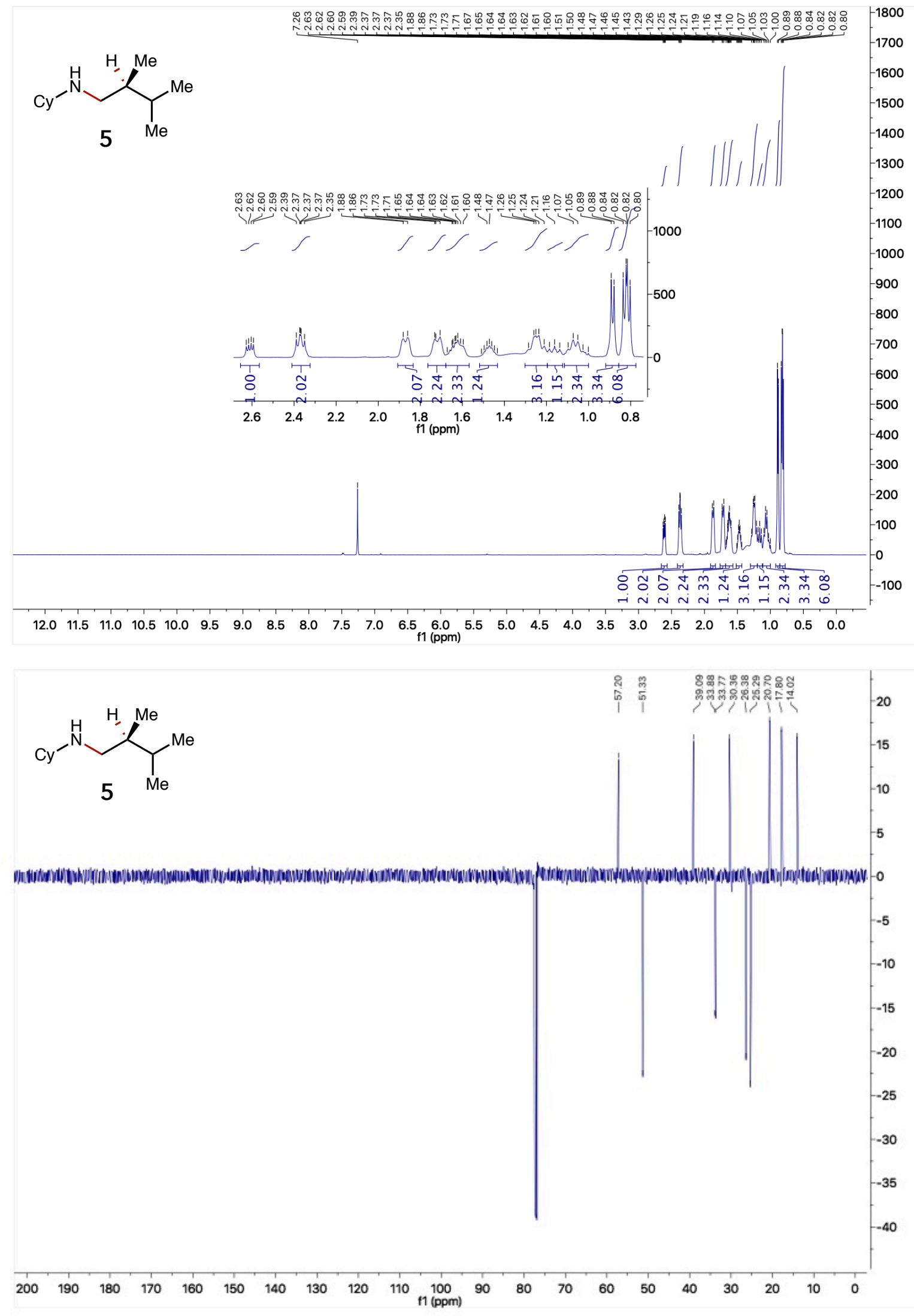




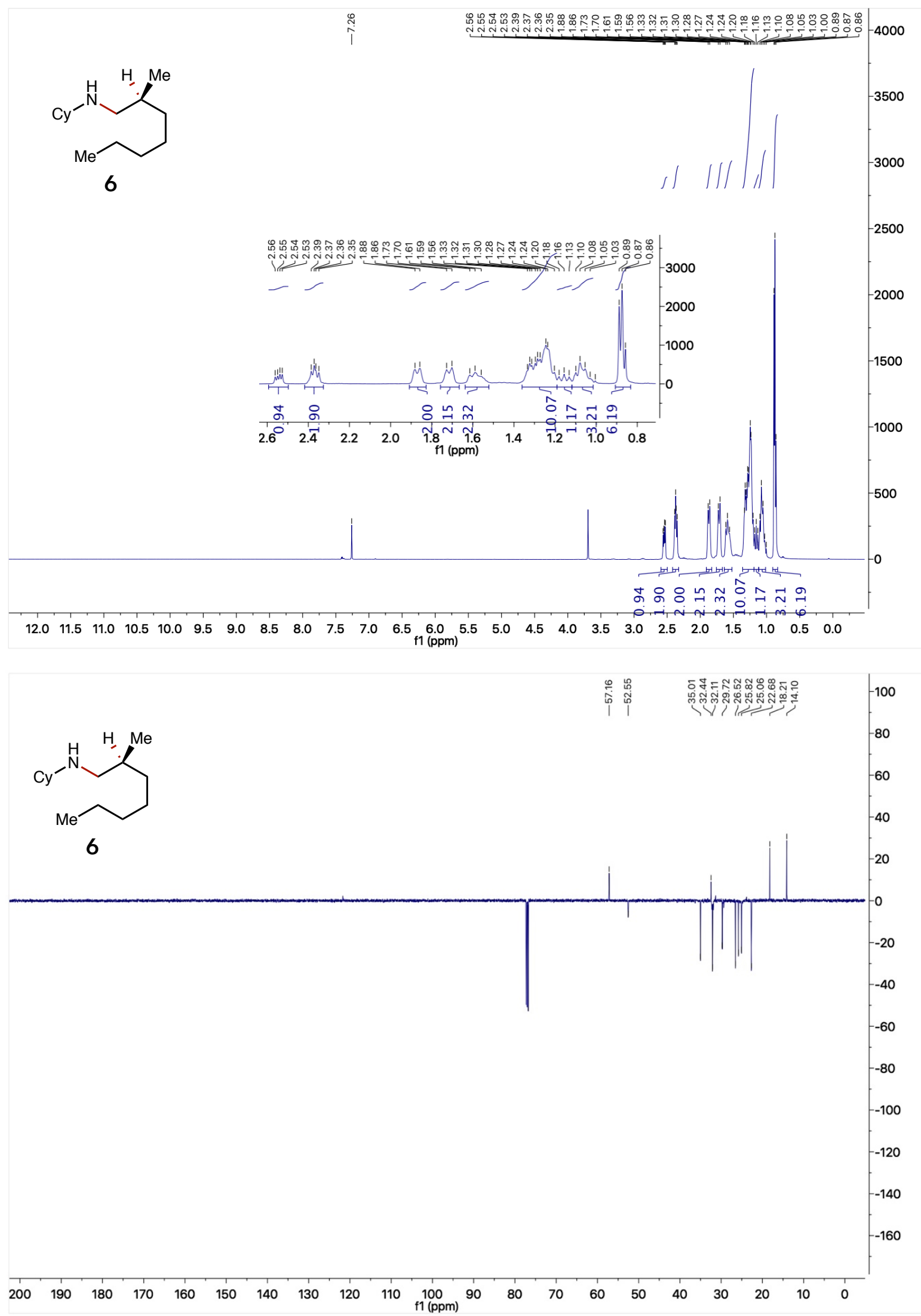




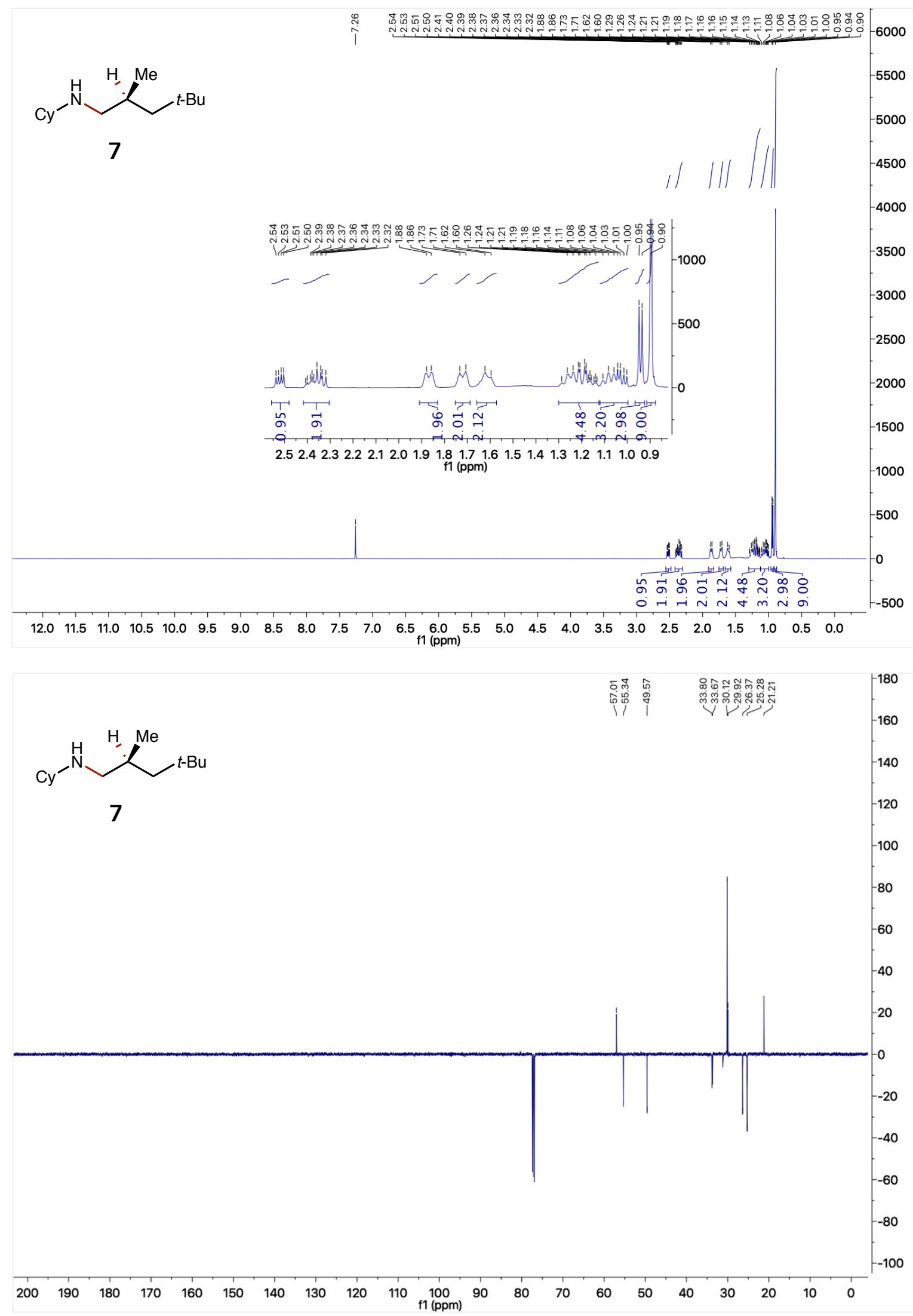




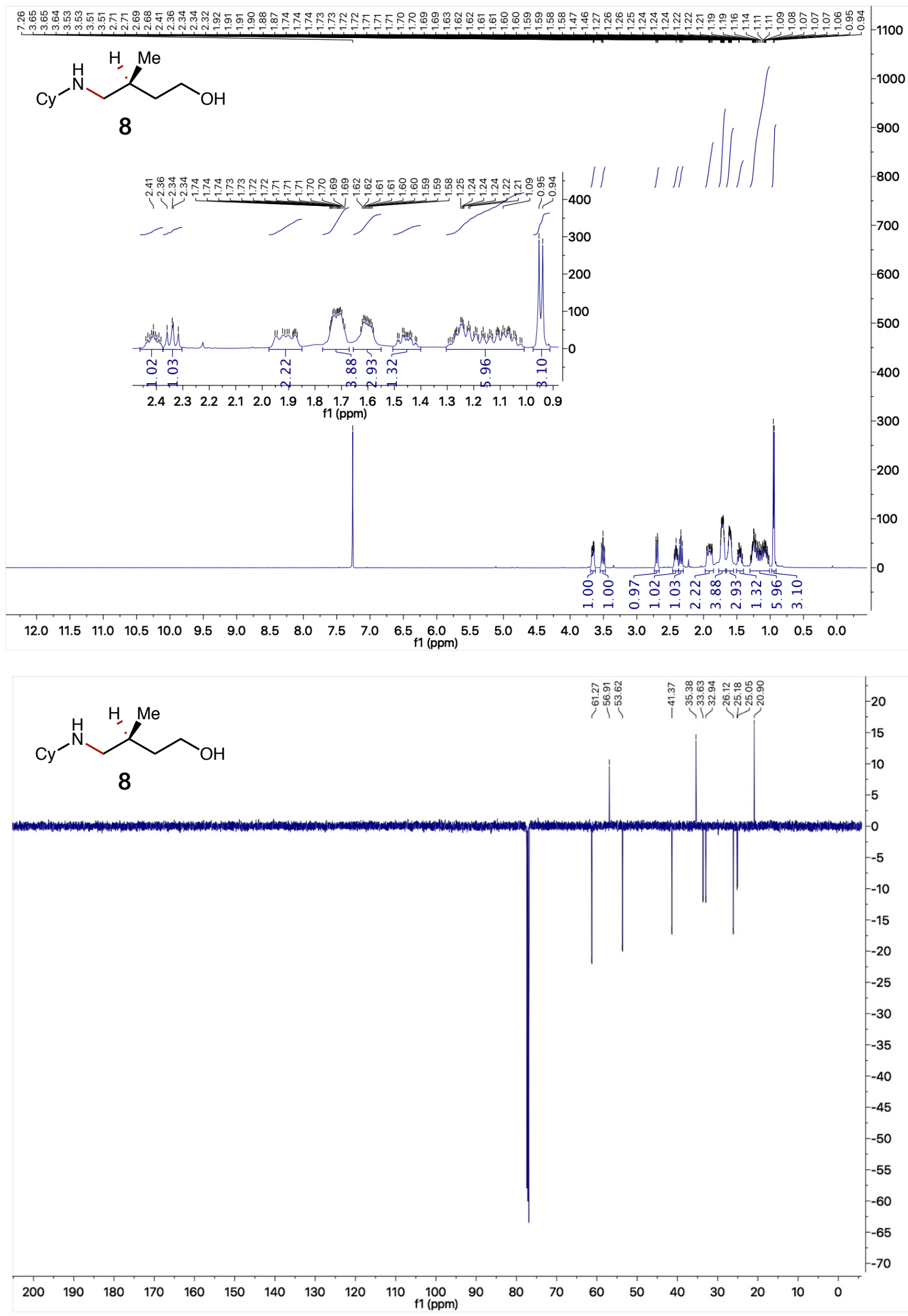




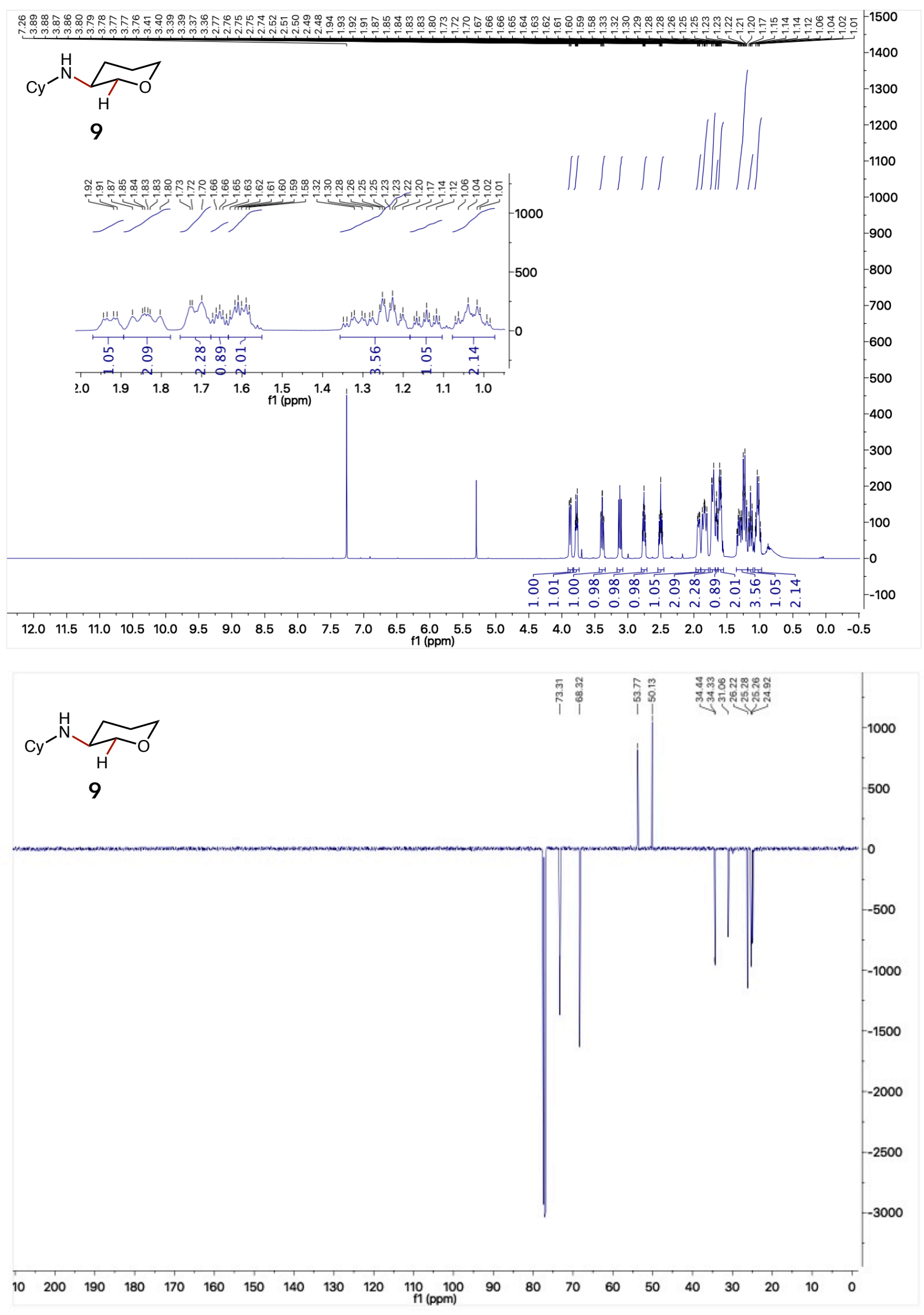




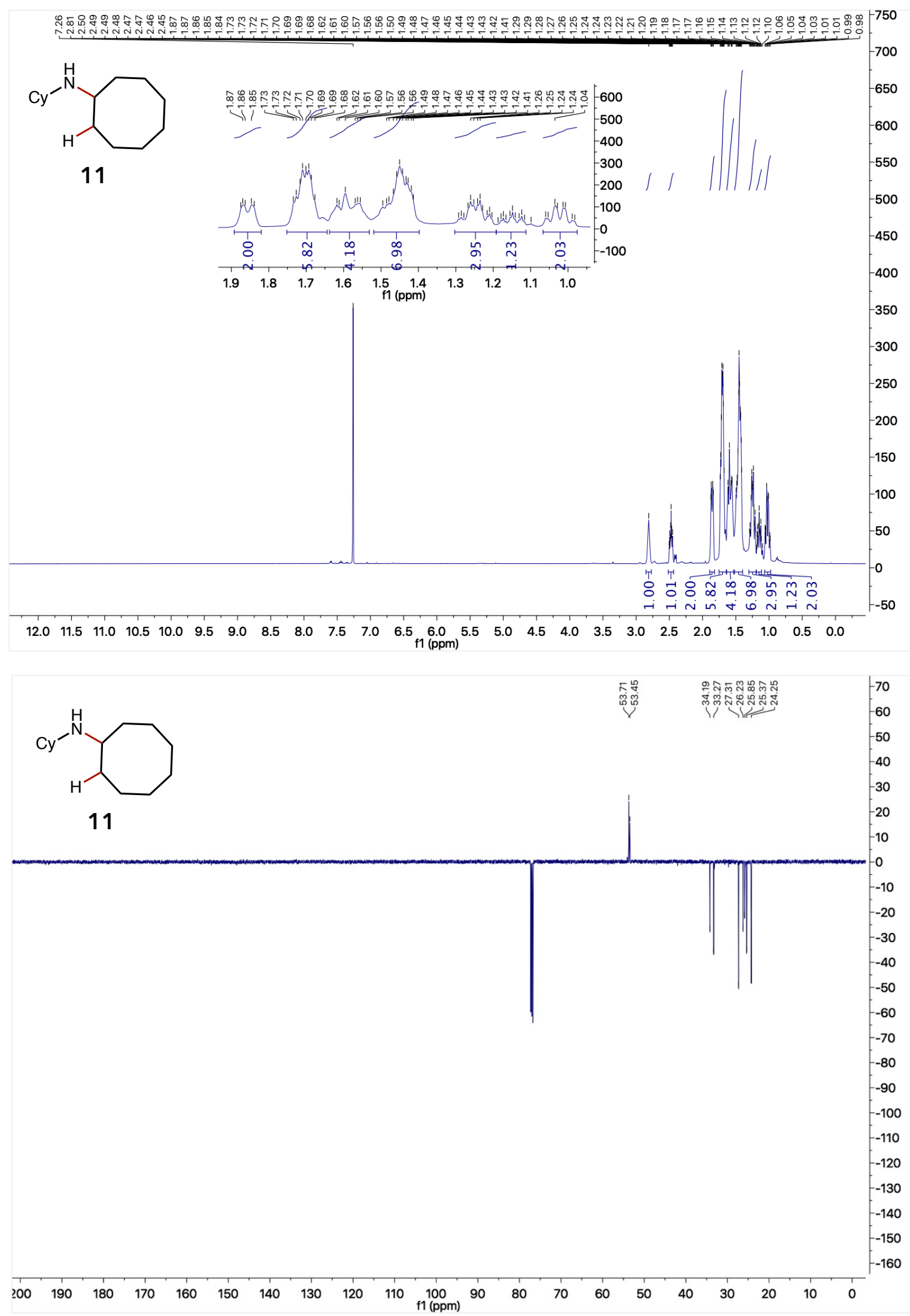




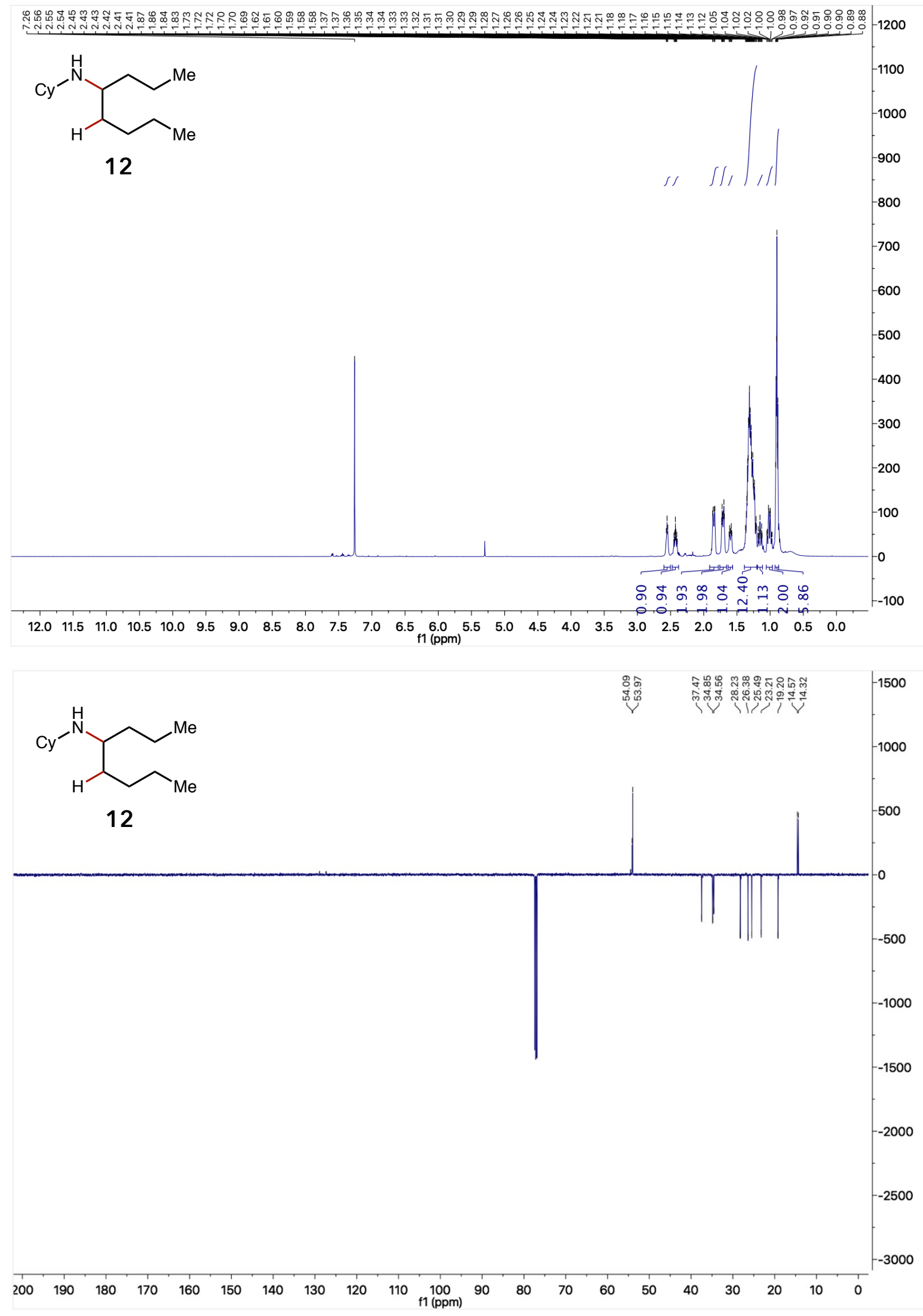




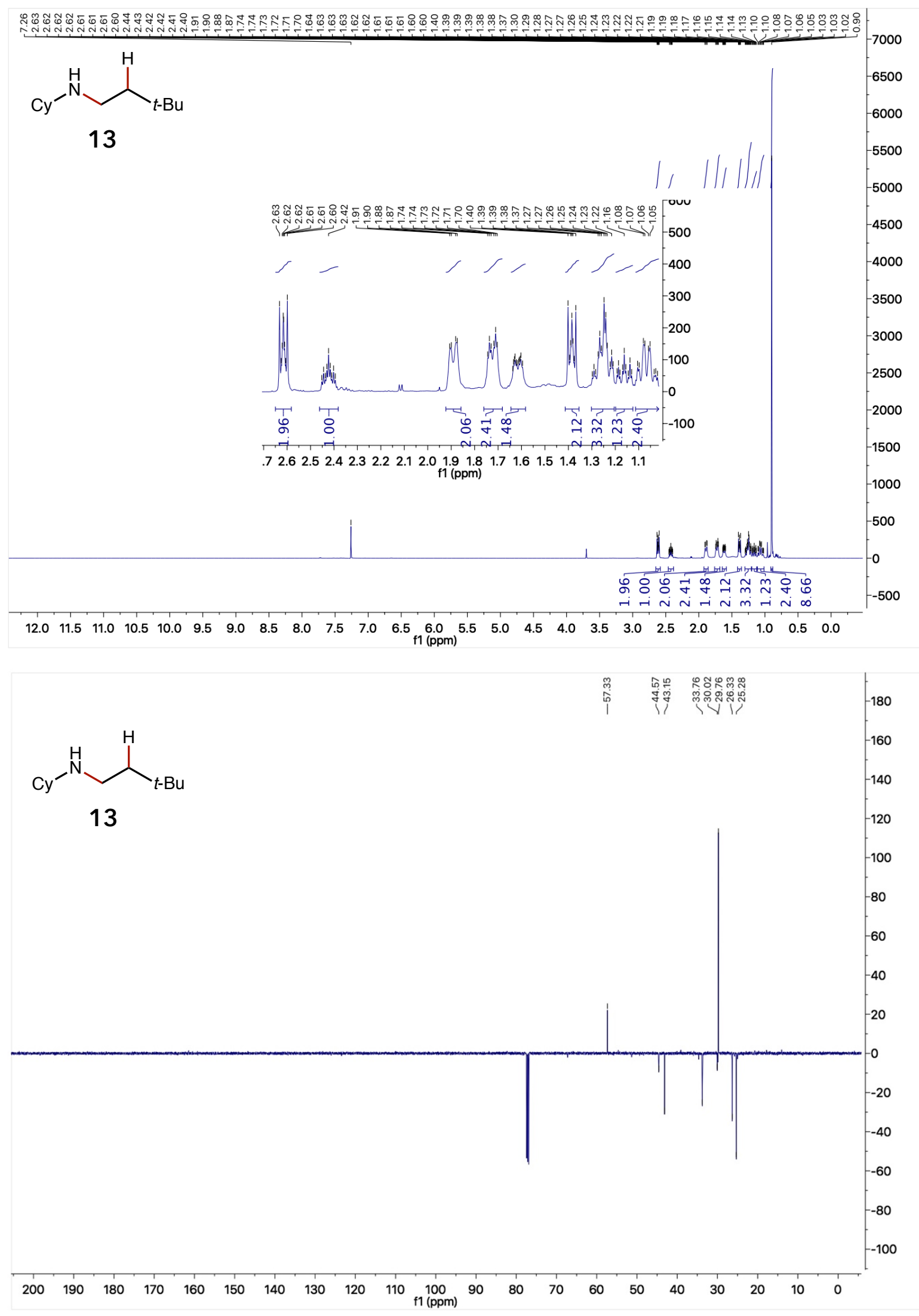




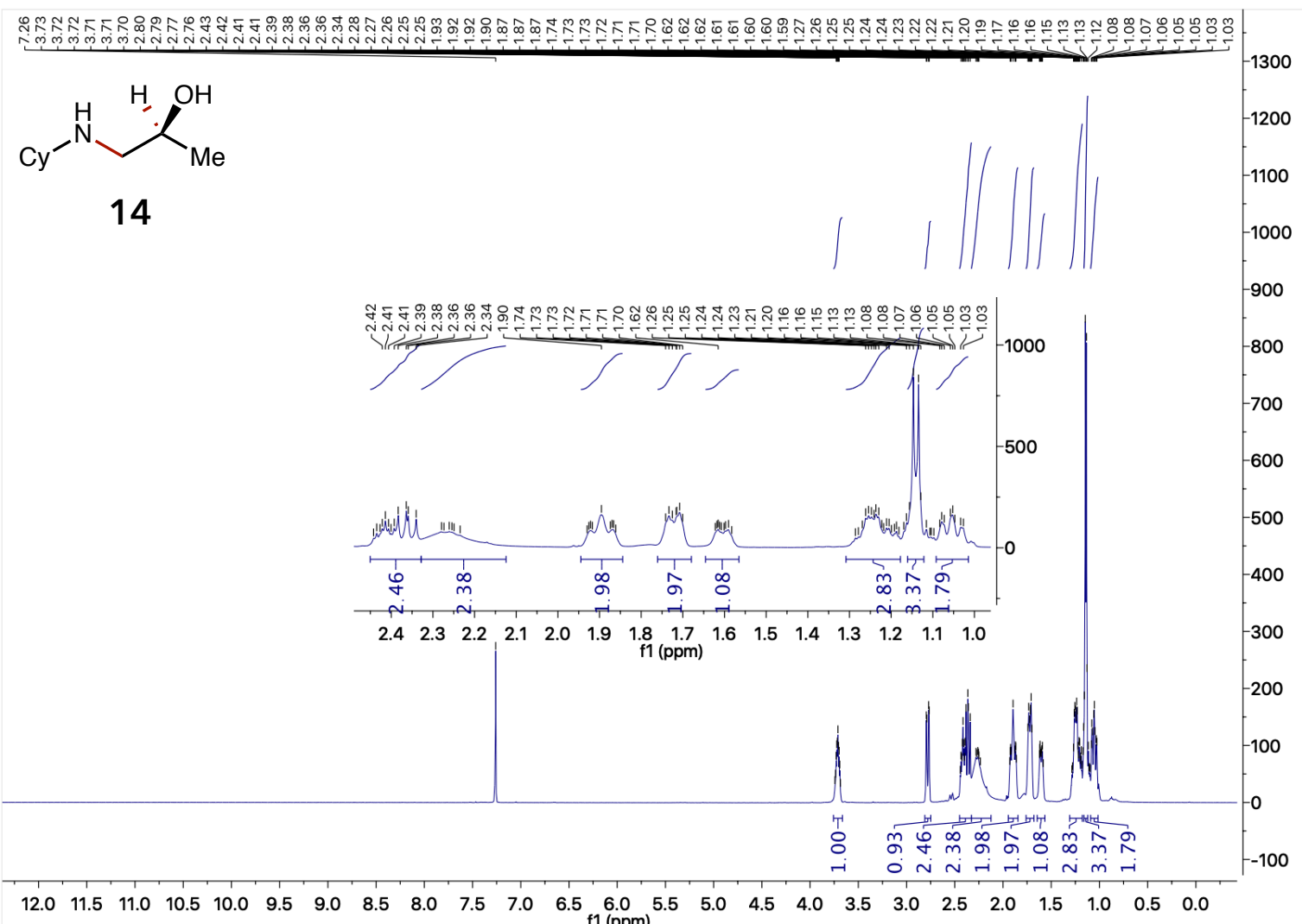

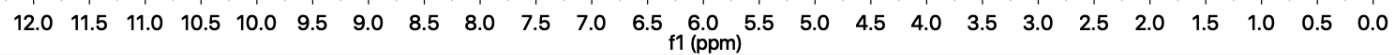

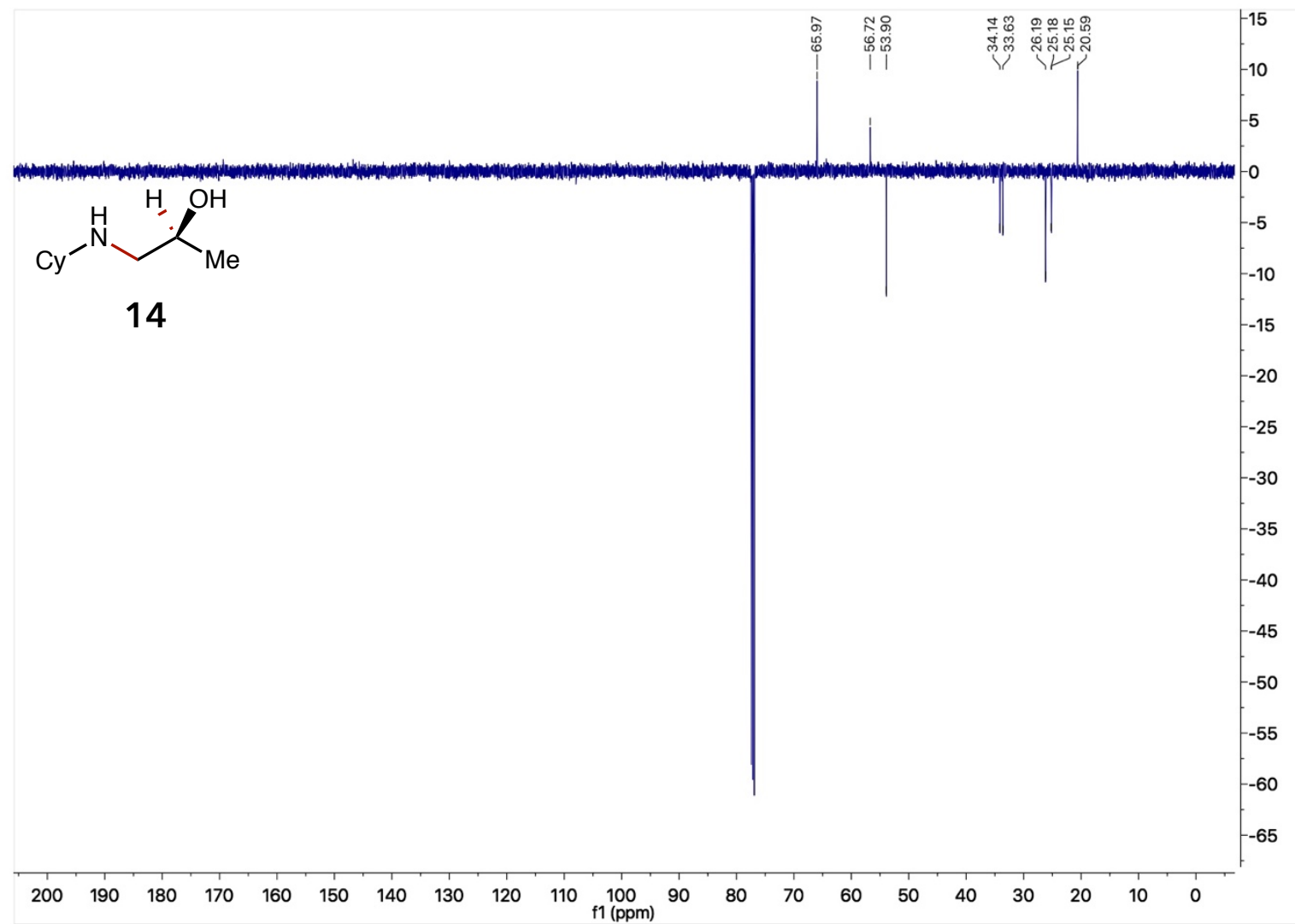




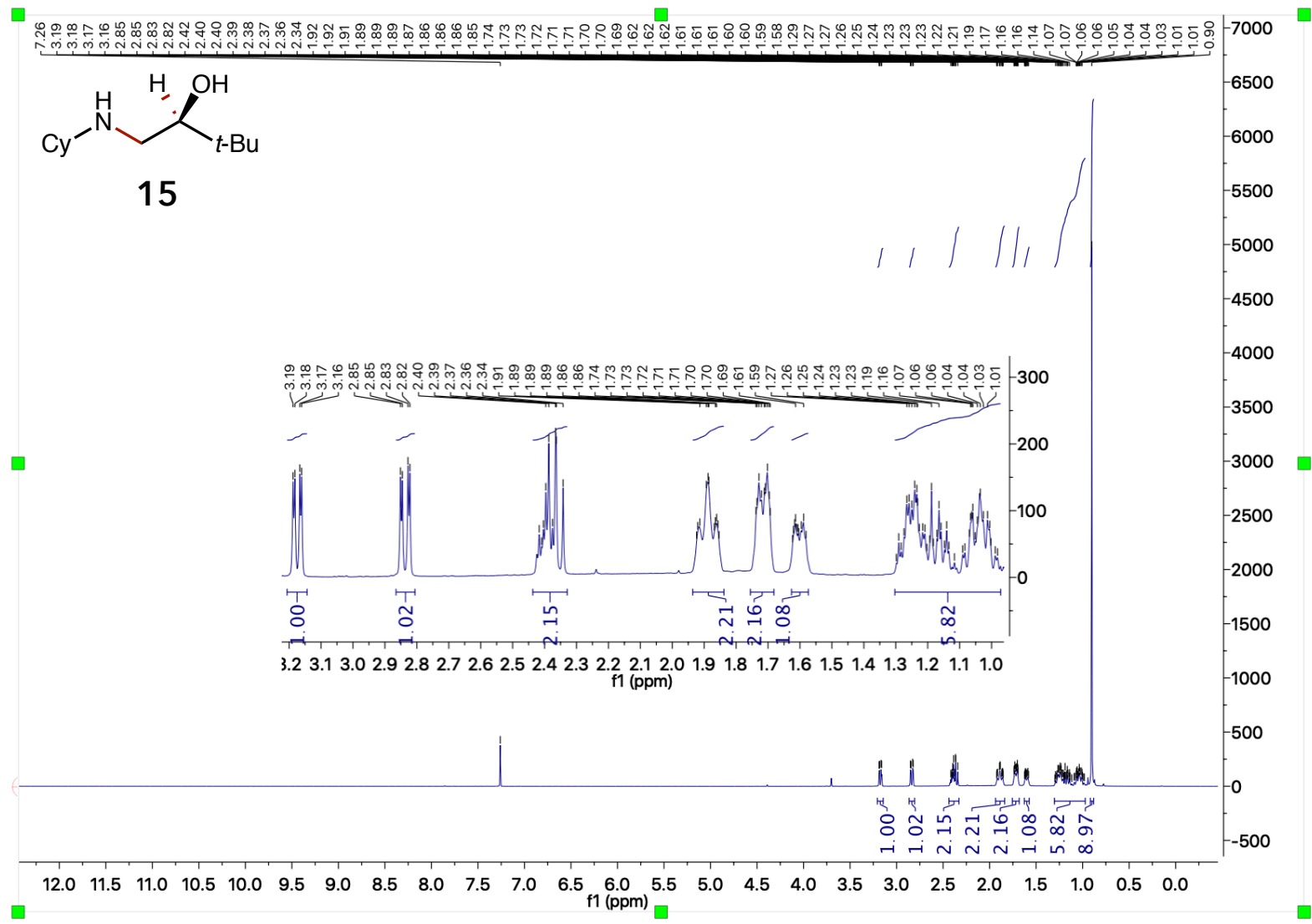<smiles>[CH2]CN[Al]NC[C@@H](O)C(C)(C)C</smiles>

$t-B u$

15

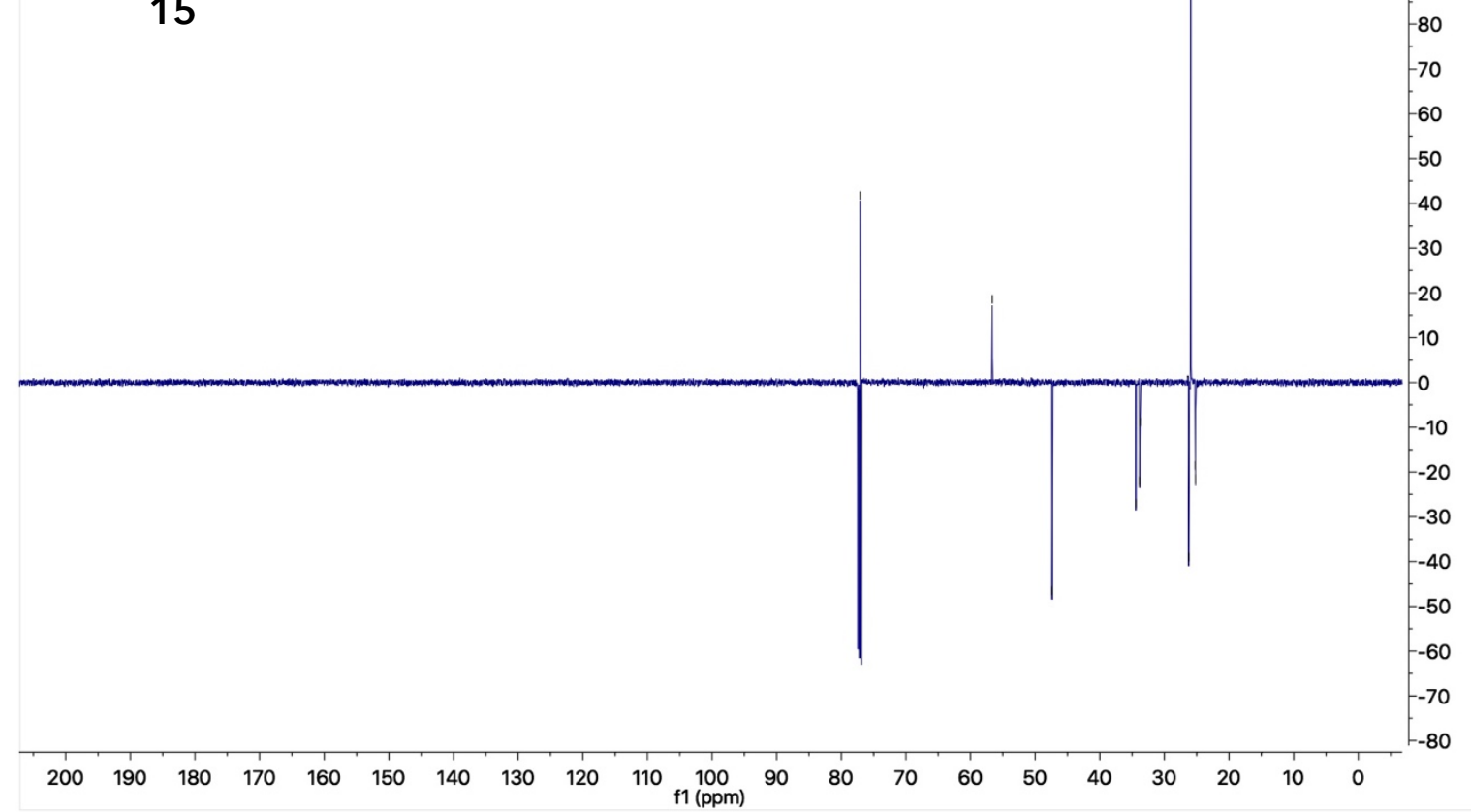




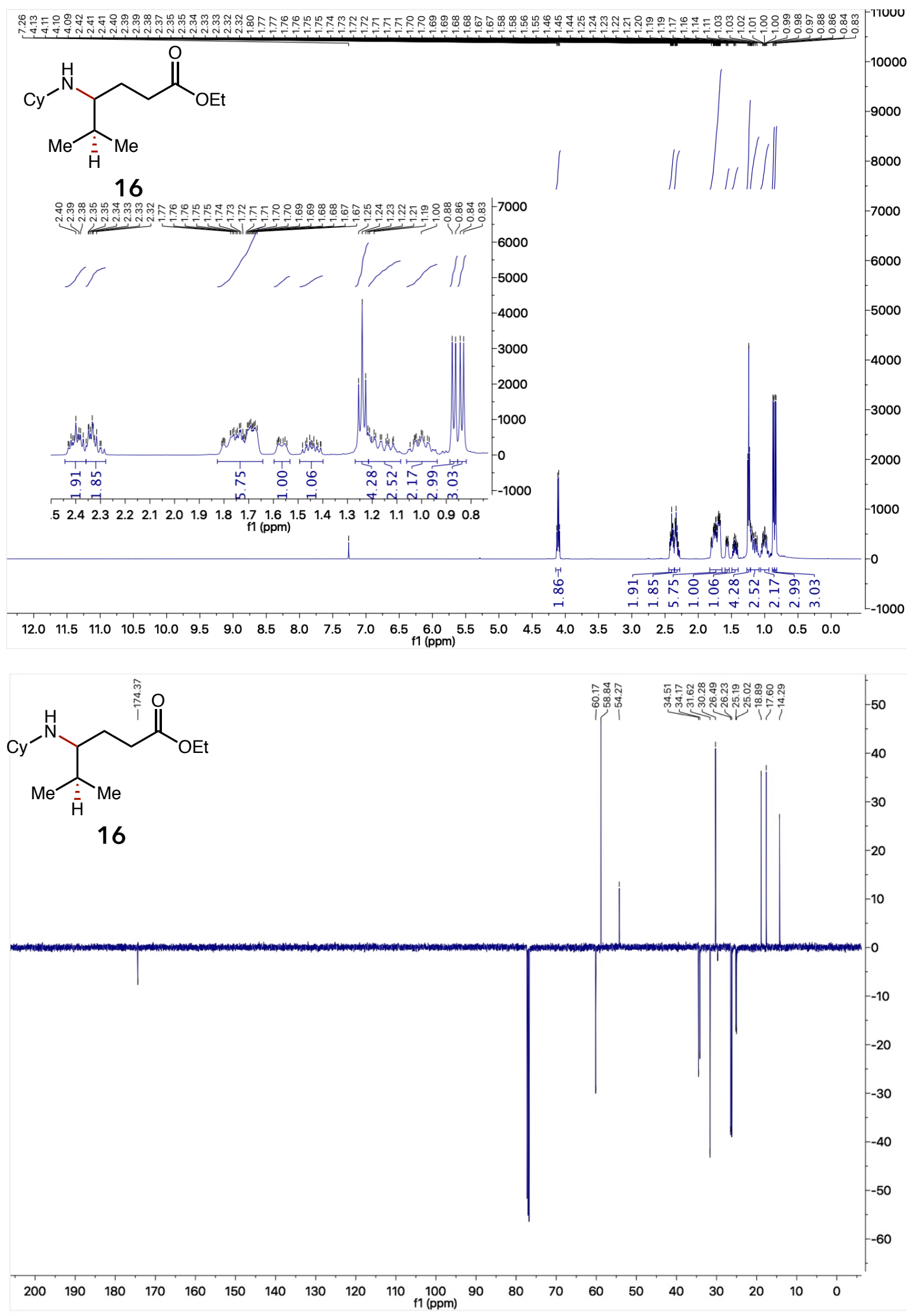




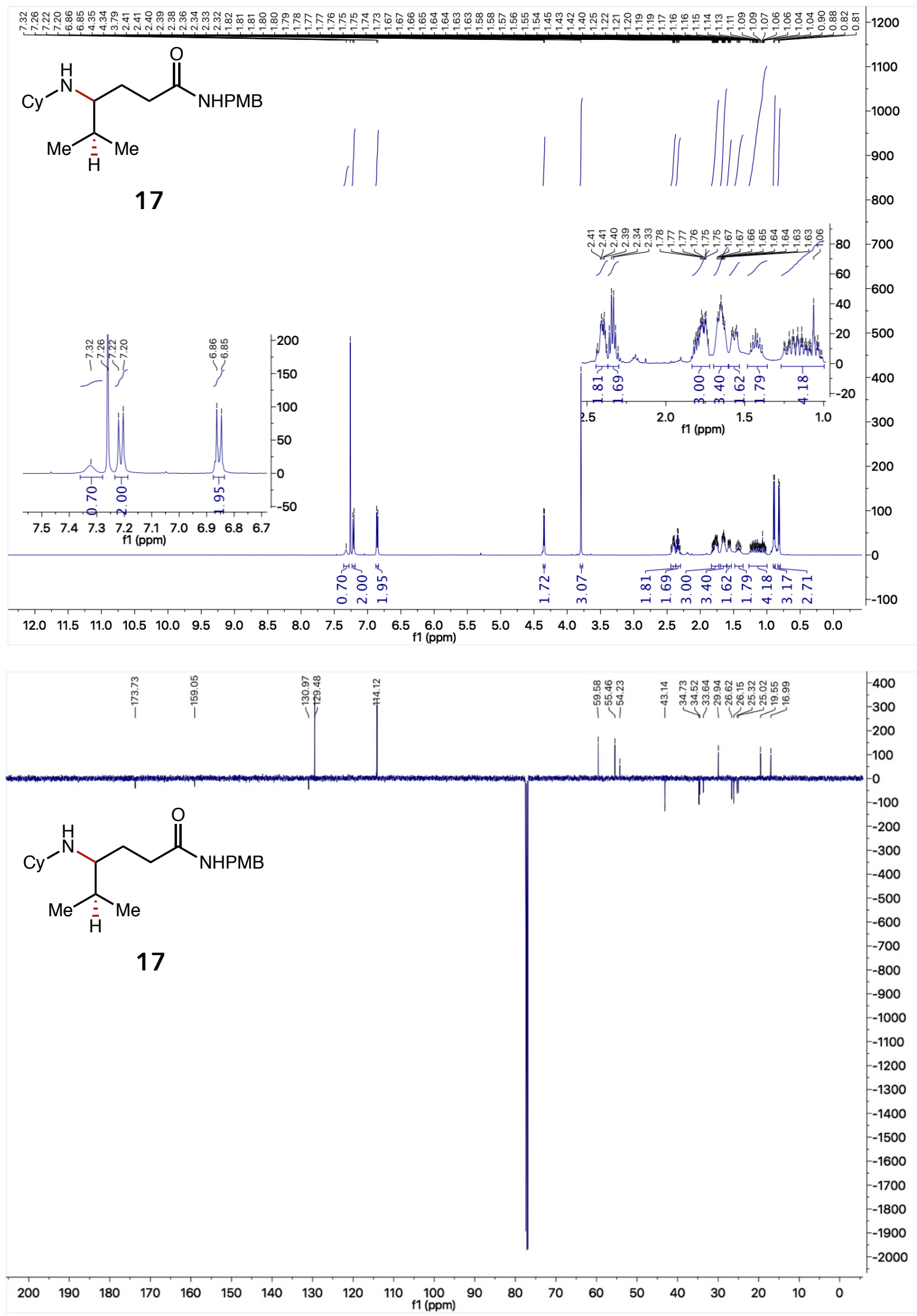




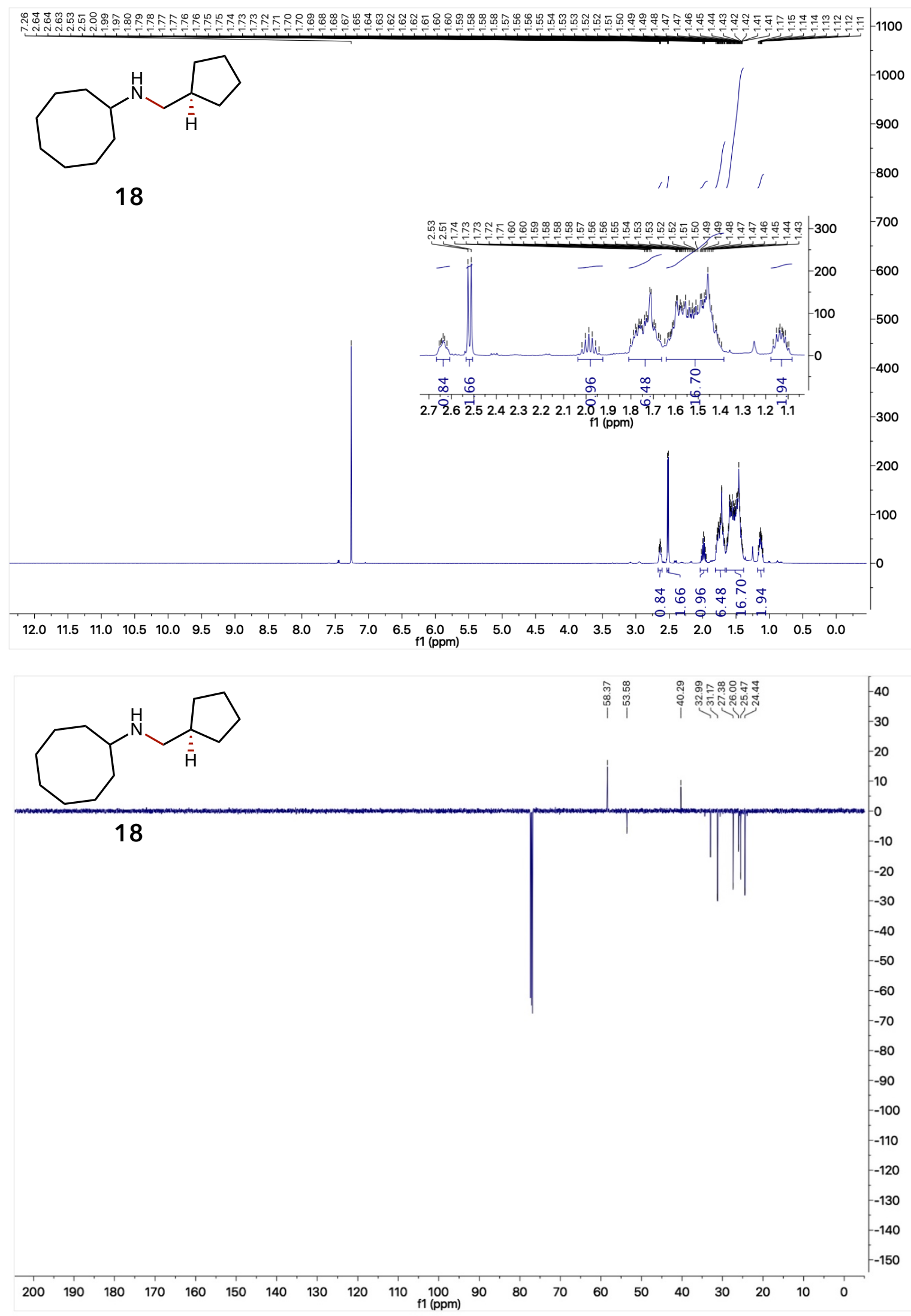




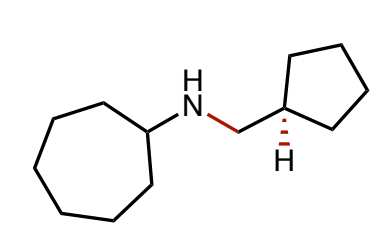

19
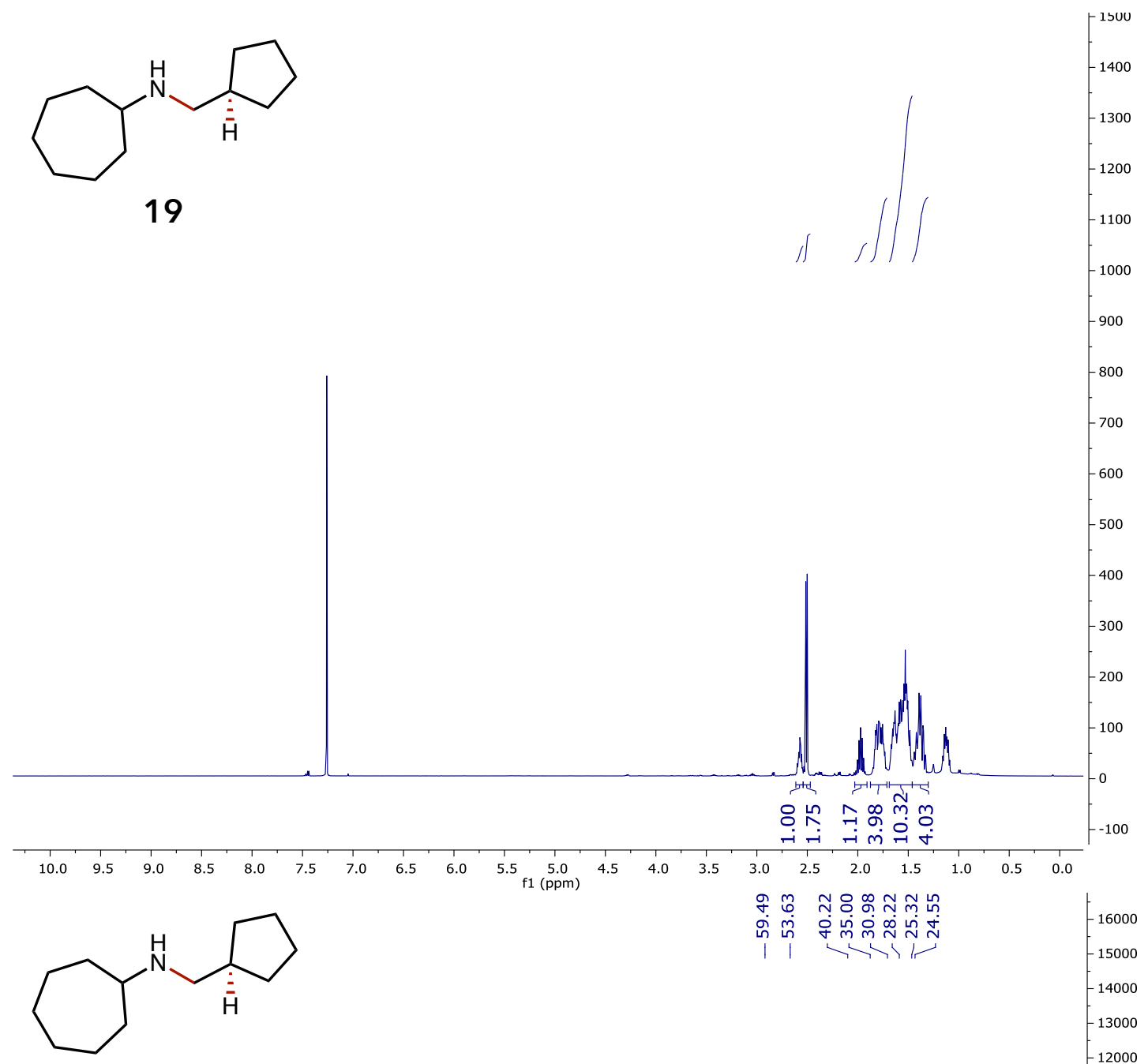

19

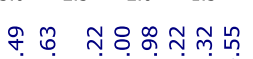

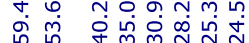

l

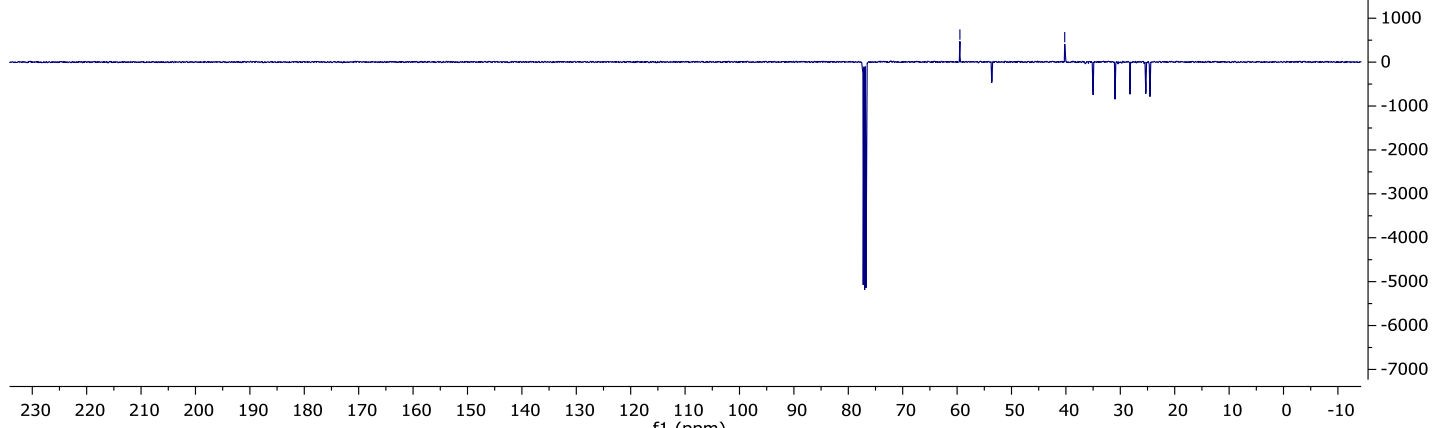




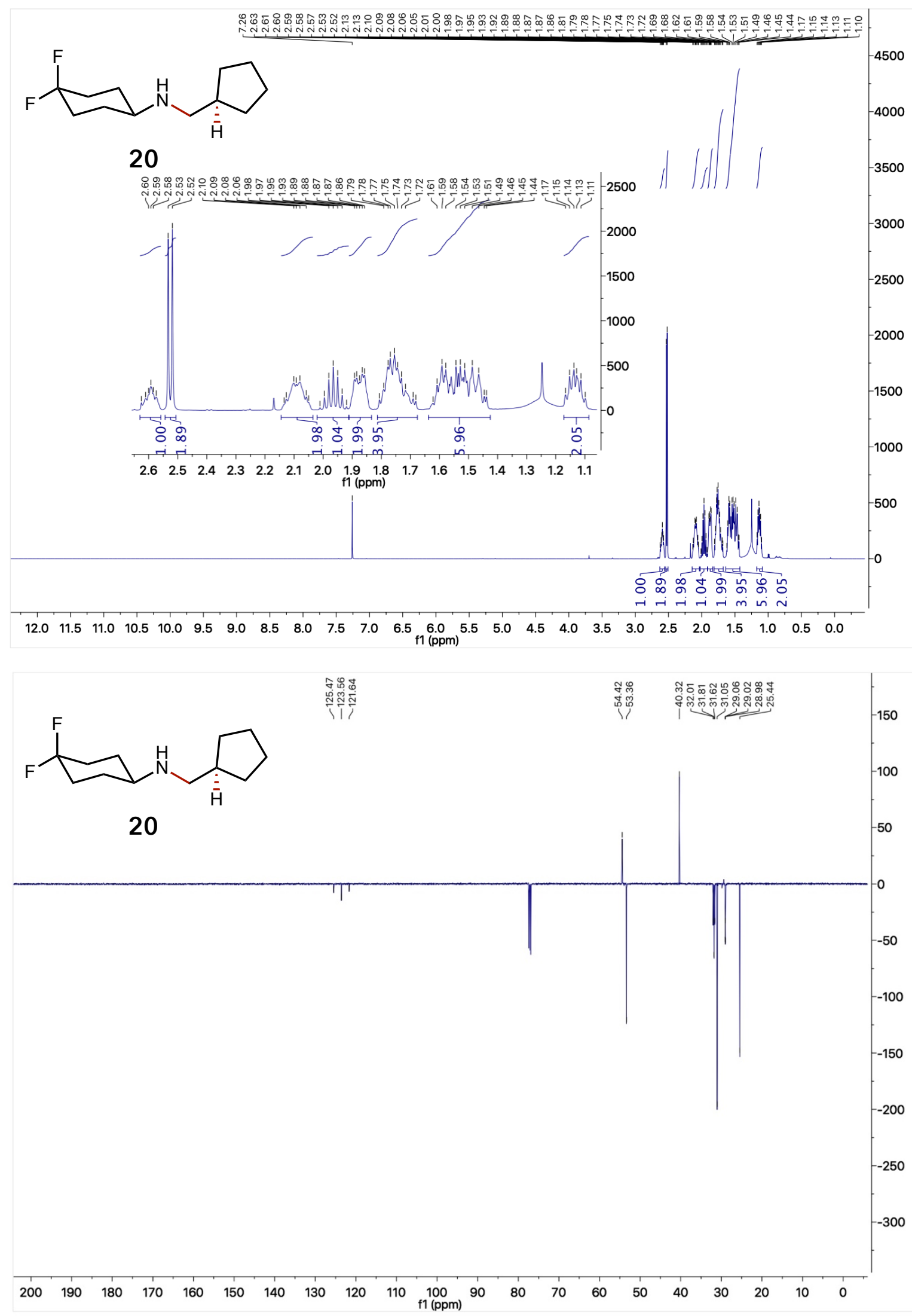




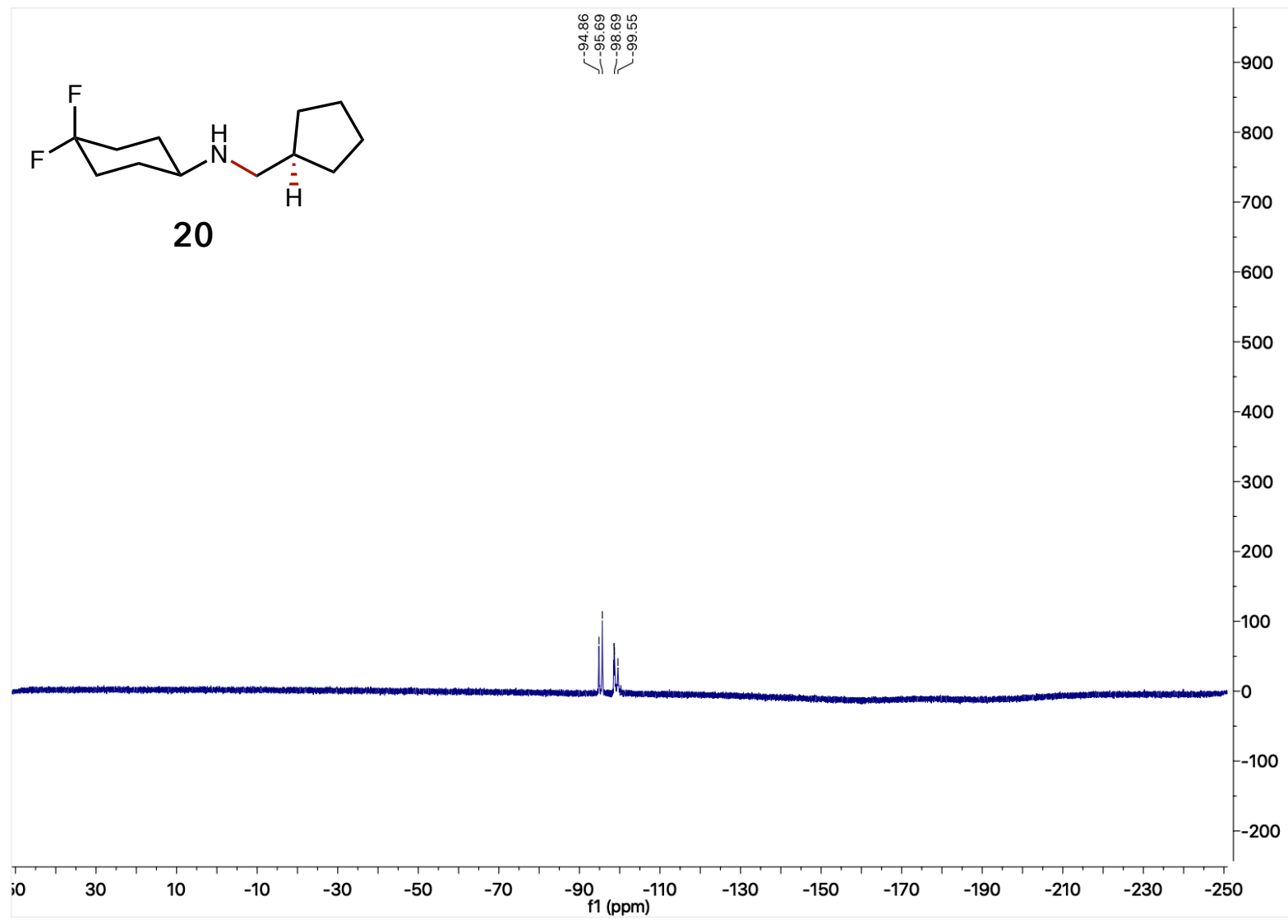




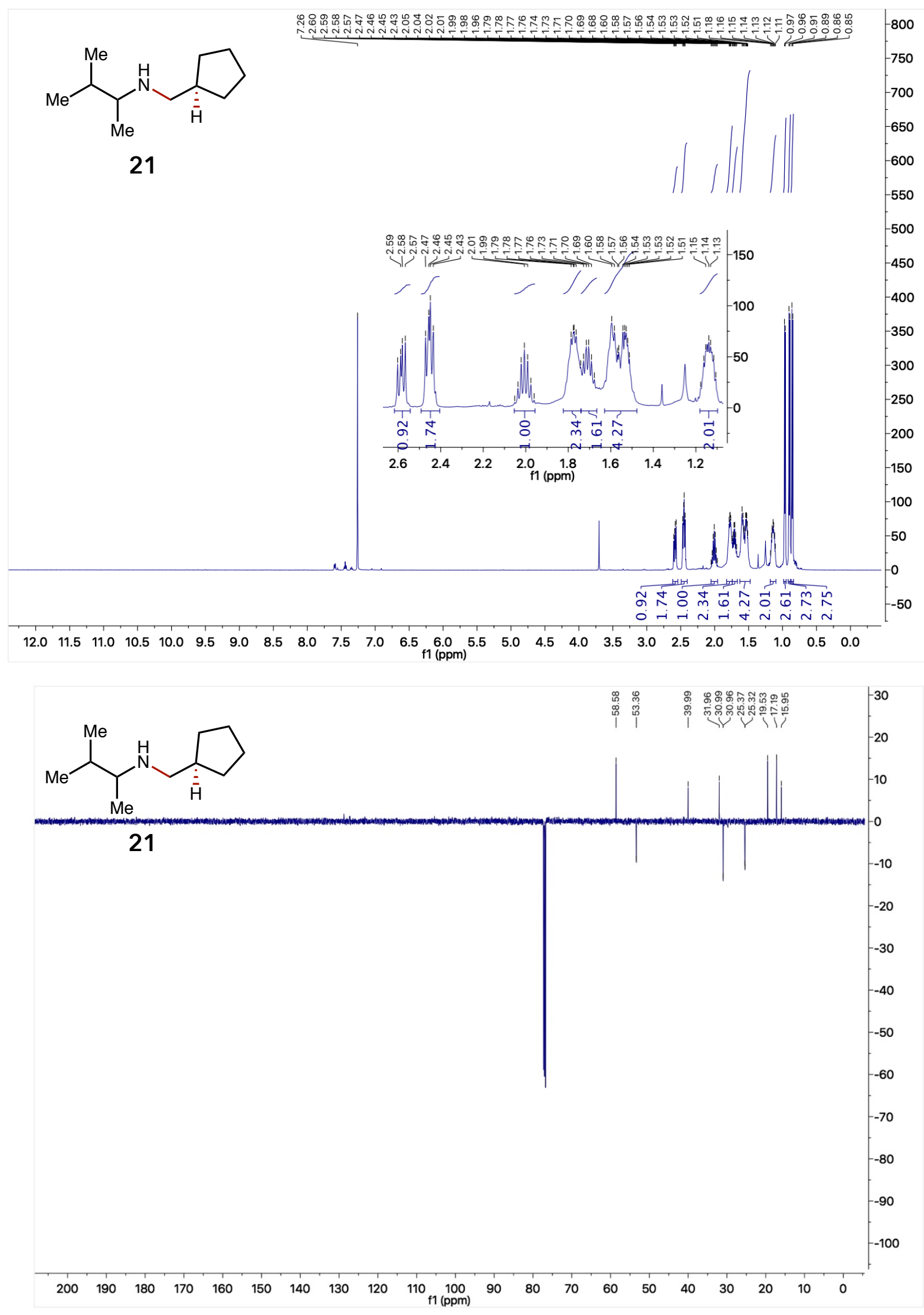




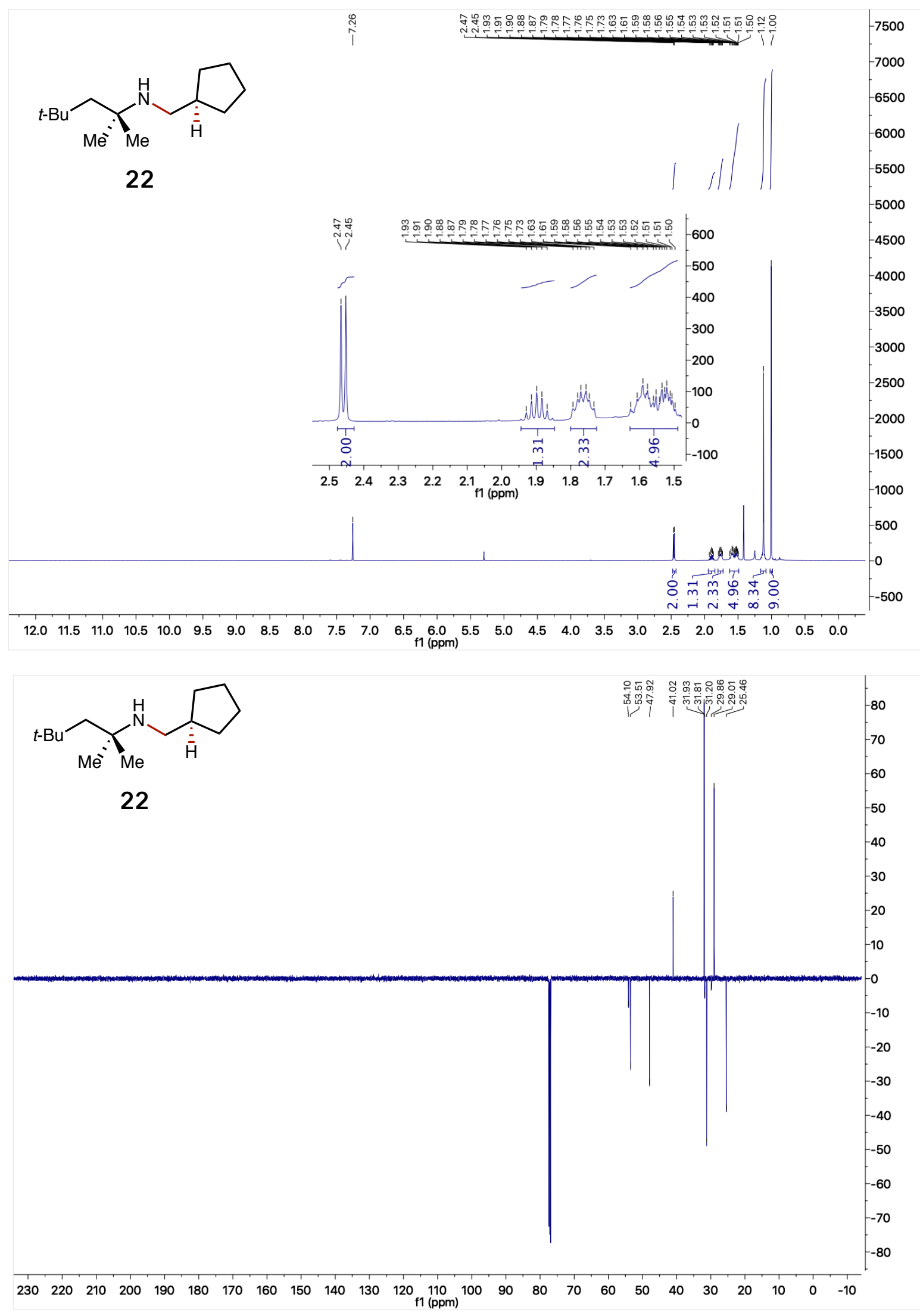




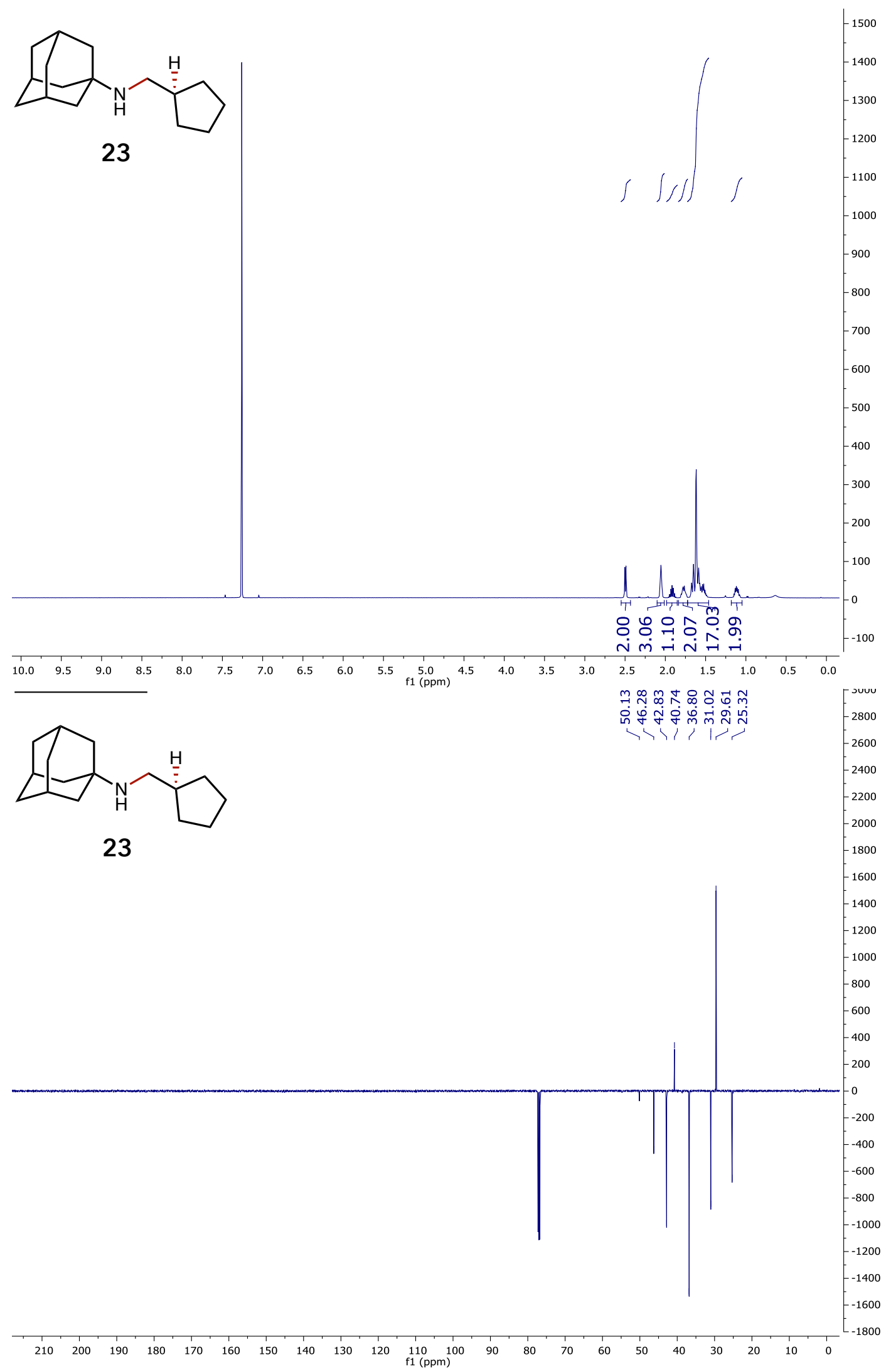




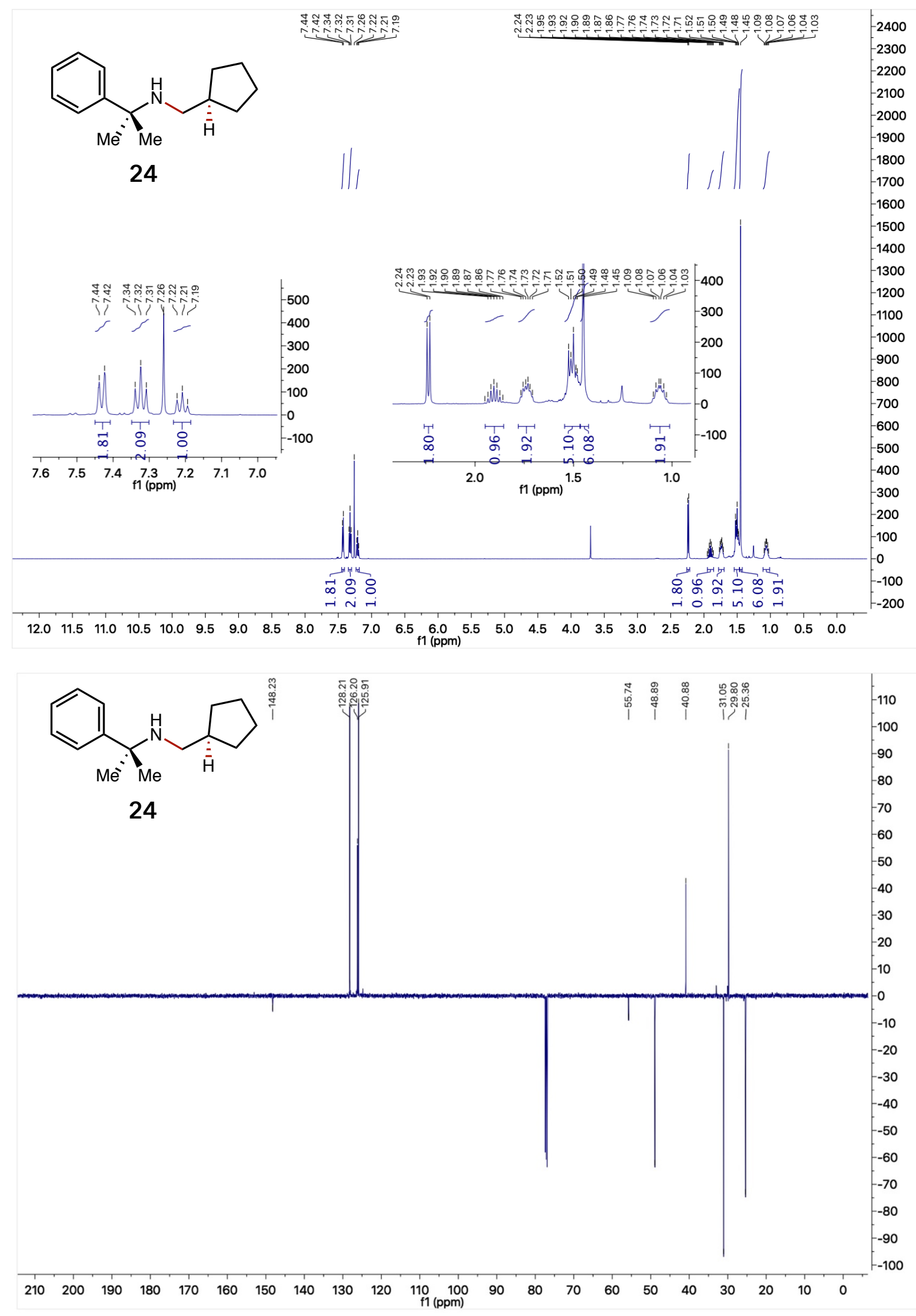




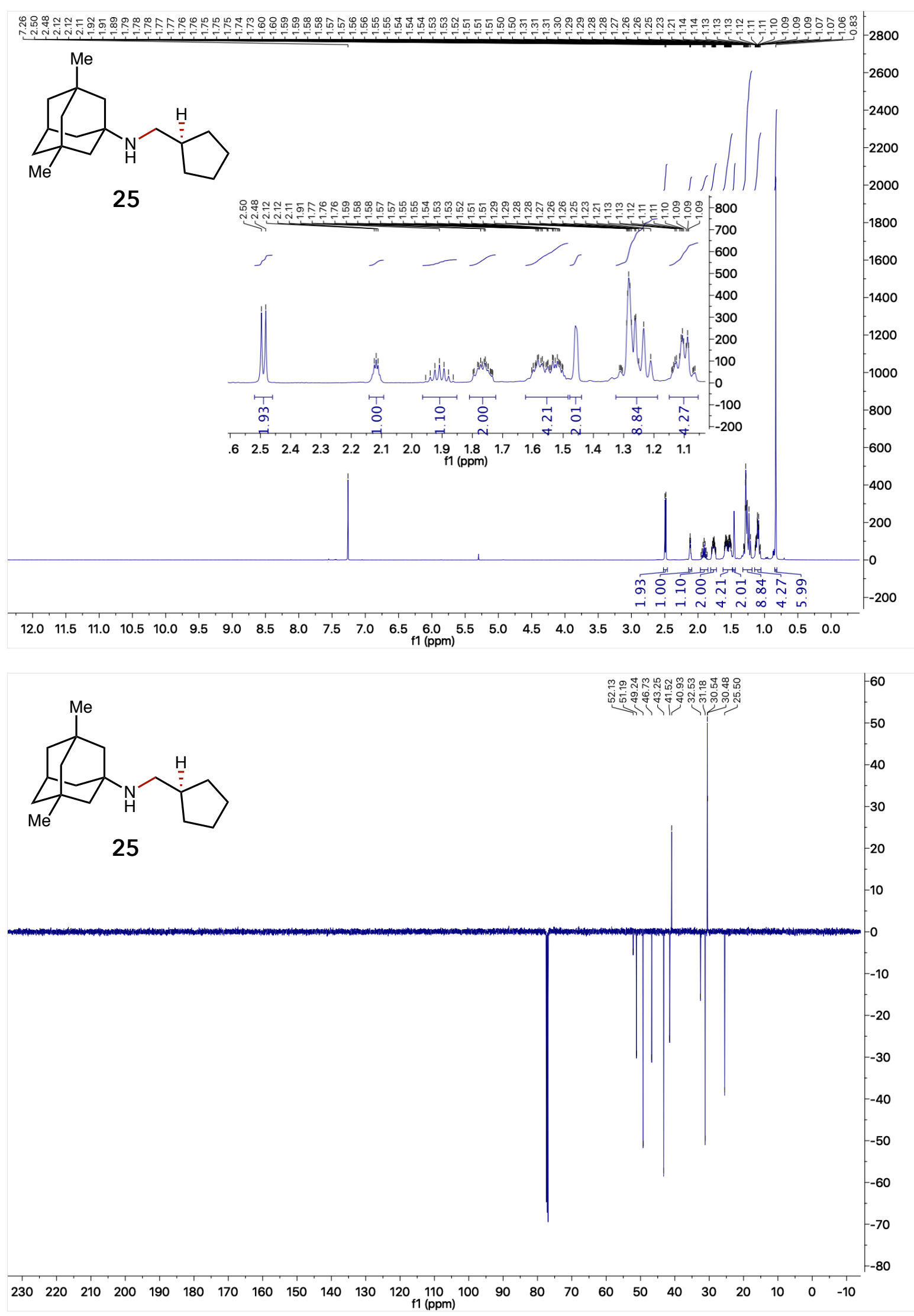




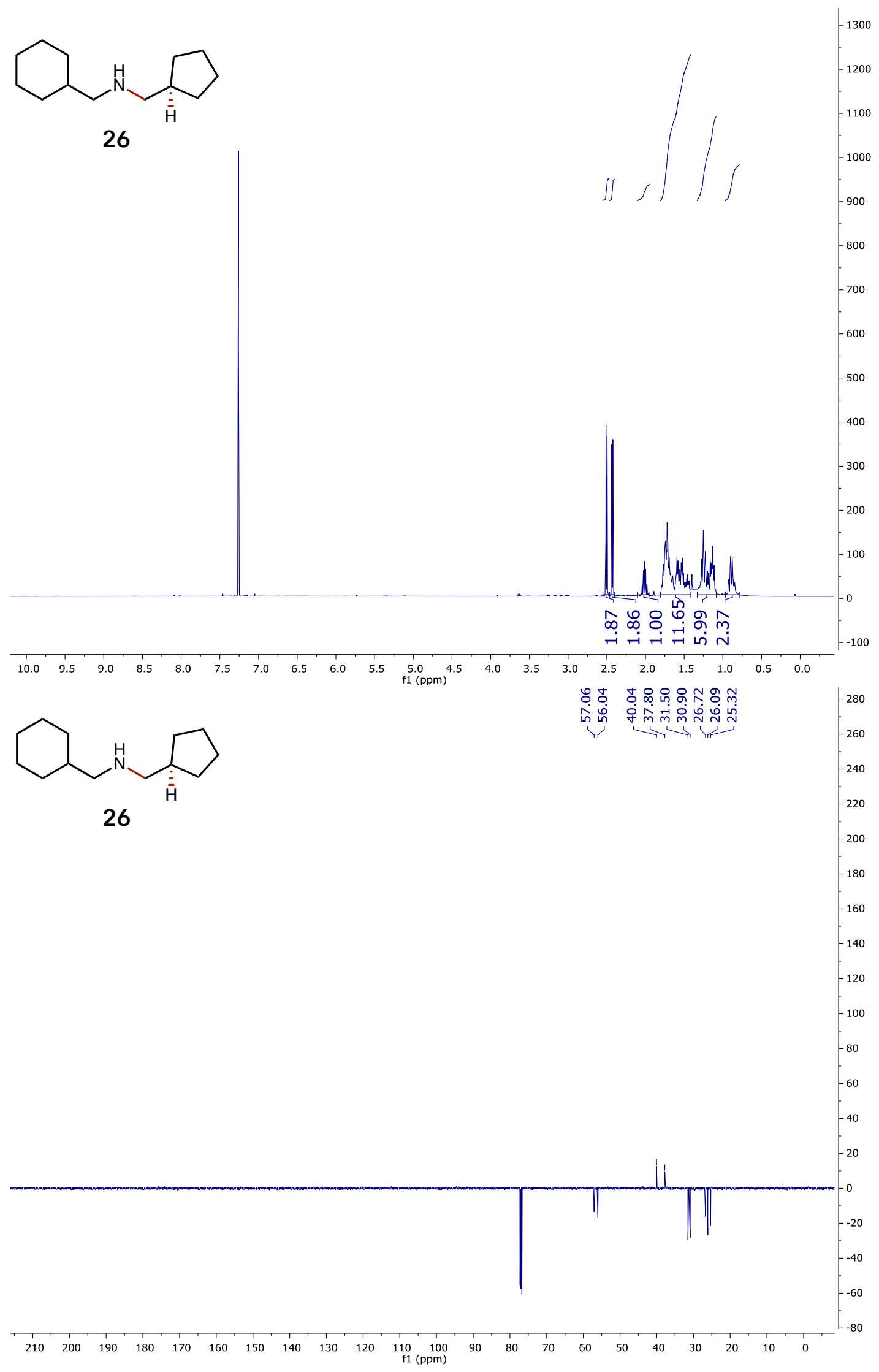



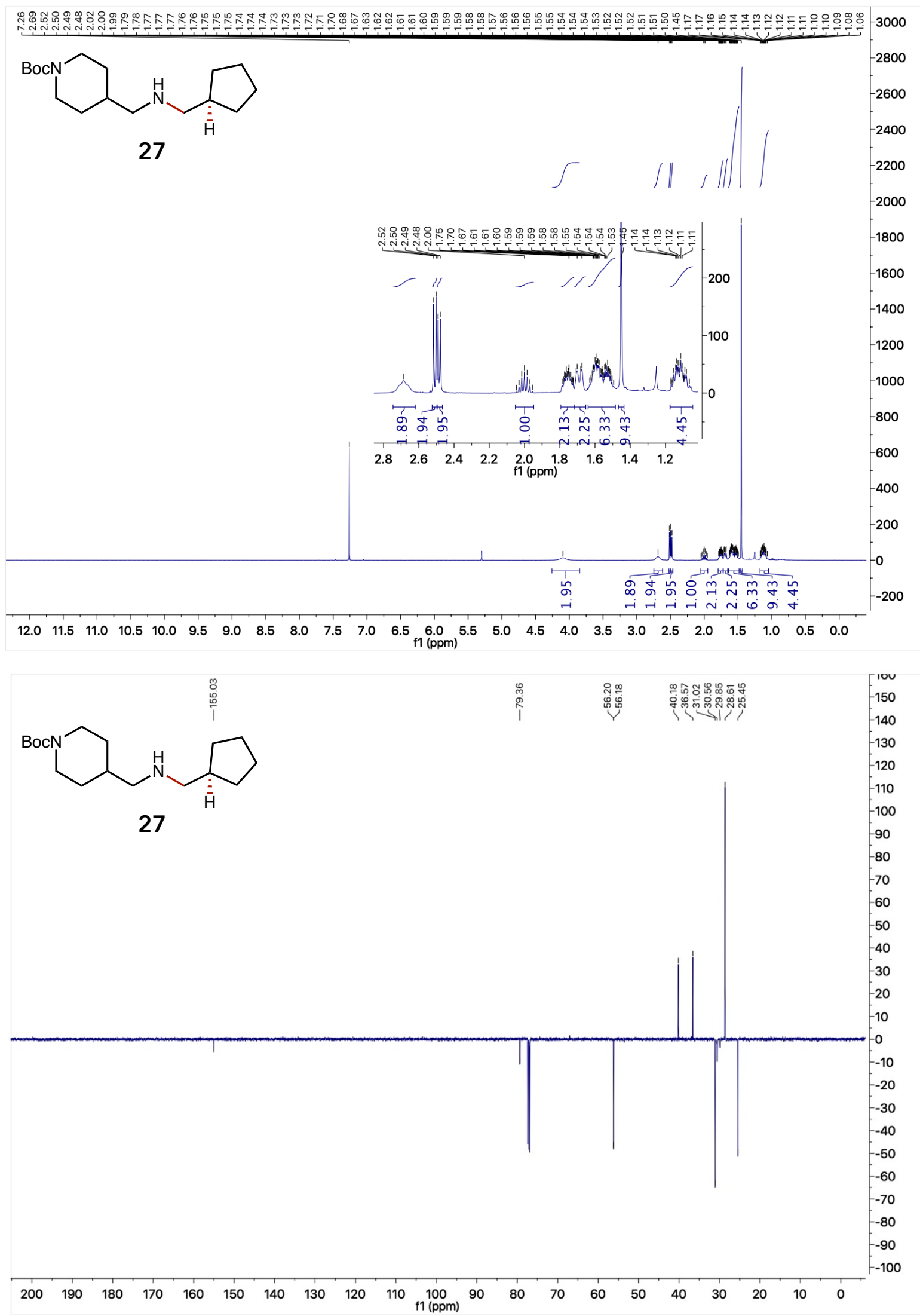


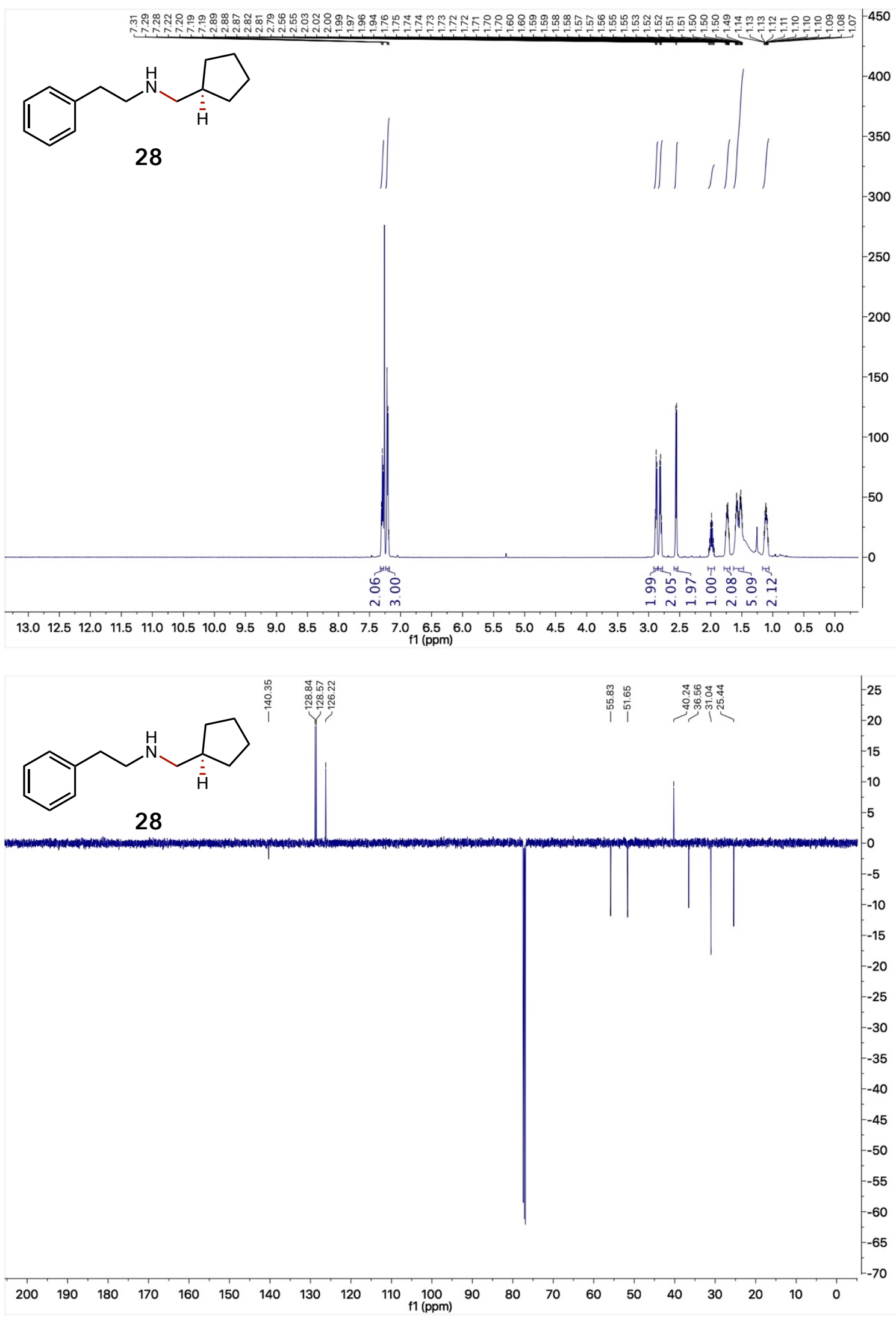



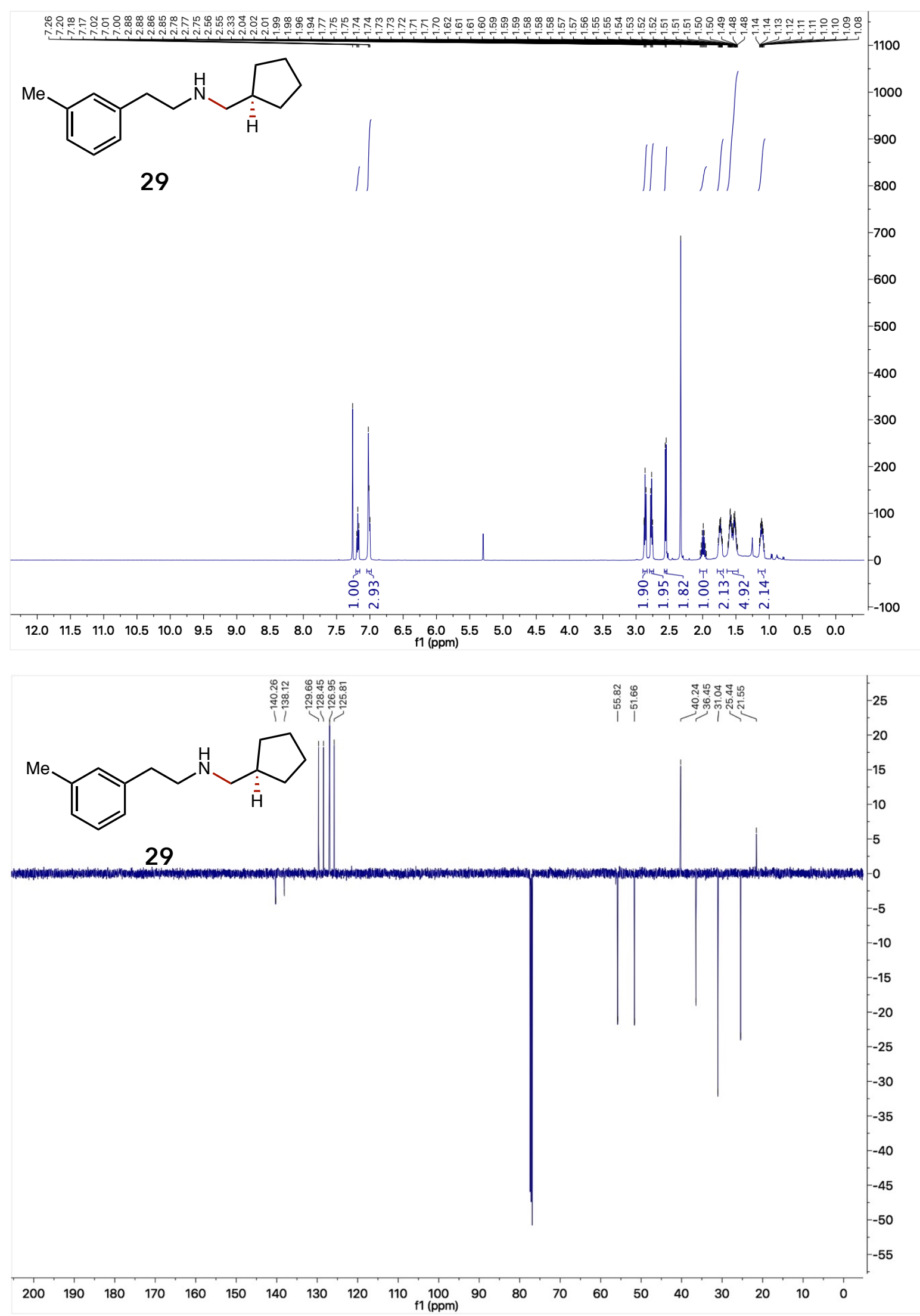


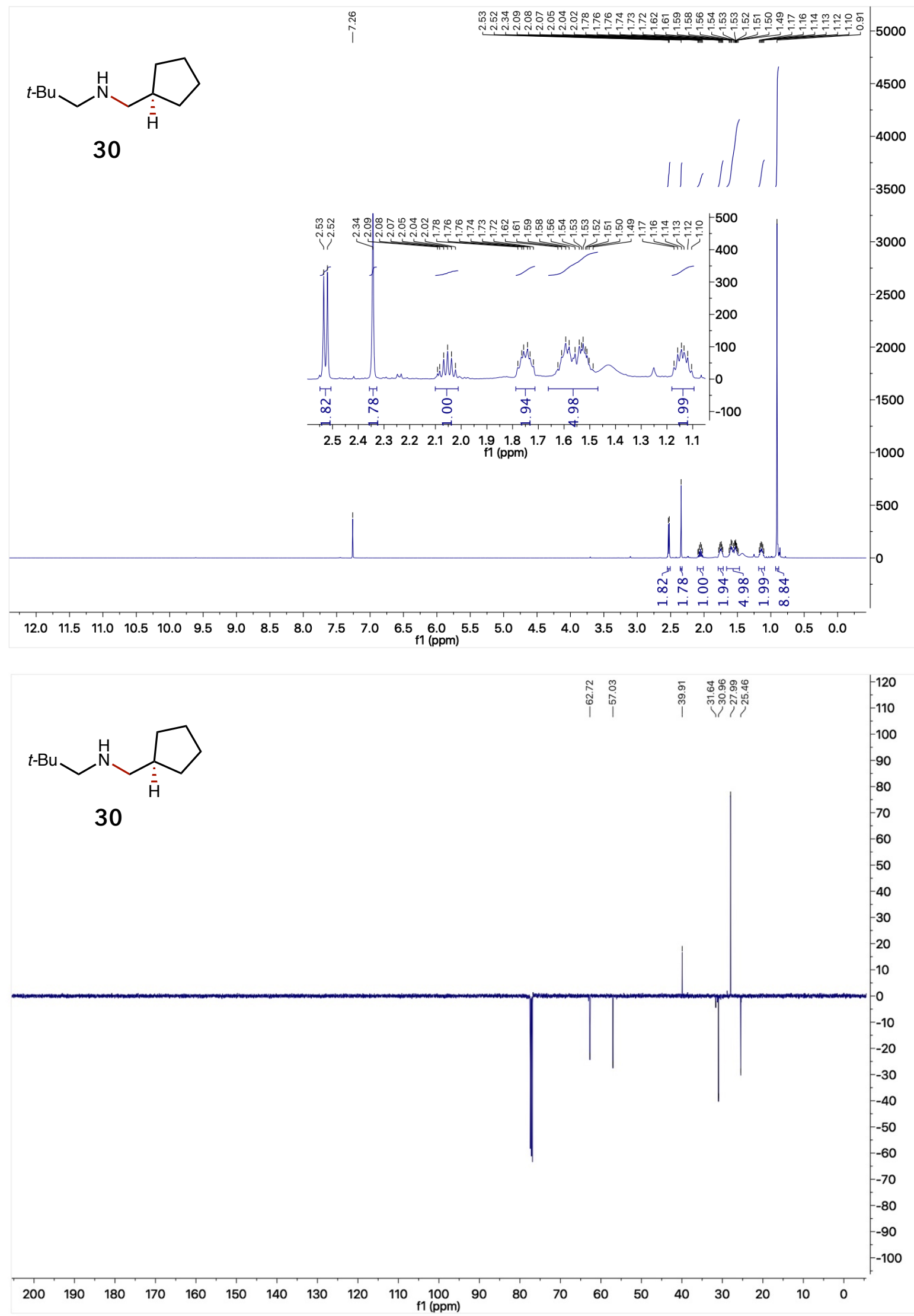




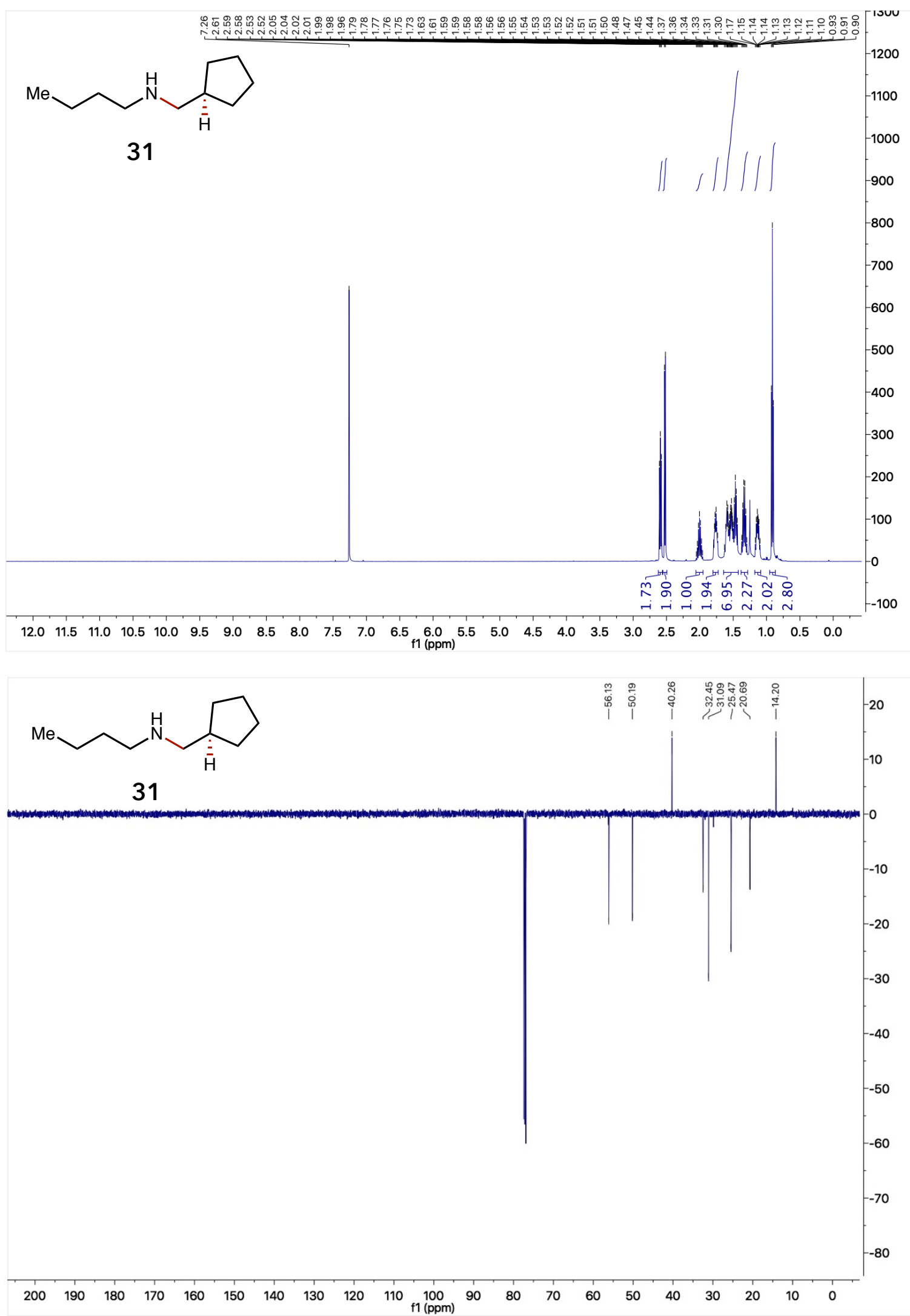




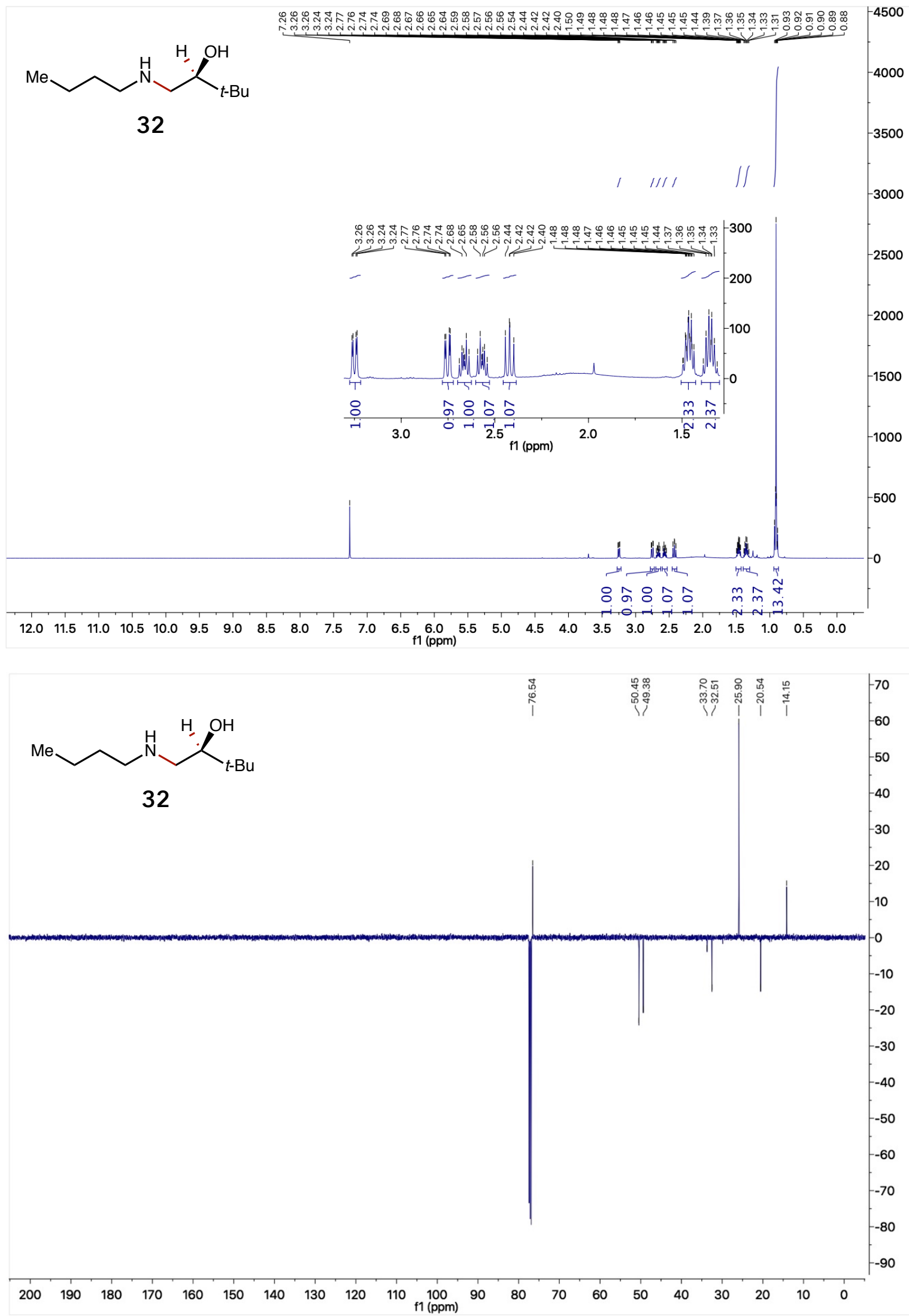




\section{Synthesis and Quantification of Tertiary Amine Side Products}

In all cases, we observed $<5 \%$ of the tertiary amine resulting from overalkylation. In order to further quantify the degree of overalkylation, we opted to independently synthesize two tertiary amines and quantify their abundance via GC analysis of the crude reaction mixture. For the reaction of cyclohexylmethanamine and methylene cyclopentane, it was determined that the ratio of 1-Cyclohexyl- $N$-(cyclopentylmethyl)methanamine to 1-Cyclohexyl- $N, N$ bis(cyclopentylmethyl)methanamine was 34:1. For the reaction of cycloheptylamine and methylene cyclopentane, it was determined that the ratio of $N$ (Cyclopentylmethyl)cycloheptanamine to $N, N$-bis(cyclopentylmethyl)cycloheptanamine was 59:1.
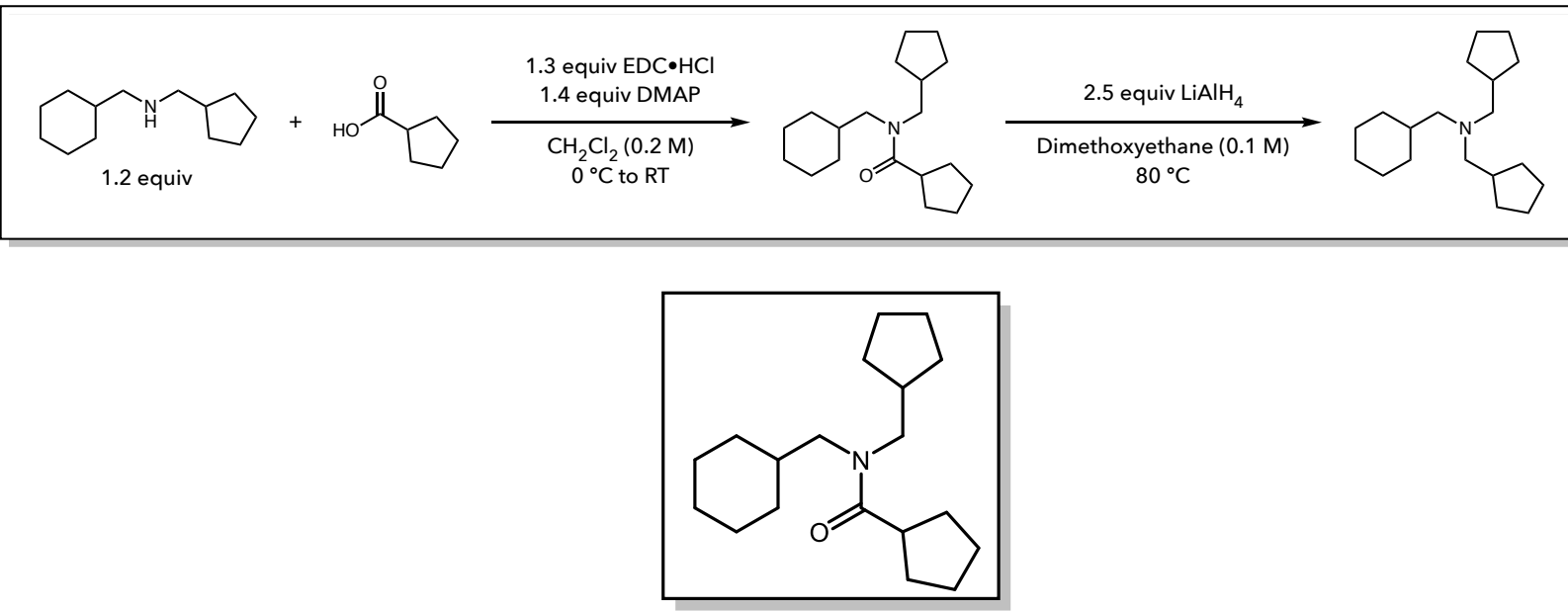

\section{$N$-(Cyclohexylmethyl)- $N$-(cyclopentylmethyl)cyclopentanecarboxamide}

To an oven-dried 2-dram vial with stirbar was added EDC-HCl (1-(3- dimethylaminopropyl)-3ethylcarbodiimide hydrochloride, $86 \mathrm{mg}, 0.47 \mathrm{mmol}, 1.3$ equiv) and DMAP (59 mg, $0.48 \mathrm{mmol}$, 1.4 equiv). The reaction vial was capped with a septa, evacuated under vacuum, and backfilled with nitrogen. $\mathrm{CH}_{2} \mathrm{Cl}_{2}(1 \mathrm{~mL})$ was added and the solution was cooled in an ice bath. Cyclopentanecarboxylic acid (39 mg, $0.34 \mathrm{mmol}, 1.0$ equiv) was added. After five minutes of stirring, 1-cyclohexyl- $N$-(cyclopentylmethyl)methanamine ( $80 \mathrm{mg}, 0.41 \mathrm{mmol}, 1.2$ equiv) was added in a $1 \mathrm{~mL}$ solution of $\mathrm{CH}_{2} \mathrm{Cl}_{2}$. The ice bath was then removed and the reaction allowed to stir at RT until starting material was consumed, as observed by TLC. The reaction was quenched with $1 \mathrm{M} \mathrm{HCl}(2 \mathrm{~mL})$ and the organics separated. The aqueous layer was then extracted with $\mathrm{CH}_{2} \mathrm{Cl}_{2}(2 \times 2 \mathrm{~mL})$. The organic layers were combined and dried over $\mathrm{Na}_{2} \mathrm{SO}_{4}$ and concentrated to provide $78 \mathrm{mg}$ ( $78 \%$ yield) of the title compound as a viscous, colorless oil. This compound is immediately carried forward to the subsequent step with no additional purification. 


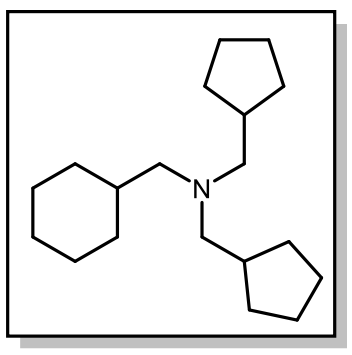

\section{1-Cyclohexyl- $N, N$-bis(cyclopentylmethyl)methanamine}

To an oven-dried 2-dram vial with stirbar was added lithium aluminum hydride $(25 \mathrm{mg}, 0.67$ mmol, 2.5 equiv). The reaction vial was capped with a septa, evacuated under vacuum, and backfilled with nitrogen. DME $(1 \mathrm{~mL})$ was added and the reaction cooled in an ice bath. Once equilibrated, $N$-(cyclohexylmethyl)- $N$-(cyclopentylmethyl)cyclopentanecarboxamide (78 $\mathrm{mg}$, $0.27 \mathrm{mmol}, 1.0$ equiv) was added in $1.6 \mathrm{~mL}$ of DME. The reaction was brought to $80{ }^{\circ} \mathrm{C}$ in an oil bath; upon equilibration, the nitrogen inlet was removed from the flask and the reaction was allowed to stir until the entirety of the starting amine was consumed, as observed by GC analysis of a reaction aliquot. Once done, the reaction was allowed to cool to RT before it is diluted with diethyl ether $(2 \mathrm{~mL})$ and cooled in an ice bath. The crude reaction mixture was quenched with water (three drops), then $10 \% \mathrm{NaOH}$ solution (three drops), and finally an additional portion of water (ten drops). $\mathrm{MgSO}_{4}$ was added to the resulting suspension until the aluminum salts cleanly flocculated: at this point the reaction was filtered and the solid washed copiously with ether. The volatiles were removed to provide $61 \mathrm{mg}(82 \%$ yield $)$ of the title compound as a colorless oil in high purity. IR (neat): 2922, 2852, 2789, 1450, 1379, 1276, 1113, 860. ${ }^{\mathbf{1}} \mathbf{H}$ NMR (500 MHz, $\left.\mathbf{C D C l}_{3}\right) \delta 2.18(\mathrm{~d}, J=7.5 \mathrm{~Hz}, 4 \mathrm{H}), 2.09$ (d, $\left.J=7.1 \mathrm{~Hz}, 2 \mathrm{H}\right), 2.02$ (hept, $\left.J=7.6 \mathrm{~Hz}, 2 \mathrm{H}\right), 1.86-$ $1.78(\mathrm{~m}, 2 \mathrm{H}), 1.77-1.64(\mathrm{~m}, 6 \mathrm{H}), 1.63-1.47(\mathrm{~m}, 8 \mathrm{H}), 1.45-1.10(\mathrm{~m}, 9 \mathrm{H}), 0.87-0.75(\mathrm{~m}, 2 \mathrm{H})$. ${ }^{13}$ C NMR (126 MHz, CDCl $) \delta$ 62.54, 61.40, 38.12, 36.32, 31.93, 31.10, 27.05, 26.29, 25.23. HRMS (ESI) exact mass calculated for $[\mathrm{M}+\mathrm{H}]^{+}\left(\mathrm{C}_{19} \mathrm{H}_{36} \mathrm{~N}\right)$ requires $\mathrm{m} / \mathrm{z} 277.27695$, found $\mathrm{m} / \mathrm{z}$ 277.27730, difference 1.27 ppm.
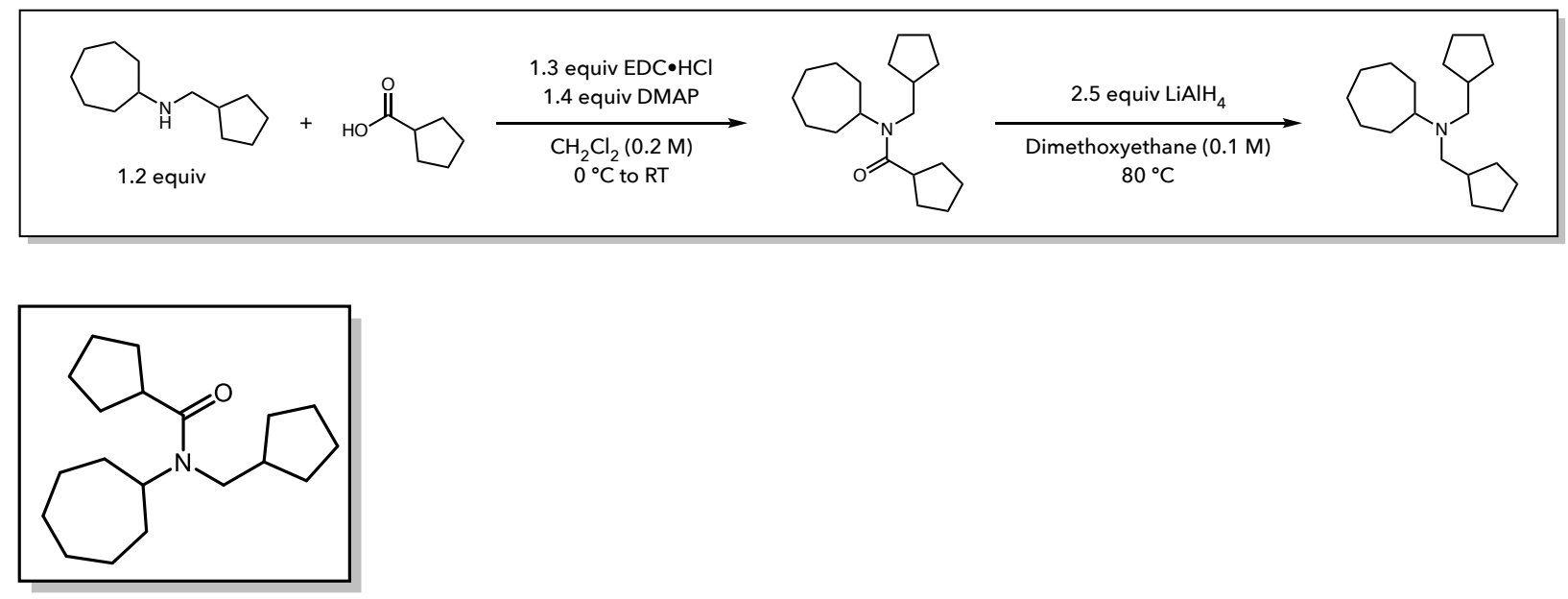

\section{$\mathrm{N}$-Cycloheptyl- $\mathrm{N}$-(cyclopentylmethyl)cyclopentanecarboxamide}

To an oven-dried dram vial with stirbar was added EDC-HCl (1-(3- dimethylaminopropyl)-3ethylcarbodiimide hydrochloride, $86 \mathrm{mg}, 0.45 \mathrm{mmol}, 1.3$ equiv), and DMAP (59 $\mathrm{mg}, 0.48 \mathrm{mmol}$, 1.4 equiv). The reaction vial was capped with a septa, evacuated under vacuum, and backfilled 
with nitrogen. $\mathrm{CH}_{2} \mathrm{Cl}_{2}(1 \mathrm{~mL})$ was added and the reaction flask was cooled in an ice bath. Cyclopentanecarboxylic acid (39 mg, $0.34 \mathrm{mmol}, 1.0$ equiv) was added. After five minutes of stirring, $N$-(Cyclopentylmethyl)cycloheptanamine ( $80 \mathrm{mg}, 0.41 \mathrm{mmol}, 1.2$ equiv) was added in a $1 \mathrm{~mL}$ solution of $\mathrm{CH}_{2} \mathrm{Cl}_{2}$. The ice bath was then removed and the reaction allowed to stir at RT until starting material was consumed, as observed by TLC. The reaction was quenched with $1 \mathrm{M}$ $\mathrm{HCl}(2 \mathrm{~mL})$ and the organics separated. The aqueous layer was then extracted with $\mathrm{CH}_{2} \mathrm{Cl}_{2}(2 \times 2$ $\mathrm{mL}$ ). The organic layers were combined and dried over $\mathrm{Na}_{2} \mathrm{SO}_{4}$ and concentrated to provide 76 $\mathrm{mg}(76 \%$ yield $)$ of the title compound as a white solid. The amide was carried forward immediately with no additional purification.

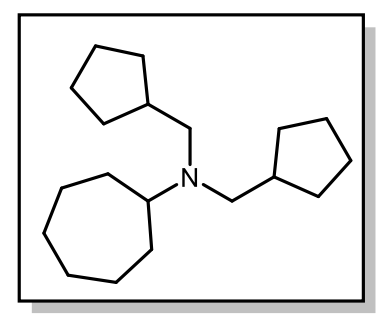

\section{$N, N$-Bis(cyclopentylmethyl)cycloheptanamine}

To an oven-dried dram vial with stirbar was added lithium aluminum hydride $(25 \mathrm{mg}, 0.65 \mathrm{mmol}$, 2.5 equiv). The reaction vial was capped with a septa, evacuated under vacuum, and backfilled with nitrogen. DME $(1 \mathrm{~mL})$ was added and the reaction cooled in an ice bath. Once equilibrated, $N$-Cycloheptyl- $N$-(cyclopentylmethyl)cyclopentanecarboxamide (76 mg, $0.26 \mathrm{mmol}, 1.0$ equiv) was added in $1 \mathrm{~mL}$ of DME. The reaction was brought to $80^{\circ} \mathrm{C}$ in an oil bath; upon equilibration, the nitrogen inlet was removed from the flask and the reaction was allowed to stir until the entirety of the starting amine was consumed, as observed by GC analysis of a reaction aliquot. Once done, the reaction was allowed to cool to RT before it was diluted with diethyl ether $(2 \mathrm{~mL})$ and cooled in an ice bath. The crude reaction mixture was quenched with water (three drops), then $10 \% \mathrm{NaOH}$ solution (three drops), and finally an additional portion of water (ten drops). $\mathrm{MgSO}_{4}$ was added to the resulting suspension until the aluminum salts cleanly flocculated: at this point the reaction was filtered and the solid washed copiously with ether. The volatiles were removed to provide $57 \mathrm{mg}$ (79\% yield) of the title compound as a colorless oil in high purity. IR (neat): 2927.95, 2858, 2780, 1453, 1341, 1207, 1116. ${ }^{1} \mathbf{H}$ NMR (500 MHz, $\left.\mathbf{C D C l}_{3}\right) \delta 2.59(\mathrm{~m}, 1 \mathrm{H}), 2.19(\mathrm{~d}, J=7.6 \mathrm{~Hz}, 4 \mathrm{H})$, 1.95 (hept, $J=7.4 \mathrm{~Hz}, 2 \mathrm{H}), 1.81-1.71(\mathrm{~m}, 2 \mathrm{H}), 1.71-1.60(\mathrm{~m}, 6 \mathrm{H}), 1.59-1.42(\mathrm{~m}, 12 \mathrm{H}), 1.40$ - $1.28(\mathrm{~m}, 4 \mathrm{H}), 1.23$ - 1.11 (m, 4H). ${ }^{13} \mathbf{C}$ NMR (126 MHz, $\left.\mathbf{C D C l}_{3}\right) \delta$ 60.66, 56.03, 38.70, 30.84, $30.30,27.98,26.16,25.14$. HRMS (ESI) exact mass calculated for $[\mathrm{M}+\mathrm{H}]^{+}\left(\mathrm{C}_{19} \mathrm{H}_{36} \mathrm{~N}\right)$ requires $\mathrm{m} / \mathrm{z}$ 277.27695, found $\mathrm{m} / \mathrm{z} 277.27641$, difference $1.97 \mathrm{ppm}$. 


\section{Stern-Volmer Experiments}

Stern-Volmer experiments were conducted on an Agilent Technologies Cary Eclipse Fluorescence Spectrophotometer using the Cary Eclipse Scan Application. Rigorously degassed solutions of each component were prepared prior to each set of experiments. Because the photocatalyst is poorly soluble in dioxane, luminescence quenching experiments were run with acetonitrile as the solvent. The solutions were irradiated at $400 \mathrm{~nm}$ and luminescence was measured at $586 \mathrm{~nm}$. Each experiment was run in duplicate. $\mathrm{I}_{0} / \mathrm{I}$ values per run are generated from the average of all three scans per data point. For determination of $K_{\mathrm{SV}}$, the value for $\mathrm{I}_{0} / \mathrm{I}$ from each run is averaged to yield an $\mathrm{I}_{0} / \mathrm{I}$ value for the experiment and is composed of six total measurements of $\mathrm{I}_{0} / \mathrm{I}$. Linear regression of $\mathrm{I}_{0} / \mathrm{I}$ against concentration to yield $K_{\mathrm{SV}}$ is done in Microsoft Excel. 
Table S1: Fluorescence quenching data with solutions of $\left[\operatorname{Ir}\left(\mathrm{dF}\left(\mathrm{CF}_{3}\right) \mathrm{ppy}\right)_{2}\left(4,4{ }^{\prime}-\mathrm{dCF}_{3}-\mathrm{bpy}\right)\right] \mathrm{PF}_{6}$ $[0.00071 \mathrm{M}]$ and Cyclohexylamine.

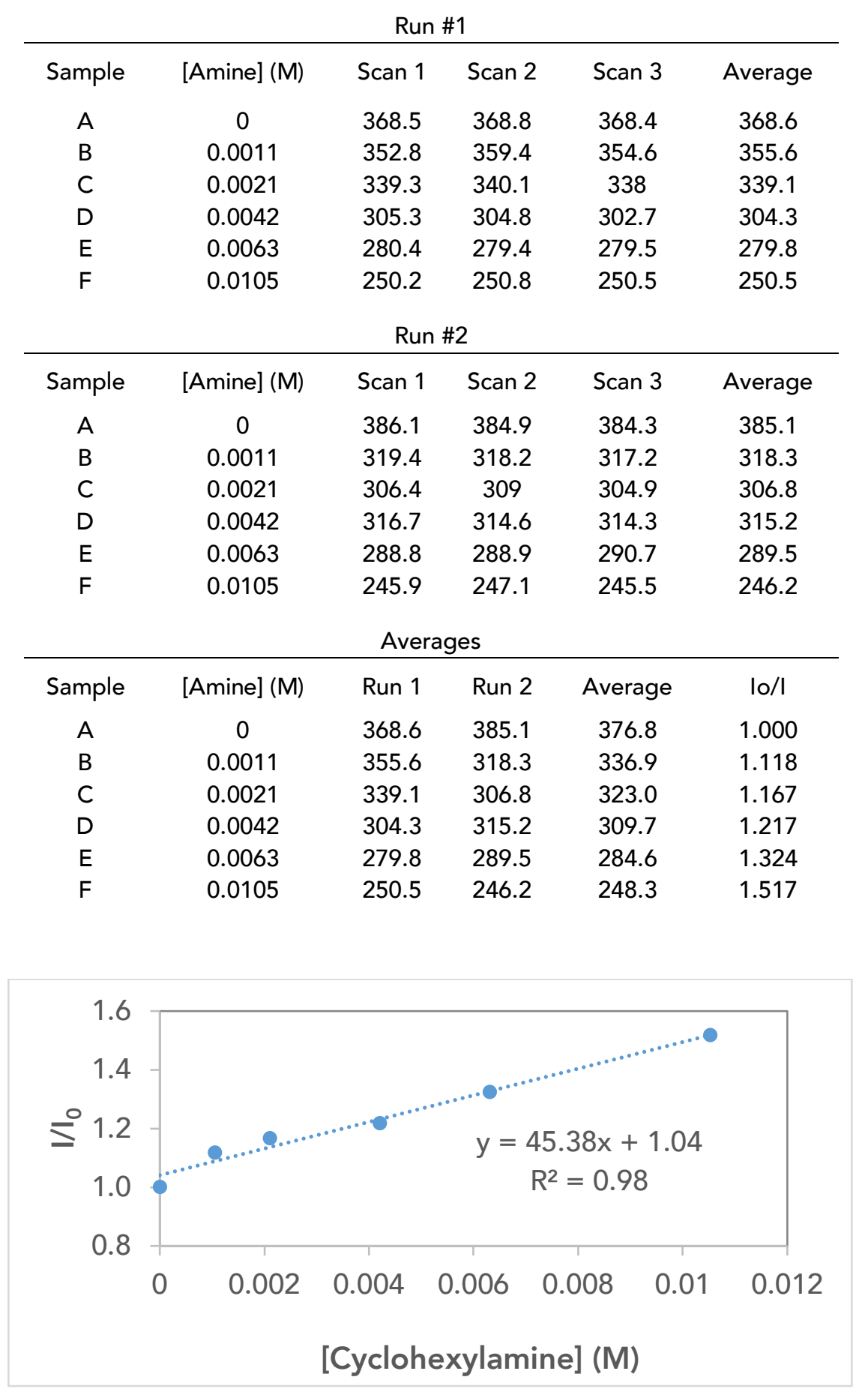

Figure S1: Stern-Volmer plot of $\left[\operatorname{Ir}\left(\mathrm{dF}_{(}\left(\mathrm{CF}_{3}\right) \mathrm{ppy}\right)_{2}\left(4,4{ }^{\prime}-\mathrm{dCF}_{3}-\mathrm{bpy}\right)\right] \mathrm{PF}_{6}$ quenching with varying concentration of Cyclohexylamine. 
Table S2: Fluorescence quenching data with solutions of $\left[\operatorname{Ir}\left(\mathrm{dF}\left(\mathrm{CF}_{3}\right) \mathrm{ppy}\right)_{2}\left(4,4{ }^{\prime}-\mathrm{dCF}_{3}-\mathrm{bpy}\right)\right] \mathrm{PF}_{6}$ $[0.00076 \mathrm{M}]$ and $N$-(Cyclopentylmethyl)cyclohexylamine.

\begin{tabular}{cccccc}
\multicolumn{5}{c}{ Run \#1 } \\
\hline Sample & [Amine] (M) & Scan 1 & Scan 2 & Scan 3 & Average \\
A & 0 & 385.6 & 383.1 & 382.3 & 383.7 \\
B & 0.0002 & 341.6 & 340.8 & 342.9 & 341.8 \\
C & 0.0004 & 306.2 & 305 & 305 & 305.4 \\
D & 0.0007 & 253.5 & 251.2 & 252.1 & 252.3 \\
E & 0.0011 & 206.6 & 207.8 & 208 & 207.5 \\
F & 0.0018 & 143 & 140 & 140 & 141.0
\end{tabular}

\begin{tabular}{cccccc}
\multicolumn{6}{c}{ Run \#2 } \\
\hline Sample & [Amine] (M) & Scan 1 & Scan 2 & Scan 3 & Average \\
A & 0 & 379.7 & 379.1 & 379.9 & 379.6 \\
B & 0.0002 & 331.7 & 335.5 & 335.4 & 334.2 \\
C & 0.0004 & 306.7 & 308.5 & 304.8 & 306.7 \\
D & 0.0007 & 244.5 & 244.6 & 244.8 & 244.6 \\
E & 0.0011 & 201.4 & 201.8 & 201.2 & 201.5 \\
F & 0.0018 & 141.4 & 140.9 & 140.9 & 141.1
\end{tabular}

\begin{tabular}{cccccc}
\multicolumn{5}{c}{ Averages } \\
\hline Sample & {$[$ Amine] $(\mathrm{M})$} & Run 1 & Run 2 & Average & lo/I \\
A & 0 & 383.66667 & 379.566667 & 381.61667 & 1.000 \\
B & 0.0002 & 341.76667 & 334.2 & 337.98333 & 1.129 \\
C & 0.0004 & 305.4 & 306.666667 & 306.03333 & 1.247 \\
D & 0.0007 & 252.26667 & 244.633333 & 248.45 & 1.536 \\
E & 0.0011 & 207.46667 & 201.466667 & 204.46667 & 1.866 \\
F & 0.0018 & 141 & 141.066667 & 141.03333 & 2.706
\end{tabular}

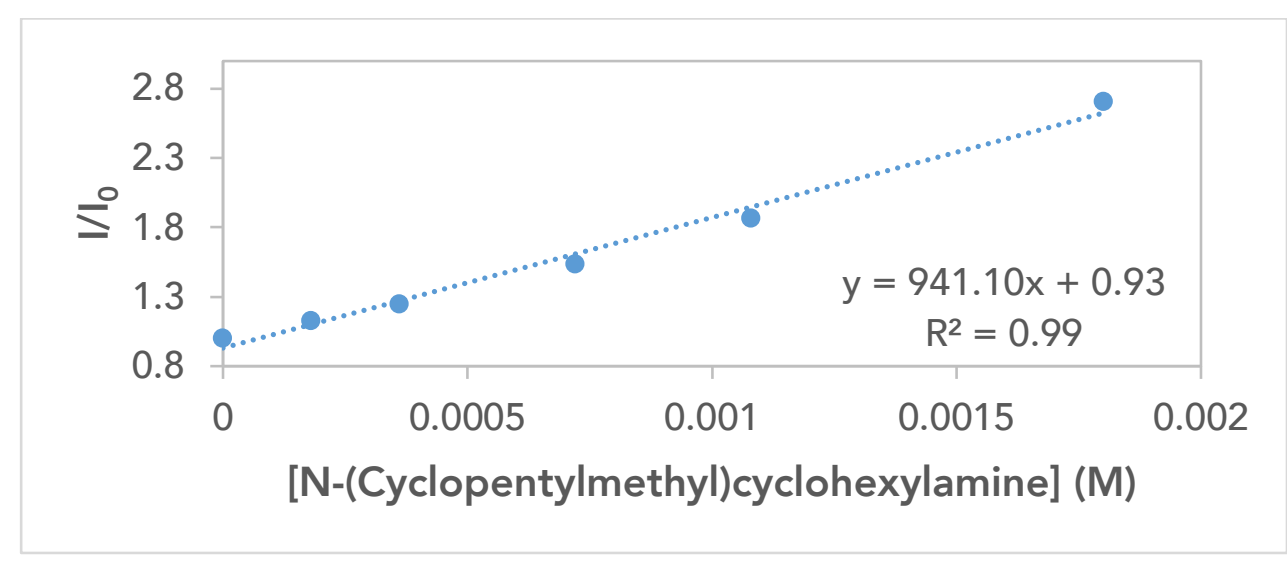

Figure S2: Stern-Volmer plot of $\left[\operatorname{Ir}\left(\mathrm{dF}\left(\mathrm{CF}_{3}\right) \text { ppy }\right)_{2}\left(4,4{ }^{\prime}-\mathrm{dCF}_{3}-\mathrm{bpy}\right)\right] \mathrm{PF}_{6}$ quenching with varying concentration of $N$-(Cyclopentylmethyl)cyclohexylamine. 


\section{References}

(1) Perrin, D. D.; Armarego, W. L. F. Purification of Laboratory Chemicals; 4th ed.; Butterworth-Heinemann: Oxford, 1997.

(2) Pangborn, A. B.; Giardello, M. A.; Grubbs, R. H.; Rosen, R. K.; Timmers, F. J. Organometallics 1996, 15, 1518.

(3) Still, W. C.; Kahn, M.; Mitra, A. J. Org. Chem. 1978, 43, 2923.

(4) Singh, A.; Teegardin, K.; Kelly, M.; Prasad, K. S.; Krishnan, S.; Weaver, J. D. J. Organomet. Chem. 2015, 776, 51.

(5) Porras, J. A.; Mills, I. N.; Transue, W. J.; Bernhard, S. J. Am. Chem. Soc. 2016, 138, 9460.

(6) Schultz, D. M.; Sawicki, J. W.; Yoon, T. P.; Beilstein J. Org. Chem. 2015, 11, 61.

(7) Choi, G. J.; Zhu, Q.; Miller, D. C.; Gu, C. J.; Knowles, R. R. Nature 2016, 539, 268.

(8) Ladouceur, S.; Fortin, D.; Zysman-Colman, E. Inorg. Chem. 2011, 50, 11514.

(9) Lorentz-Peterson, L. R.; Jensen, P.; Madsen, R. Synthesis 2009, 24, 4110. 